\title{
Student Aid, Academic Achievement, and Labor Market Behavior.
}

\author{
Juanna Schrøter Joensen* $\quad$ Elena Mattana ${ }^{\ddagger}$
}

February 15, 2016

- PRELIMINARY AND INCOMPLETE -

\begin{abstract}
Does it matter whether study aid is provided as grants or loans? We provide a framework for quantifying the impacts of financial aid on student debt, academic capital, and labor market outcomes. We specify and estimate a dynamic discrete choice model of simultaneous education, work, and student loan take-up decisions. We use administrative panel data and exploit exogenous variation from the 2001 Swedish Study Aid reform for identification of the model parameters. This enables ex-ante evaluation of various changes to financial aid schemes. We find that additional years of aid and more generous means testing on student income substantially reduce dropout rates and increase graduation rates with more advanced degrees, but at the cost of students staying enrolled longer and accumulating more debt. Moving from an income-contingent to an annuity-based loan repayment scheme decreases student debt accumulation and improves the effectiveness of academic capital accumulation. If study aid consists mostly of grants, a reduction in loans and increase in grants reduces graduation rates. However, once loans are larger than grants, further changes have little impact on dropout and graduation rates. This means that once aid is mostly provided as loans, the government can decide who bears the college cost without affecting human capital accumulation.
\end{abstract}

JEL: D90, H52, I21, I22, I28, J22, J24, J31.

Keywords: Student Aid, Education and Labor Market Outcomes, Dynamic Discrete Choice Model.

\footnotetext{
${ }^{*}$ University of Chicago. Email: JJoensen@uchicago.edu

${ }^{\ddagger}$ University of Chicago. Email: EMattana@uchicago.edu.

We thank Flavio Cunha, Lars Ljungqvist, Mårten Palme, Björn Öckert, seminar participants at Copenhagen Business School, CORE-UCLouvain, IFAU Uppsala, IFS London, IFN Stockholm, IIES Stockholm University, NHH Norwegian School of Economics, SOFI Stockholm University, SSE, University of Bergen, University of Chicago, University of Edinburgh, University of Pennsylvania, University of Wisconsin-Madison, University of Calgary, Aarhus University, ISER Essex, and University of Cagliari. We are immensely grateful to IFAU for sharing their data. We also thank Nina Jalava and Svante Midander for research assistance, Jörgen Moen for assistance with the data and the servers, and the CSN staff for providing us with all the details of the Swedish study aid scheme. We gratefully acknowledge financial support from the Swedish Research Council (VR) and Mattana also from the Jan Wallander och Tom Hedelius Research Foundations and FNRS (Fonds de la Recherche Scientifique) Belgium (Research Project PDR T.0044.13). The usual disclaimers apply.
} 


\section{Introduction}

Does it matter whether study aid is provided as grants or loans? This paper provides a dynamic model to analyze the impacts of different types of financial aid on debt accumulation, course credit accumulation, graduation rates, and labor market behavior of college students. The model captures the joint education, work, and loan take-up decisions and how they affect outcomes. We estimate the model using administrative panel data for all students who graduated from high school in Sweden between 1990 and 2002, exploiting exogenous variation from a 2001 reform in the Swedish study aid scheme to identify key model parameters. We find that if study aid consists mostly of grants, a reduction in loans and increase in grants reduces graduation rates. However, once loans are larger than grants, further changes have little impact on dropout and graduation rates. This means that once aid is mostly provided as loans, the government can decide who bears the college cost without affecting human capital accumulation.

Despite the tremendous amounts of financial aid to students attending higher education, little is known about the effects of aid on human capital formation and labor market behavior. Even less is known about the effects of frequently suggested and much debated policy reforms of financial aid schemes. We analyze how financial aid can be spent more cost-effectively in order to obtain the declared social goals of increasing graduation rates and the speed at which individuals graduate.

These are challenging empirical questions to answer, since they depend on individual budget constraints and which individuals are close to college enrollment and graduation margins, as well as how strongly they respond to financial incentives. We directly observe individual budget sets and have exogenous variation in budget sets - both affecting current and intertemporal trade-offs. The uniformity of study aid rules and the detailed panel data enable us to model important aspects of student choices and outcomes, while both taking their simultaneous and sequential nature into account. This enables us to better assess which students are at the relevant margins of change and how strongly they respond to financial incentives.

We specify and estimate a dynamic discrete choice model of joint education, employment, and loan take-up decisions of college students. The model embeds how these choices affect college productivity (in terms of how many course credits are accumulated) and labor market productivity (in terms of labor income). Students stay enrolled as long as their expected degree 
premium exceeds the opportunity costs of staying enrolled. Students derive consumption from college enrollment and three sources of income: grants, loans, and labor income. Grants lower the direct cost of enrollment. Loans also lower the direct college cost, however, they introduce a trade-off between current and future consumption as the loan needs to be repaid after college exit and thus lowers future consumption. Different repayment schemes entail different intertemporal trade-offs. For example, an income-contingent loan is a proportional tax on labor income and may reduce the value of graduating and taking a high-paid job. On the other hand, it also ensures that those with a lower labor market return to college bear a lower cost of college. Working lowers current opportunity costs, but increases future opportunity costs of enrollment through increased labor market experience. Working can also increase the direct costs by lowering study aid because of the means testing. Working may even decrease the consumption value of education and decrease future opportunity costs to the extent that there are adverse effects on academic achievement. The strength of these effects further depends on the direct effects of working on wages and course credit accumulation. Importantly, we allow for different trade-offs between working and college productivity depending on whether the student works during the summer or during the semesters. Quantifying both the direct and indirect effects of financial aid and student employment is pivotal in order to assess the most cost-effective policy instruments and spend scarce public resources on higher education more effectively.

The Swedish reform of the study aid scheme in 2001 provides us with a quasi-experiment to identify the key parameters of the structural dynamic model. Student aid in Sweden is universal and central-government-run. It guarantees a maximum yearly amount of around SEK 80,000 (around USD 12,000) to all eligible students. Around one third of this amount is a non-repayable grant and the remaining two thirds are provided as a student loan. In 2001, four main aspects of the study aid scheme were changed: the amount of grant relative to loan was increased, the loan repayment installments went from a fixed proportion of labor income to an annuity-based scheme, the eligibility rules were made more stringent, and the means testing was relaxed as the income threshold above which the aid amount is taxed increased - effectively reducing the implicit income tax for students. We use the exogenous variation provided by this reform and administrative panel data of the Swedish population of high school graduates in 1990-2002, to estimate the parameters of the model. The increased weight on grants lowered student debt and increased both the extensive and intensive margins of student labor supply, the means testing affected the intensive margin of student labor supply, while the change in 
loan repayment schemes affected the intertemporal consumption trade-off by making it more attractive to opt for a high-paid job after graduation.

Our empirical strategy combining a structural dynamic model and a quasi-experiment has four main advantages: First, the key model parameters are identified by exogenous variation in the data, thus not purely driven by functional form assumptions and potentially endogenous wage variation. Second, it allows us to estimate a richer model, including the parameter of relative risk aversion (RRA) through the intertemporal elasticity of substitution (IES). Third, it enables us to go beyond ex-post evaluation of total effects and to disentangle the mechanisms by which specific parts of the study aid scheme affect debt accumulation, academic achievement, and labor market behavior. For example, the weight on grants relative to loans, the loan repayment scheme, means testing, and eligibility rules. Fourth, we are able to simulate the exante effects of various potential policy reforms of the study aid scheme. This way we quantify how debt, academic, and labor market outcomes are affected by the different aspects of financial aid packages. This allows us to analyze the impacts of strengthening or weakening different policy instruments. For example, putting even more weight on grants relative to loans or strengthen income-contingency in loan repayment schemes.

The dynamics of the model are important for three reasons: First, current loan take-up increases student debt, which in turn decreases the future expected value of labor market participation. Second, accumulation of course credits increases academic capital and thus the value of future labor market participation. Third, current work choices increase labor market experience and thus the future value of labor market participation. However, working too much in the current period may also decrease study aid (because of the means testing) and hamper academic capital accumulation. The estimation of our structural dynamic model accounts for self-selection of student employment and loan take-up (based on both observed and unobserved heterogeneity) as well as of dynamic selection in terms of who is dropping out and graduating at various points in time. The model is estimated using the Conditional Choice Probability (CCP) estimator developed in Arcidiacono and Miller (2011). Our estimated model does a good job fitting the observed patterns in the data - even along dimensions of heterogeneity (field of study, parental education and income) that we do not explicitly model.

Our estimates imply that the timing of work during the year is important. Working primarily during the summer improves academic capital accumulation, while working too much during the semesters is detrimental. Student work experience reduces the cost of the college- 
to-work transition by increasing starting salaries, but the labor market return to student work experience diminish as more experience is accumulated after college exit. We also find that the degree premiums in Sweden are small and most of the labor market return to academic capital is a return to accumulated course credits. Policy simulations show that that additional years of aid and more generous means testing on student income substantially reduce dropout rates and increase graduation rates with more advanced degrees, but at the cost of students staying enrolled longer and accumulating more debt. Moving from an income-contingent to an annuity-based loan repayment scheme decreases student debt accumulation and improves the effectiveness of academic capital accumulation. If study aid consists mostly of grants, a reduction in loans and increase in grants reduces graduation rates. However, once loans are larger than grants, further changes have little impact on dropout and graduation rates. This means that once aid is mostly provided as loans, the government can decide who bears the college cost without affecting human capital accumulation.

Quantifying the impacts of financial aid on human capital accumulation is important because a highly educated labor force is key to sustain economic development, innovation, and growth. At the same time, the high levels of student debt are a core concern, as tuition and student debt have grown rapidly over the past five decades. Whether student debt is too high or not even high enough to overcome capital market imperfections is still an open question. ${ }^{1}$ This paper does not attempt to answer whether student debt is too high, but rather to understand the behavioral impacts of student debt on human capital accumulation.

The rest of the paper is organised as follows. Section 2 reviews the related literature. Section 3 describes the details of the reform of the Swedish study aid scheme of 2001 that our identification strategy exploits as a source of exogenous variation in the estimation of the model parameters. Section 4 sets up the structural dynamic model. Section 5 describes the estimation method and discusses identification. Section 6 describes the data. Section 7 presents the results of the estimation and assesses model fit. Section 8 discusses various policy simulations based on the estimated model. Finally, section 9 concludes.

\footnotetext{
${ }^{1}$ Friedman (1962) first noted that student loans can improve economic efficiency by raising the supply of talented workers with a college degree and thus help overcome social underinvestment in human capital due to capital market imperfections; e.g. credit constraints, growth externalities, and static externalities to the extent that education improves health and the democratic process or lowers crime and unemployment rates.
} 


\section{Related Literature}

There is a large and rapidly growing literature on how financial incentives affect educational attainment and achievement. ${ }^{2}$ The impacts of student aid schemes depend on how strongly student behavior responds to changes in the direct and opportunity costs of education, as well as how many students are at the relevant margins of change. The literature provides ambiguous evidence on the impacts of financial aid on academic achievement. However, most of this literature does not control adequately for confounding unobservable factors. Quasi-experimental studies find that financial aid has a negative impact on college drop-out and retention, while it has a positive impact on completion (Bound et al., 2007; Dynarski, 2003; Bettinger, 2004; Dynarski, 2008). Goodman (2008), Oreopoulos et al. (2009), Scott-Clayton (2011), DesJardins and McCall (2010), Garibaldi et al. (2012), and Joensen (2013b) demonstrate the potential effectiveness of providing incentives related to merit and timing in financial aid packages. These papers study the effectiveness of one particular grant or scholarship at one particular margin in the financial aid distribution. They are thus neither informative as to which margins of choice are affected by the financial incentive nor how small changes to the incentive would change the magnitudes of the effects. ${ }^{3}$ Our paper contributes to this literature by providing estimates of the direct effects of study aid on academic achievement and the indirect effects operating through student employment and loan take-up choices. The structural approach provides a framework that allows us to disentangle how different incentives affect different margins of college-workloan choices. This also enables comparison of ex ante predictions to ex post evaluations, and a coherent and unified framework for interpreting existing evidence through evaluation of the effects of various study aid policy interventions on debt accumulation, academic and labor market outcomes.

Most of the earlier literature focuses on enrollment, mainly because the traditional models of human capital investment ignore the role of uncertainty by equating enrollment with graduation. In this paper, we build on the model of Joensen $(2013 \mathrm{a}, \mathrm{b})$ who incorporates study grants into the model of Eckstein and Wolpin (1999). This model is more consistent with the empirical facts of high dropout rates, excess time to graduation, and students who work part-time while enrolled. ${ }^{4}$

\footnotetext{
${ }^{2}$ Recent contributions include Angrist et al. (2002), Oreopoulos et al. (2009) and Leuven et al. (2010).

${ }^{3}$ Joensen (2013b) is a notable exception, but she does not include loans in financial aid packages.

${ }^{4} 30 \%$ dropped out of higher education in the average OECD country in 2007; see OECD (2009). For the US, Altonji (1993) reports that in the NLS72 about $60 \%$ of college candidates actually complete college. Bound et al. (2007) show that both drop-out rates and times-to-graduation have increased over time in the US, where around $40 \%$ of students at 4-year colleges are employed, and $10 \%$ of students work more than 20 hours a week.
} 
The structural dynamic model of education and student work hours choices in Joensen (2013a,b) is estimated exploiting a change in the threshold for maximum allowable students earnings and the implicit tax above this threshold in the Danish study aid scheme. We are able to extend and strengthen this estimation strategy by having exogenous variation in three additional policy instruments for identifying the key model parameters. Most importantly, we include a student loan take-up choice and loan accumulation into the model, as well as have exogenous variation in loan amounts and repayment schemes. The idea of combining a quasi-experiment with a structural dynamic model has been strongly advocated (Card and Hyslop, 2005; Todd and Wolpin, 2006; Heckman, 2010; Keane et al., 2011; Attanasio et al., 2012; Blundell and Shephard, 2012). This approach allows us to: (i) estimate a richer structural model exploiting exogenous reform variation to identify key parameters, (ii) make more elaborate model validation, and (iii) simulate effects of potential policies never previously implemented.

Students self-finance a considerable amount of their college costs through working part-time while enrolled in college: Leslie (1984) reports that US students self-finance around $20 \%$ of college expenses. Bound et al. (2007) show that student employment has increased over time and speculate that this reflects students self-financing increased tuition fees. Joensen (2013a) stresses the importance of explicitly modelling student employment choices when quantifying the impacts of study grants. ${ }^{5}$ Joensen (2013a) demonstrates that the impact of student work hours on academic achievement is non-linear: working 1-9 hours a week is complementary to academic success, while working more than 18 hours is very detrimental. Therefore, redistributing study grants from those working more to those working less only leads to negligible positive increases in college graduation rates - less than 5 percentage points - while it has no impact on timesto-graduation. The declared social objectives of higher graduation rates and lower times-tograduation can thus not be obtained through tilting the study grant scheme only. Joensen (2013b) extends these findings to further consider how redistribution across time (e.g. timely graduation bonuses) and from students who perform under a specified academic standard to those who perform better during college (e.g. merit aid) affects academic achievement. The

\footnotetext{
Joensen (2013a) shows the same tendency for university students in Denmark, where both drop-out rates and the amount of student employment is similar to US 4-year colleges. In 2007, an average OECD country 15-29 year old student was employed the equivalent of $27 \%$ of full-time employment while enrolled in education.

${ }^{5}$ Ignoring students' ability to self-finance their studies through student employment will overestimate the opportunity costs of college. This introduces a systematic bias in the opportunity cost of college, since it is not random which students work and how much they work. Furthermore, ignoring the direct impacts of student employment on academic achievement further biases any estimated effects of student aid on outcomes to the extent that these are correlated with college-work choices.
} 
main conclusion is that merit aid, where study grant eligibility is conditional on passing a requisite amount of courses each year, is the most effective way to induce students to graduate at a higher rate and faster.

Another way to redistribute student aid across time and students is to provide study loans. Although study loans are widespread,${ }^{6}$ little is known about the impacts of more generous loans or different loan repayment schemes on student performance. The interest in understanding the consequences of student loans has increased recently given the rise of student debt in the US. ${ }^{7}$ The structural dynamic models of Joensen (2013a) and Joensen (2013b) are estimated on Danish data, where take-up rates of student loans are too low to feasibly quantify the impacts of loans. We extend those models with the intertemporal dependence implicit in undertaking a loan and analyze the effects of this particular aspect. This enables us both to analyze how providing student aid in the form of a grant (or scholarship) or a loan, and whether the nature of the loan repayment scheme matters for student behavior and economic success. Including student loans as an additional source of income and having having exogenous variation in both the current loan amounts and the intertemporal trade-off they entails through changing repayment schemes, allows us to also estimate the student's risk and loan aversion.

This paper also contributes to the literature on borrowing constraints. This literature finds that despite the tightness of borrowing constraints, removing them has a small and negligible impact on educational attainment and achievement. This is found both for the US; Keane and Wolpin (2001), Carneiro and Heckman (2002), Cameron and Taber (2004), Johnson (2013) and for Denmark; Nielsen et al. (2010). Recently, some papers have questioned this result. Lochner and Monge-Naranjo (2011a) underline the increasing importance of credit constraints for students in the US, with raising tuition fees and an increasing share of students borrowing the maximum student loan amounts. Solis (2011) exploits the design of student loans in Chile to estimate the effects on college enrollment and finds that access to loans eliminates the importance of parental background. Brown et al. (2012) and Mattana (2013) stress the importance of strategic interactions in the family to understand the real impact of credit constraints on educational outcomes. These papers make significant contributions to our understanding of the

\footnotetext{
${ }^{6}$ According to OECD (2009), $75 \%$ of Swedish, $65 \%$ of Norwegian, and $80 \%$ of UK, $55 \%$ of US students in higher education have loans, while very few Danish and Finnish students have loans. This amounts to $61 \%$ of student aid in Sweden, $67 \%$ in Norway, and $58 \%$ in the US.

${ }^{7}$ Lochner and Monge-Naranjo (2011b) and Avery and Turner (2012) provide recent reviews. Debt burdens can have various consequences for individuals. Rothstein and Rouse (2011) show that high debt burdens decrease the likelihood of choosing low-payed careers (e.g. as teachers) and Gicheva (2012) shows that a higher student debt decreases the probability of getting married.
} 
nature and importance of borrowing constraints. However, none of these papers allow students to self-finance consumption during college by working, which is an important source of income and a potential source of bias in assessing the importance of borrowing constraints (Leslie, 1984; Bound et al., 2007; Joensen, 2013a). Keane and Wolpin (2001) and Johnson (2013) allow student income to be a source of consumption, however, do not allow it to directly affect college achievement which we show is a significant channel when evaluating study aid policies.

To the best of our knowledge, this is the first paper to simultaneously model study grants and loans in great detail embedded in a dynamic model of key student choices (enrollment, employment, and loan take-up) and outcomes (course credit production and earnings). The register based panel data and the universal nature of the Swedish study aid scheme enable us to specify the educational and student aid environment in great detail. Two other notable papers assessing borrowing constraints in a dynamic model of joint college enrollment and student employment choices have to be mentioned here: Keane and Wolpin (2001) and Johnson (2013). Johnson (2013) introduces student loans into the Keane and Wolpin (2001) model by approximating the Federal Family Loan Program (FFEL) loan program rules in a dynamic model also including private credit limits, tuition differences across states, as well as need- and merit-based grants. However, due to the complexity and multiplicity of the US student aid and limited data availability, it is not possible to get a good measure of actual student aid. We need to highlight some important aspects of the student aid schemes in order to understand how we minimize non-trivial non-random measurement error, and thus better address core policy concerns related to student aid. ${ }^{8}$ Important differences between the US and Sweden make it easier to accurately model potential funding opportunities of Swedish students. First, US grants and loans are mainly provided by the federal government, states and colleges, while Swedish aid is predominantly provided by the central government. The multiplicity of scholarship and loan programs and complexity of eligibility rules make it impossible to estimate study aid opportunities in the US. The uniformity and simplicity of study aid rules in Sweden enable accurate measurement of actual study aid oppotunities that can be matched up with actual loan take-up choices observed in the data. Second, US grants depend on parental income - typically grants are a decreasing function of parental income, because of need based grants and loans (e.g. the Pell grant and the Stafford loans) whereas Swedish student aid is largely independent of

\footnotetext{
${ }^{8}$ Kane (2006), Lochner and Monge-Naranjo (2011a), Brown et al. (2012), Avery and Turner (2012), and Dynarski and Scott-Clayton (2013) provide a more detailed description of financial aid in the US.
} 
parental income. Third, Swedish aid depends on student earnings, making it pivotal to jointly model student employment choices and their impacts on academic achievement. Fourth, tuition is university-specific and depends on student characteristics. Most papers assume a uniform tuition level, while Johnson (2013) proxies tuition differences by setting state as an initial condition. Tuition is uniformly zero in Sweden. On top of having very precise information on the public study aid scheme and the college costs individuals face, we also have individual level data on students' (and their parents') income. This allows us to estimate their alternative funding opportunities with more accuracy than is previously done.

Two additional measurement and modelling issues are worth highlighting. First, previous papers on borrowing constraints have not been able to measure student debt directly, but try backing it out from survey questions on total debt. Student loan borrowing has thus been indirectly assessed by including net worth as a state variable. We have individual panel data on student aid from age 16 and can directly measure student loan amounts. Second, we are able to distinguish between time spent in college relative to accumulated course credits. Previous papers only estimates degree premiums and model degree completion, as no other college achievement measure is available in datasources like the NLSY79 and NLSY97. We model grade level progression at the course credit level, as we have detailed data on accumulated course credits each semester. This is another important margin, as it allows us to assess achievement much more accurately and estimate how close students are to degree completion. A significant contribution is thus that we can both model students college progression and actual funding opportunities much more accurately.

Student aid policies can play a welfare enhancing role by increasing college graduation rates. This has been known since Friedman (1962), but if they actually do and by how much is still an open question. Dynarski (2008) concludes that dropout rates are high even with free tuition. This suggests that the direct costs of college are not the only impediments to college completion. Hence, more than tuition reductions is needed in order to substantially increase college graduation rates; for example, aid that extends beyond direct costs to opportunity costs. Since there is no variation in the US data for college costs extending below zero, evaluating these types of policies is not possible using US data. For example, the most generous relaxation of borrowing constraints in the policy simulations in Keane and Wolpin (2001) and Johnson (2013) allows students to borrow up to the full cost of college. Sweden provides an ideal environment to analyze study aid policies that include student loans, because it is one of the most generous 
in the world with free tuition and large public grants and loans to which most enrolled students are eligible. A substantial fraction of students also take up the loan. Moreover, the reform of the study aid scheme provides a unique quasi-experimental setting for our analysis. Avdic and Gartell (2015), analyze the impact of the 2001 Swedish study aid reform on individual study efficiency. We depart substantially from their approach, both in means and in scope. Avdic and Gartell (2015) estimate short run ex-post total effects of the reform as a whole, hence are not able to separate out its various components; e.g. loan repayment schemes, less weight on loans relative to grants, tighter eligibility requirements, and more generous income means testing. Furthermore, they do not account for student employment decisions and important dynamic selection; i.e. the fact that it is not random who is still enrolled in college at any given point in time. Hence, they are neither able to disentangle the impacts of the various policy instruments changed by the reform nor the mechanisms by which they affect study efficiency. This paper contributes to the literature by providing estimates of the direct effects of study grants and loans on academic achievement, as well as their indirect effects operating through student employment choices. These estimates are pivotal for better ex-ante policy evaluation and knowing which components of the study aid scheme affect which margins of choices and outcomes.

College enrollment, grade level progression, student debt accumulation, and work experience are thus all endogenously determined in our model. Thus building the study aid scheme into our model enables us to disentangle the effects of financial aid and student employment on drop-out rates, college achievement, timing of college graduation, accumulated student debt, and labor market productivity. Particularly, the impacts of loan repayment schemes have not been previously quantified.

\section{The Swedish Study Aid System}

Sweden is one of the European countries with the highest share of college graduates in the population. The annual public expenditure per student in tertiary education is about 14,000 euros per year - one of the highest in Europe with an average of 8,000 euros per year. ${ }^{9}$ Higher education is free of tuition for all students and largely financed by the government. Moreover, $26 \%$ of the sizable total public expenditure on higher education is targeted to grants and loans

\footnotetext{
${ }^{9}$ Source: Eurostat (2009)
} 
for students. Student financing is administered by the central study aid authority, Centrala Studiestödsnämnden (CSN).

Students who are eligible for study aid can decide whether to receive the grant and to take up the student loan. Eligibility for study aid and the amount of aid are determined both through means testing and through merit. Means testing (inkomstprövning) determines the total amount per week the student is eligible for. Students are required to complete $75 \%$ of the course credits (ECTS) they enrol for in order to maintain eligibility for the following year. The student can decide how many weeks of loan to receive - up to a maximum of 20 weeks per semester for full-time students and 10 weeks per semester for part-time (50\%) students.

\subsection{The 2001 Reform}

The 2001 reform affected four major aspects of the study aid scheme: the proportion of grant and loan in the total aid amount, means testing and income requirements, time and merit requirements, and the loan repayment schemes. These aspects of change are detailed in the following four subsections. ${ }^{10}$

\subsubsection{Grant and Loan Proportions}

The total amount of aid available to every student remained unchanged after the reform, but the grant part was made more generous: the proportion of grant to loan went from $27.8 \%$ to $34.5 \%$. Higher grants imply looser credit constraints and lower incentives to take up loans. This is also evident from the loan propensities in the data: $82 \%$ of students receiving grants also take up loans in 2000, compared to $77.3 \%$ in 2001.

\subsubsection{Student Income Thresholds and Means Testing}

Students are means tested on a half-year basis. If student income is above the maximum allowable threshold, the aid amount the student is eligible for decreases as labor income increases. As illustrated in Figure 1, after 2001 the semestral threshold went from 23,985 SEK in the first semester of 2001 to 46,125 SEK in the second semester (from an average of 0.75 0.65 in the spring semester and 0.85 in the fall - to 1.25 of the inflation adjusted base amount, prisbasbelopp). This is equivalent to a reduction of the labor income tax: the income of students, composed of aid and labor income, is thus taxed less after the reform. This is depicted

\footnotetext{
${ }^{10}$ See CSNFS (2001) for even more details on the reform.
} 
Figure 1: Maximum Study Aid and Grant as a function of Student Income.

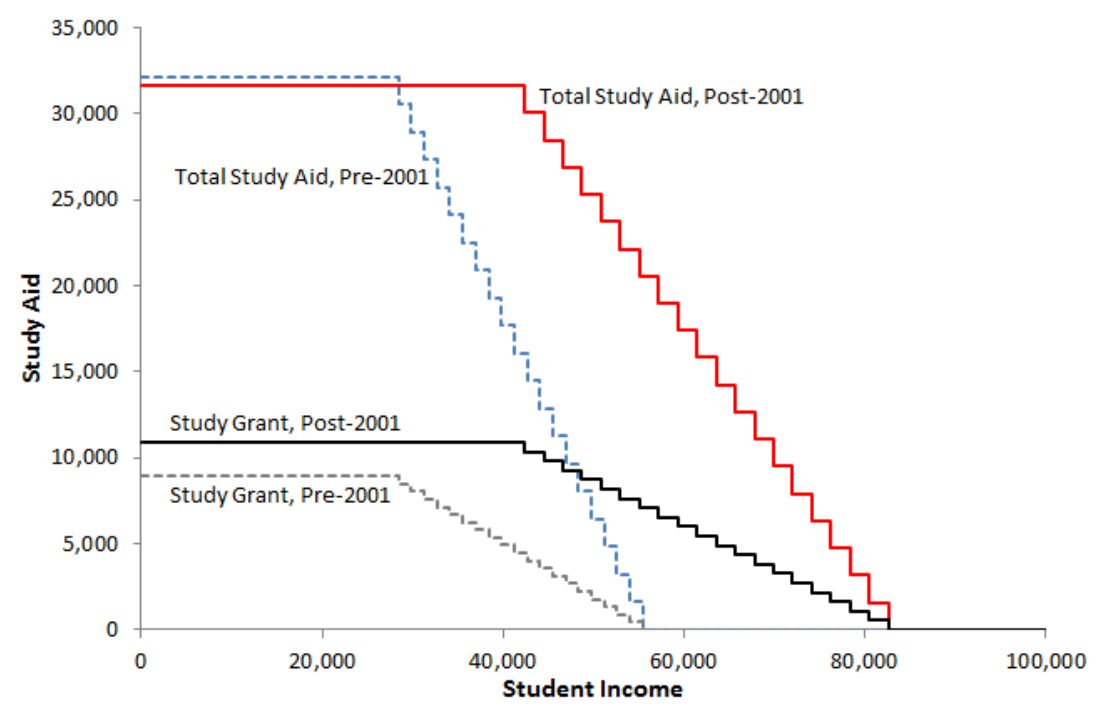

The Figure displays the maximum student aid and grant amount as a function of student income. All amounts are per semester in real SEK 2000. The exchange rate ultimo December 2000 was 9.3955 SEK/USD and 8.8263 SEK/EUR.

in Figure 2. An immediate effect of the maximal income threshold increase was that only 5,500 students got a reduction in their grant because of too high income in fall 2001, compared to 22,300 students in 2000 (CSN (2002)).

\subsubsection{Time and Merit Eligibility Requirements}

Eligibility requirements were also changed along five dimensions: First, students became eligible for study aid up to a maximum amount corresponding to 240 weeks (12 semesters) of higher education and enforcement of this eligibility rule was tightened. ${ }^{11}$ Second, part-time enrollment choices were expanded to include $75 \%$ of full-time studies, compared to only $50 \%$ before the reform. The merit requirements for the first year of higher education were relaxed from $75 \%$ to $62.5 \%$ of the ECTS enrolled for at the beginning of the year. ${ }^{12}$ Finally, it became easier to regain eligibility after losing it for one or more semesters.

\footnotetext{
${ }^{11}$ According to CSN (2002) the enforcement of this rule was not very strict before the reform, so the real time limit was more like 14-15 semesters. However, we do not include this stricter enforcement in the model, since we do not observe any change in actual study aid by time since initial enrollment in the data.

${ }^{12}$ One year of full-time courseload amounts to 60 ECTS, however, we observe many students enrolling for more than 60 ECTS.
} 
Figure 2: Total Student Income, Before and After the Reform.

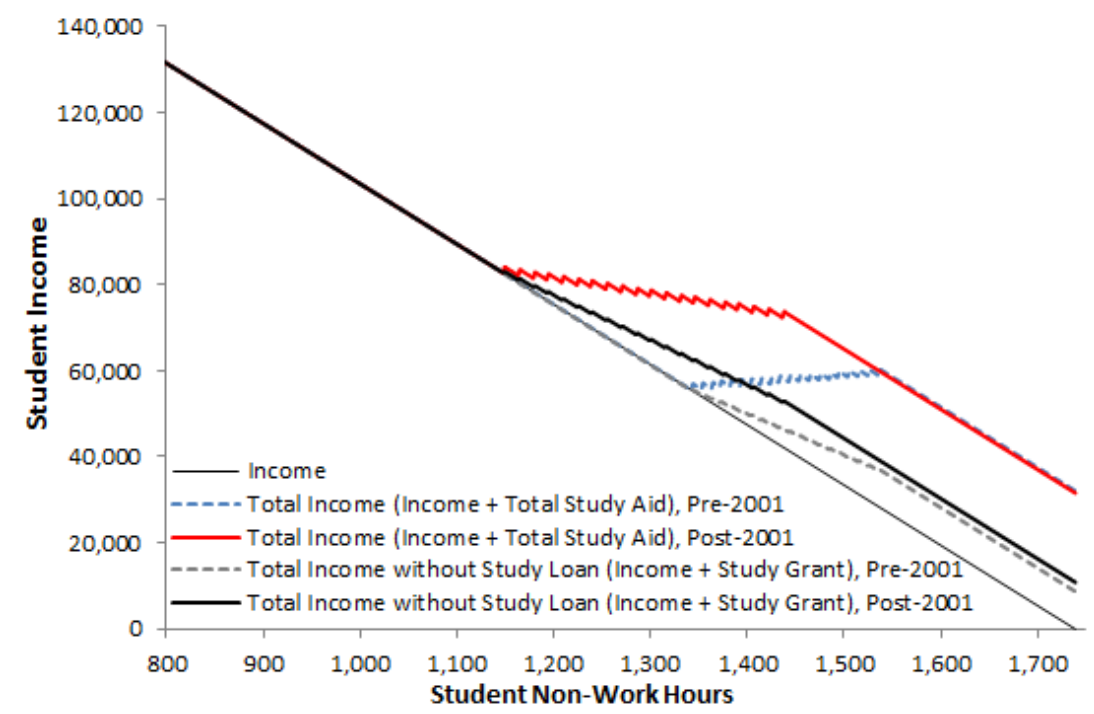

The Figure displays total student income - including the maximum student aid and grant amount - as a function of student leisure hours; i.e. yearly hours not worked. The figure is constructed assuming a non-working student has 1739 leisure hours a year and working students have an hourly wage of 140 SEK. All amounts are per semester in real SEK 2000. The exchange rate ultimo December 2000 was 9.3955 SEK/USD and 8.8263 SEK/EUR.

\subsubsection{Loan Repayment Schemes}

The loan repayment scheme went from an income contingent repayment scheme (studielain) to an annuity based scheme (annuitetslan). Before the reform the installments consisted of $4 \%$ of the labor income from 2 years earlier (with a minimum installment of 1,320 SEK). The debt was written off in case of (a) 65 years of age are reached, (b) death, (c) sickness. After the reform the installments became a 25 years annuity calculated according to the following formula:

$$
\widehat{a}_{t}=D_{t-1} \times(r-p) \times \frac{\left(\frac{1+r}{1+p}\right)^{25}}{\left(\frac{1+r}{1+p}\right)^{25}-1} \times(1+p)^{(t-1)} .
$$

Where $D_{t-1}$ is cumulated student debt, $p=2 \%$ is an increment of the annuity to mimic wage growth and the interest rate $r$ is set by the government to be $70 \%$ of the average cost of government borrowing over the past three years. A flavor of income contingency was kept: it is in fact possible to apply twice for a reduced installment. The requirements for the reduced installment are either a negative income shock or obtaining unemployment or disability benefits. The reduced installment consists of $5 \%$ of current income - after which the 25 years annuity repayment scheme is recalculated. The debt is now written off in case of (a) 68 years of age are reached, (b) death, (c) sickness. Figure 11 show the expected repayment schedules under the 
Figure 3: Expected Repayment Scheme and Evolution of Debt

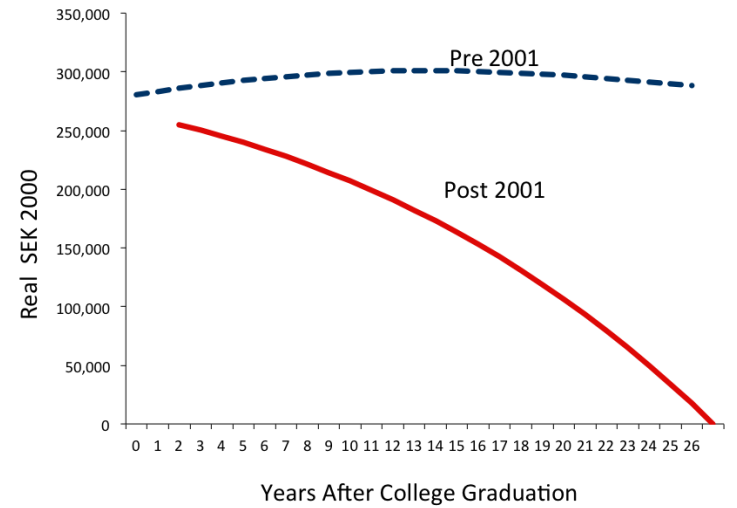

(a) Evolution of Debt, starting salary SEK 105,116

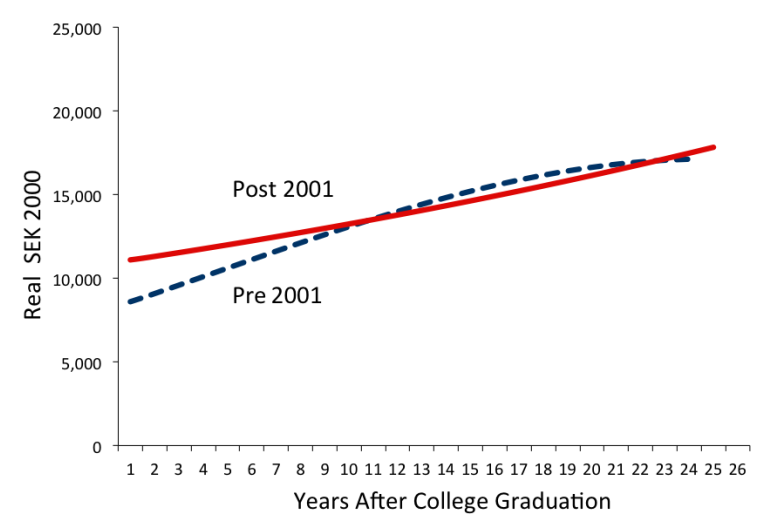

(c) Expected Repayment, starting salary SEK 202,229

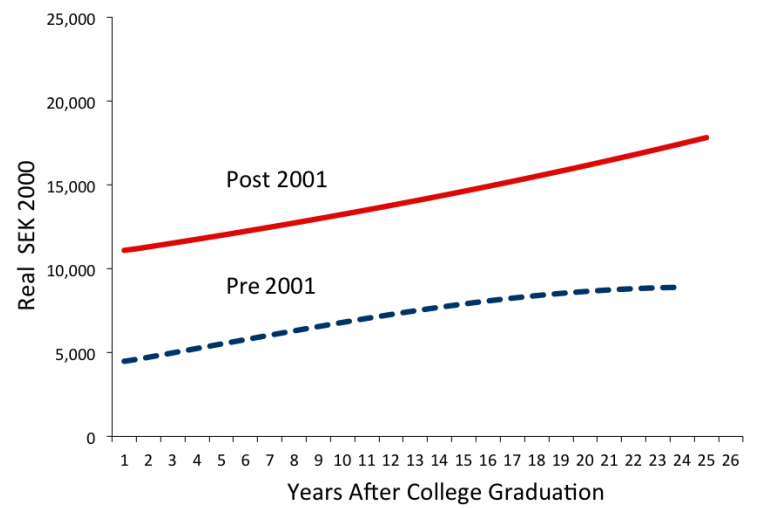

(b) Expected Repayment, starting salary SEK 105,116

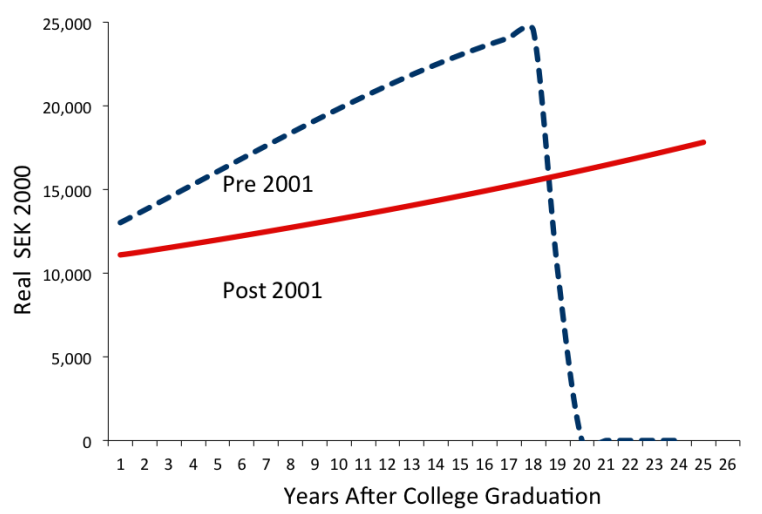

(d) Expected Repayment, starting salary SEK 306,678

The Figure displays the expected repayment scheme and evolution of cumulative debt for a full-time student with maximum loan (240 weeks), with starting yearly income equal to the average in our sample minus one standard deviation (SEK 105,116), the average in our sample (SEK 202,229), and the average in our sample plus one standard deviation (SEK 306,678). The income equation is assumed to be $\ln (w)=\ln \left(w_{0}\right)+0.06 H_{t}-0.0012 H_{t}^{2}$ and the loan interest rate $2.5 \%$. Pre reform figures are displayed with dashed lines and post reform figures with solid lines.

two regimes for a simulated student with maximum cumulated loan and different labor market entry incomes. For an entry income of SEK 20,000 per month (slightly higher than the average income of a college dropout) the two regimes are not very different. For lower starting salaries however the new repayment scheme consists of much higher installments than the old, while the opposite is true for higher starting salaries. ${ }^{13}$ The new regime thus reduces the disincentive to work in high-paid jobs, which is typical for income contingent repayment schemes.

\footnotetext{
${ }^{13}$ Figures 11 are constructed without the reduced installment possibly allowed twice.
} 
Figure 4: Immediate Impact of Reform on Student Income and Aid.

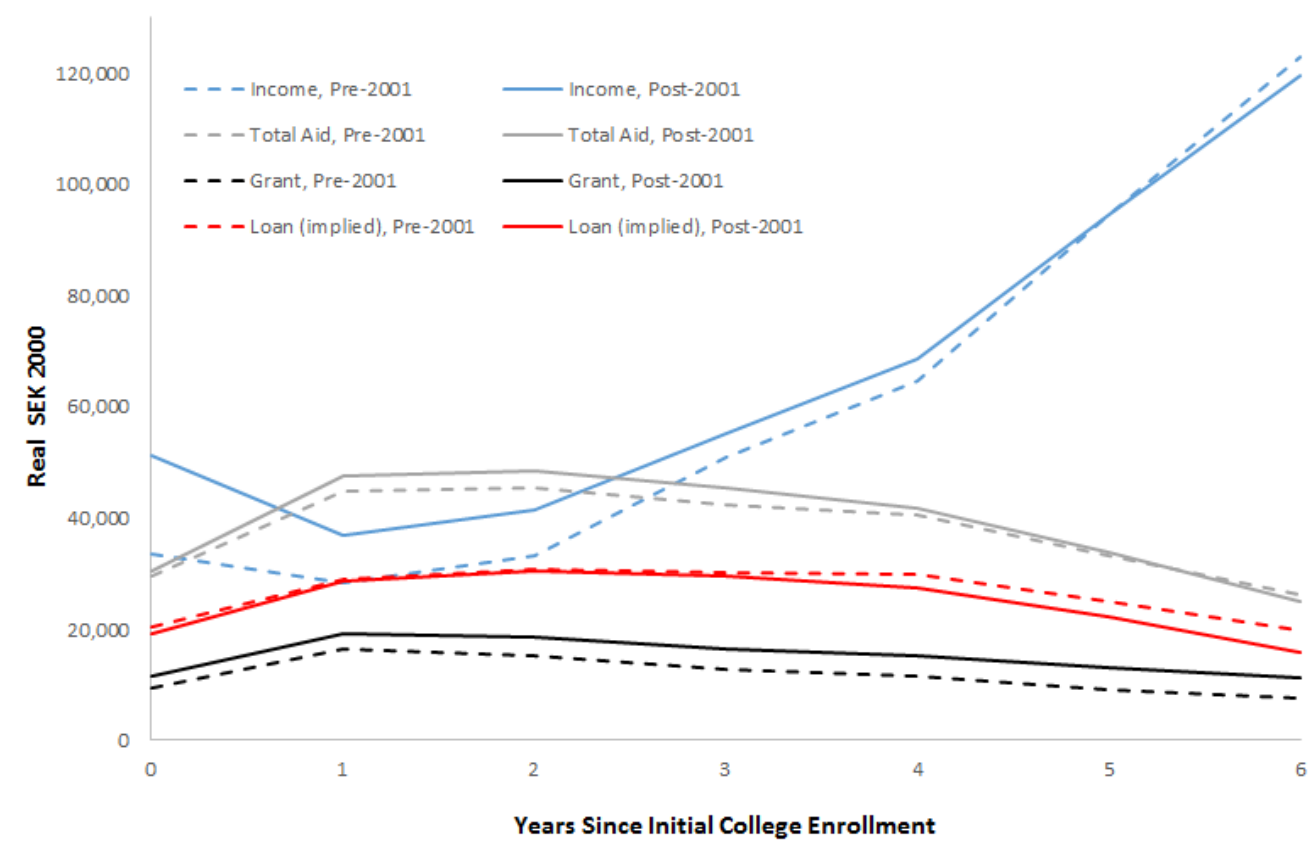

The Figure displays student income, total aid, grant, and loan amounts before and after the 2001 reform. All amounts are in real SEK 2000 and displayed separately by years since initial college enrollment (on the x-axis). The exchange rate ultimo December 2000 was 9.3955 SEK/USD and 8.8263 SEK/EUR.

\subsection{Immediate Impacts of the 2001 Reform}

Did the reform actually have an impact on student choices and outcomes? Figure 4 displays student income, total aid, grant, and loan amounts before and after the reform, while Figure 5 displays student employment and loan take-up rates. All numbers are displayed separately by years since initial college enrollment. Figure 4 shows that student income increases for all enrollment years. In accordance with the study aid scheme: total aid stays roughly constant, while the grant amount increased and the loan amount decreased. Students thus tend to self-finance more of their college education through working and accumulate less debt after the reform. Thus the intensive margins of outcomes seem to have been affected by the reform. Figure 6 reveals that student debt decreased both for dropouts and those who eventually acquired a more advanced college degree. This decrease is present already during their first enrollment year. A closer look at student choices reveals that even the extensive margins changed. Figure 5 shows that more students decide to work after the reform and fewer students take up loans. Student employment increases particularly much during the first college years, while loan take-up decreases most during the first college years. 
Figure 5: Immediate Impact of Reform on Student Employment and Loan Status.

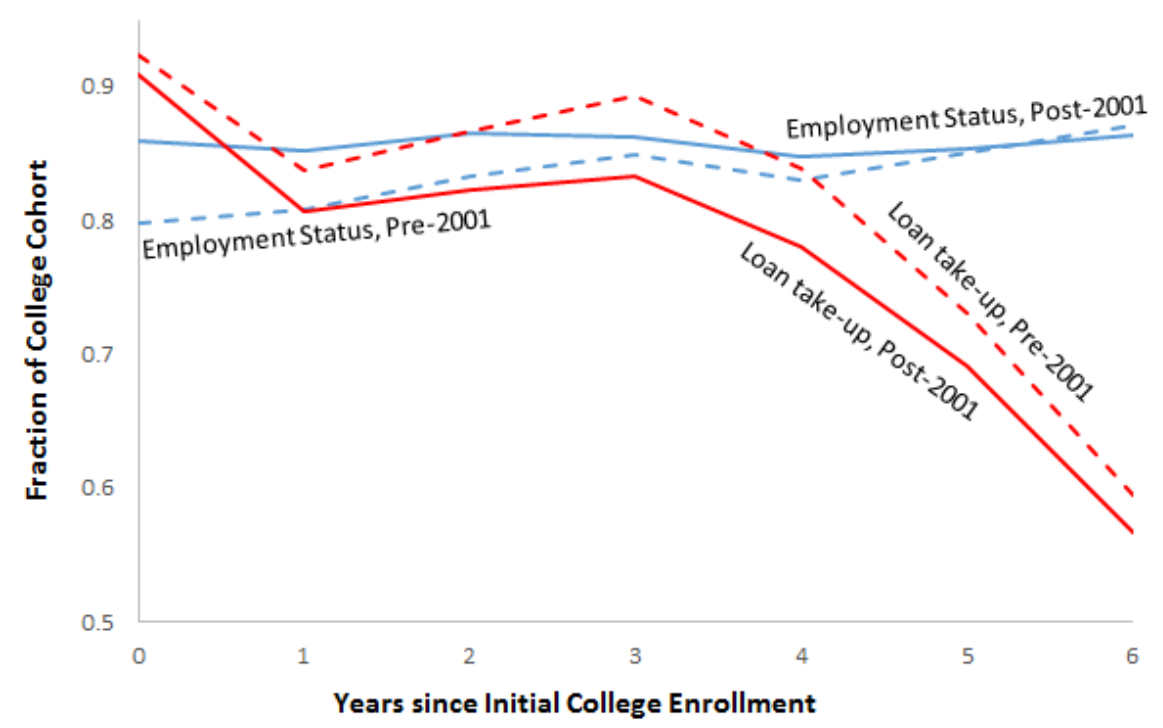

The Figure displays student employment and loan take-up choices before and after the 2001 reform. All numbers are displayed separately by years since initial college enrollment (on the $\mathrm{x}$-axis).

Figure 6: Immediate Impact of Reform on Cumulated Loan by College Degree.

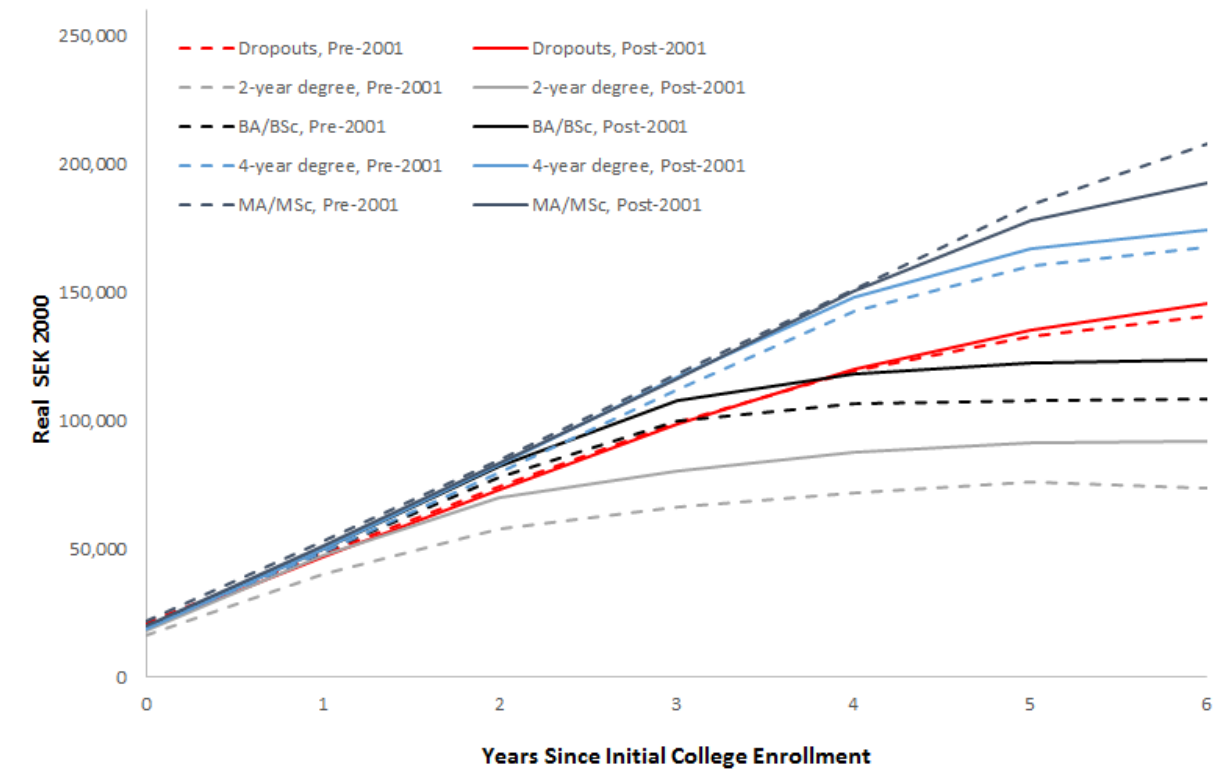

The Figure displays the loan cumulated before and after the 2001 reform. All amounts are in real SEK 2000 and displayed separately by years since initial college enrollment (on the $\mathrm{x}$-axis). The exchange rate ultimo December 2000 was 9.3955 SEK/USD and 8.8263 SEK/EUR. 
Overall, the major reform of the study aid scheme seems to have increased student employment and income, while is has decreased loan take-up rates and student debt. This is the exogenous variation in the data we exploit in order to identify our model parameters. We now turn to describing the model that will assist us in quantifying and disentangling the channels through which the various components of the reform affected student choices and outcomes.

\section{The Model}

In this section we set up the dynamic discrete choice model of joint education, employment, and student loan take-up decisions. Choices are made at the individual level, but we suppress individual subscripts throughout this section for ease of exposition.

\subsection{Individual choices}

We model choices from time of initial college enrollment to exit. At every point in time students are characterized by initial abilities and skills $A$ and $K$, cumulated course credits $G_{t}$, highest achieved education $E_{t}$, cumulated loan $D_{t}$, cumulated labor market experience $H_{t}$, and labor market experience cumulated during university, $\tilde{H}_{t}$. We also keep track of last period's choices of work and student loan take-up. After graduating high school at $t=0$, every period agents have to choose if to continue with university studies, $S_{t} \in\{0,1\}$, whether and how much to work while studying, $h_{t} \in\left\{0, \frac{1}{2}, 1\right\}$, and how much student loan to take up, $d_{t} \in\left\{0, \frac{1}{2}, 1\right\}$. These choices are going to determine next period's cumulated course credits, highest achieved education, cumulated loan, and labor market experience. When they exit college, either drop out or graduate, they work full-time for a wage that depends on their cumulated course credits, level of education, and labor market experience.

Students thus face ten mutually exclusive and exhaustive choices: $\left(S_{t}, d_{t}, h_{t}\right) \in$ $\left\{(0,0,1),(1,0,0),\left(1, \frac{1}{2}, 0\right),(1,1,0),\left(1,0, \frac{1}{2}\right),\left(1, \frac{1}{2}, \frac{1}{2}\right),\left(1,1, \frac{1}{2}\right),(1,0,1),\left(1, \frac{1}{2}, 1\right),(1,1,1)\right\}$. The discrete choices are denoted by $\delta_{t} \in\left(\delta_{t}^{0}, \delta_{t}^{1}, \delta_{t}^{2}, \delta_{t}^{3}, \delta_{t}^{4}, \delta_{t}^{5}, \delta_{t}^{6}, \delta_{t}^{7}, \delta_{t}^{8}, \delta_{t}^{9}\right)$ where $\delta_{t}^{k}$ takes value 1 if the corresponding alternative is chosen and zero otherwise. Students discount the future at rate $\beta \in[0,1]$ and maximize their expected utility. They choose $\left\{\delta_{t}^{*}\right\}_{t=1}^{T}$, a set of decision rules for every possible realization of the observed and unobserved variables each period, denoted by 
$\left(X_{t}, \epsilon_{t}\right)$, such that:

$$
\delta_{t}^{*}=\arg \max _{k} \mathbb{E}\left[\sum_{\tau=t}^{T} \beta^{\tau-t} \sum_{k=0}^{7}\left[\delta_{\tau}^{k} U_{\tau}^{k}\left(X_{\tau}\right)+\epsilon_{\tau}\right]\right] .
$$

The state variables in $X_{t}=\left(A, K, G_{t}, D_{t}, H_{t}, \tilde{H}_{t}, h_{t-1}, d_{t-1}, t\right)$ are also observed by the econometrician, while those in $\epsilon_{t}=\left(\epsilon_{t}^{w}, \epsilon_{t}^{g}, \epsilon_{t}^{0}, \epsilon_{t}^{1}, \epsilon_{t}^{2}, \epsilon_{t}^{3}, \epsilon_{t}^{4}, \epsilon_{t}^{5}, \epsilon_{t}^{6}, \epsilon_{t}^{7}, \epsilon_{t}^{8}, \epsilon_{t}^{9}\right)$ are observed only by the individuals. The utility of the individual is assumed to be additively separable in $X_{t}$ and $\epsilon_{t} .{ }^{14}$ All stochastic components are revealed after the choices for the period are made, hence students observe the deterministic state variables, form expectations about the stochastic components of the state vector, and then make decisions.

By the Bellman principle of optimality, the problem can be rewritten as:

$$
V_{t}\left(X_{t}, \epsilon_{t}\right)=U_{t}^{k}+\beta \mathbb{E}\left[V_{t+1}\left(X_{t+1}, \epsilon_{t+1}\right)\right]
$$

and, given the discrete nature of the choices, it can also be written as:

$$
\begin{aligned}
& V_{t}\left(X_{t}, \epsilon_{t}\right)=\max _{k} V_{t}^{k}\left(X_{t}, \epsilon_{t}\right) \\
& V_{t}^{k}\left(X_{t}, \epsilon_{t}\right)=U_{t}^{k}+\beta \mathbb{E}\left[V_{t+1}\left(X_{t+1}, \epsilon_{t+1}\right) \mid X_{t}, \epsilon_{t}, \delta_{t}^{k}=1\right]
\end{aligned}
$$

where $V_{t}^{k}\left(X_{t}, \epsilon_{t}\right)$ denotes the alternative specific value function. The last term is typically referred to as the $\mathbb{E} \max$ as it is the expectation over future optimal values, which makes solution and estimation of the model challenging.

In the following subsections we analyze the details of the specifications of the labor market, the academic environment, and the preferences of the individuals over the feasible college-workloan choices.

\subsubsection{Academic Environment}

Individuals enrolled in a university program complete one year when they produce 60 ECTS. The minimum requirements for 2-year college degree are 120 ECTS, 180 ECTS for a BA/BSc degrees, 240 ECTS are necessary for acquiring a 4-year degree, and 300 ECTS for a MA/MSc degree. We normalize a completed year of university education to $g_{t}=6$ course credits, equiv-

\footnotetext{
${ }^{14}$ This assumption is crucial for the CCP method we apply. Keane and Wolpin (1994) and Keane et al. (2011) provide thorough discussions of this assumption.
} 
alent to actual ECTS production being $g_{t} * 10$. Highest completed education is thus a function of accumulated course credits:

$$
E_{t}= \begin{cases}0 & \text { if } G_{t}<120 \\ 1 & \text { if } 120 \leq G_{t}<180 \\ 2 & \text { if } 180 \leq G_{t}<240 \\ 3 & \text { if } 240 \leq G_{t}<300 \\ 4 & \text { if } G_{t} \geq 300\end{cases}
$$

We denote course credits accumulated from $t$ to $t+1$ by $g_{t}$, accumulated credits then follow the law of motion: $G_{t+1}=G_{t}+S_{t} g_{t}$. We allow the accumulation of course credits to depend on initial abilities and skills. Initial abilities $A$ are measured by whether the student was in the top $10 \%$ of the high school cohort GPA distribution. Initial skills $K$ are proxied by whether the student completed the most advanced math-science track in high school. We also allow course credits to depend on whether the student has already acquired a two-, three- or four-year degree, $E_{t}=1,2,3$ and is continuing to study for a higher degree, already accumulated course credits, $G_{t}$, capturing self-productivity of academic skills (Cunha et al., 2006; Cunha and Heckman, $2008)$, time since initial enrollment, work status, $h_{t}$, and an idiosyncratic shock, $\epsilon_{t}^{g}$. We also include an indicator for the first year of enrollment as students typically start in September and all other observations are on calendar year. This captures differences in the time-period course credits are produced. Production of academic course credits is given by:

$$
\begin{aligned}
g_{t}^{*} & =\gamma_{1} A+\gamma_{2} K+\gamma_{3} G_{t}+\sum_{e=1}^{3} \gamma_{3+e} \mathbf{1}_{\left\{E_{t}=e\right\}}+\gamma_{7} t+\gamma_{8} \mathbf{1}_{\{t=0\}}+\gamma_{9} \mathbf{1}_{\left\{h_{t}=\frac{1}{2}\right\}}+\gamma_{10} \mathbf{1}_{\left\{h_{t}=1\right\}}+\epsilon_{t}^{g} \\
& =g\left(X_{t}\right)+\epsilon_{t}^{g}
\end{aligned}
$$

where the unobservable term $\epsilon_{t}^{g}$ is logistically distributed and the probability of producing $g_{t}$ course credits is thus of ordered logit form. Course credit production is thus probabilistic in the sense that students are not sure how many courses they will pass during the academic year about to start. The continuous latent variable $g_{t}^{*}$ reflects the academic knowledge acquired during the year, which we measure by the eight discrete values: $g_{t} \in\{0,1,2,3,4,5,6,7\}$.

Importantly, we allow students to face uncertainty about how much academic capital they will acquire and also allow it to depend on work status. Joensen (2013b) shows that the relationship between hours worked and academic achievement is nonlinear: few hours of work 
have a positive effect on credits production, while working more hours has a detrimental effect. We have less detailed data on hours worked, but better data on the timing of work during the year. We distinguish between working predominantly during the summer months (captured by $\left.\gamma_{9}\right)$ and also working a significant amount during the semesters (captured by $\gamma_{10}$ ). This flexibly allows for different trade-offs between academic performance and the timing of work months.

\subsubsection{Labor Market}

Every period the individuals receive a wage offer with probability $p_{w}=1$. The wage is assumed to depend on the highest acquired degree, $E_{t}$, accumulated course credits, $G_{t}$, work experience, $H_{t}=H_{t-1}+h_{t-1}$, work experience accumulated during university enrollment, $\tilde{H}_{t}=\tilde{H}_{t-1}+h_{t-1} S_{t-1}$, whether the individual is a student or not, $S_{t}$, and an idiosyncratic labor market productivity shock, $\epsilon_{t}^{w}$. As in the course credit accumulation equation we insert a dummy for the first year of enrolment. More specifically, earnings are given by: ${ }^{15}$

$$
\begin{aligned}
\log \left(Y_{t}\right)= & \alpha_{0}+\sum_{e=1}^{4} \alpha_{e} \mathbf{1}_{\left\{E_{t}=e\right\}}+\alpha_{5} G_{t}+\alpha_{6} \mathbf{1}_{\{t=0\}}+\left(1-S_{t}\right)\left[\sum_{e=1}^{4} \alpha_{6+e} \log \left(H_{t}-\tilde{H}_{t}+1\right) \mathbf{1}_{\left\{E_{t}=e\right\}}\right. \\
& \left.+\sum_{\tilde{h}=0}^{3} \alpha_{11+\tilde{h}} H_{t} \mathbf{1}_{\left\{\tilde{H}_{t}>\tilde{h}\right\}}\right]+S_{t}\left[\alpha_{15} \tilde{H}_{t}+\alpha_{16}+\alpha_{17} \mathbf{1}_{\left\{h_{t}=\frac{1}{2}\right\}}\right]+\epsilon_{t}^{y}
\end{aligned}
$$

The unobservable term $\epsilon_{t}^{w}$ is normally distributed with mean zero and variance $\sigma_{w}^{2}$. We are able to separate out the pecuniary importance of degrees and credits by allowing the wage to both depend on highest acquired degree and cumulated course credits during college enrollment. Thus allowing for nonlinearities in the wage return to education - meaning the individuals who have completed a degree receive higher wages than individuals that completed course credits necessary to obtain the degree but did not graduate. This is also known as sheepskin effects; if $\alpha_{1}=\alpha_{2}=\alpha_{3}=\alpha_{4}=0$ there would be no such effects. ${ }^{16}$ Note that analysing these effects has not been possible in previous papers on college attainment as Keane and Wolpin (2001) only model 4-year college completion and Johnson (2013) only models 2- and 4-year college completion, thus implicitly assuming that only degrees matter on the labor market.

\footnotetext{
${ }^{15}$ We also tried estimating standard Mincer type earnings equations with linear quadratic dependence on experience, however, given that we follow most individuals from having no experience through their very early career the $\log \left(H_{t}+1\right)$ specification fits our earnings-experience profiles much better.

${ }^{16}$ See e.g. Heckman et al. (2006) for a thorough review of non-linearities in the return to education and other specification issues of the earnings equation.
} 
The availability of detailed data on both degrees and course credits each semester allows us to distinguish between the labor market returns to course credits and degrees.

\subsubsection{Budget Constraint}

Consumption is equal to earnings, $Y_{t}$, minus the repayment of the student loan if the individual has exited college and plus aid if eligible. More specifically, the budget constraint is:

$$
\left.C_{t}=Y_{t}+S_{t} \widehat{b}\left(X_{t}\right)+d_{t} \widehat{d}\left(X_{t}\right)\right)+\left(1-S_{t}\right) \widehat{I}\left(X_{t}\right)
$$

where $\widehat{b}$ is the student grant amount, $\widehat{d}$ the student loan amount conditional on the loan choice $d_{t}$, and $\widehat{I}_{t}$ the installment of loan repayment. All these amounts were changed by the reform. The budget constraint is static in the sense that we do not model savings. Budget constraints are, however, intertemporally linked through student debt accumulation and loan repayment. We model study aid as close as possible to the scheme described in Section 3 conditional on the information we have in the data. Study aid is thus following the function plotted in Figure 1 and Figure 2 subject to the eligibility requirements described in Section 3.

The total amount of study aid is means tested on student income in the current year, $Y_{t}$, but independent of parental resources. If current income $Y_{t}$ is above the threshold $\bar{Y}$, then the study aid is taxed at the implicit tax rate $\tau_{B}$. All students enrolled in college, $S_{t}=1$, are eligible for study aid as long as the limit of maximum number of 240 weeks of student aid is not reached. This corresponds to $\bar{t}=6$ years in our model. Let $\bar{B}$ denote the maximum base aid amount. The maximum aid amount $\widehat{B}_{t}$ the student is eligible for is given by the following rule:

$$
\widehat{B}\left(X_{t}\right)=\left[\bar{B}-\tau_{B}\left(Y_{t}-\bar{Y}\right) \mathbf{1}_{\left\{Y_{t} \geq \bar{Y}\right\}}\right] \mathbf{1}_{\{t \leq \bar{t}\}} .
$$

The available aid is then divided into a grant share and a loan share. Denote the weight on grants by $b$. Thus the grant amount is given by $\widehat{b}\left(X_{t}\right)=\bar{b} \widehat{B}\left(X_{t}\right)$, and the maximum base grant amount is $\bar{b}=b \bar{B} \cdot{ }^{17}$ Similarly, the loan amount students are eligible for is given by

\footnotetext{
${ }^{17}$ The data reveal that only 2.8 percent of eligible students turn down the grant, hence in the model and estimation we assume that all eligible students receive the grant. Moreover, the data only include total student aid received during the year. We assume students will receive the full grant amount before taking up the loan. In order to calculate the loan amount, we thus subtract the grant amount the student is eligible for from the total study aid observed in the data.
} 
$\widehat{d}\left(X_{t}\right)=(1-b) \widehat{B}\left(X_{t}\right)$, and the law of motion of student debt is:

$$
D_{t+1}\left(X_{t}\right)=D_{t}+d_{t} \widehat{d}\left(X_{t}\right)
$$

Note that despite the static budget constraint in equation(7), the current loan amount affects the expected future value through the accumulation of debt to be repaid post college exit, $\widehat{I}$. The rules for loan repayment were drastically changed with the reform in 2001 from an income contingent one to an annuity one. Before 2001, individuals would repay $4 \%$ of their income two years prior, $Y_{t-2}$, until their debt was repaid or they retired. Pre-reform repayment thus follows:

$$
\widehat{I}_{t}\left(D_{t-1}, Y_{t-2}, r\right)=\max \left\{0, \min \left\{0.04 Y_{t-2},(1+r) D_{t-1}\right\}\right\}
$$

After 2001 the instalment are calculated according to the 25 years-annuity described in equation(1) in Section 3, $\widehat{a}\left((1+r) D_{t-1}\right)$. Students enrolled prior to fall 2001 are twice allowed to choose to repay $5 \%$ of their income for three years and then reset the annuity. Let $I$ denote the indicator function that takes value 1 if the individual has chosen an income contingent payment at least twice and 0 otherwise. Post-reform repayment thus follows:

$$
\widehat{I}_{t}\left(D_{t-1}, Y_{t}, \widehat{a}, r\right)= \begin{cases}\max \left\{0, \min \left\{\widehat{a}\left((1+r) D_{t-1}\right), 0.05 Y_{t}\right\}\right\} & \text { if } I=0 \\ \left.\max \left\{0, \widehat{a}\left((1+r) D_{t-1}\right)\right\}\right\} & \text { if } I=1\end{cases}
$$

Note that the student debt accumulates interest over time, at the rate $r$. The reform changed both the grant share of the maximum base aid amount, $\bar{b}$, the maximum student income threshold, $\bar{Y}$, the implicit tax rate, $\tau_{B}$, and the enforcement of the duration of study aid, $\bar{t}$. Section 5.1 details the behavioral impacts of these changes and how they are exploited for identifying the model parameters.

\subsubsection{Preferences}

Individuals gain utility from consumption, and utility is of the CRRA form $u\left(c_{t}\right)=$ $\frac{1}{\lambda}\left(c_{t}^{\lambda}-1\right)$, where $1-\lambda$ is the risk aversion parameter. The instantaneous utility of full-time work is thus as follows:

$$
U_{t}^{0}\left(X_{t}, \epsilon_{t}^{0}\right)=u\left(Y_{t}-\widehat{I}_{t}\left(D_{t-1}, Y_{t-2}, r\right) \mathbf{1}_{\text {year } \leq 2001}-\widehat{I}_{t}\left(Y_{t}, D_{t-1}, \widehat{a}, r\right) \mathbf{1}_{\text {year } \geq 2001}\right)+\epsilon_{t}^{0}
$$


Once individuals exit university they cannot enroll again, full-time work is thus assumed to be an absorbing state. Note that utility after university exit only depends on the choices made during university enrollment. This feature is very important in the solution and estimation of the model, leading to a relatively simple expression for the value of university exit and the $\mathbb{E} \max$ in (4).

The instantaneous utility of college attendance is given by:

$$
\begin{aligned}
U_{t}^{k}\left(X_{t}, \epsilon_{t}^{k}\right)= & u\left(Y_{t}+\hat{b}_{t}\left(Y_{t}, L_{t}\right)+\hat{d}_{t}\left(Y_{t}, L_{t}\right) d_{t}\right)+n_{t}+\epsilon_{t}^{k} \\
& n_{t}=\nu_{0}+\nu_{1} t+\nu_{2} \mathbf{1}_{\{t=0\}}+\nu_{3}\left(\bar{G}-G_{t}\right)+n_{t}^{h}+n_{t}^{d} \\
& n_{t}^{h}=\nu_{4}^{h} A+\nu_{5}^{h} K+\nu_{6}^{h} \mathbf{1}_{\left\{h_{t-1}=\frac{1}{2}\right\}}+\nu_{7}^{h} \mathbf{1}_{\left\{h_{t-1}=1\right\}} \\
& n_{t}^{d}=\nu_{8}^{d} \mathbf{1}_{\left\{D_{t}>0\right\}}+\nu_{9}^{d} \mathbf{1}_{\left\{d_{t-1}=\frac{1}{2}\right\}}+\nu_{10}^{d} \mathbf{1}_{\left\{d_{t-1}=1\right\}} \\
& h \in\left\{0, \frac{1}{2}, 1\right\}, d \in\left\{0, \frac{1}{2}, 1\right\} .
\end{aligned}
$$

The utility of college attendance is determined by student income and aid. We also allow university attendance to have a consumption value, $n_{t}$ which can be thought of as the value of learning less the psychological effort cost of studying. This value depends on the abilities and skills of the student, and work status. Thus working during college may generate a utility loss, which again may depend on already having adjusted to the joint activity and student endowments. It also depends on time since enrollment, the amount of credits necessary to reach the closest degree, a time zero dummy. To capture psychological costs (or debt aversion) related to having debt, we also include an indicator for whether the student has positive cumulated loan and we allow this cost to differ by loan status. To allow some degree of habit formation, we let the choice depend on the past choices of loan accumulation and work. Finally, the alternative specific preference shocks, $\epsilon_{t}^{k}$, capture the fact that new information about alternative specific tastes is revealed to students each period.

\subsection{Mechanisms}

Our model allows for several channels through which student aid policy can affect work and study behavior and the take-up of student loans.

First, working increases current consumption through labor income. Therefore students may work in order to relax credit constraints. How much they work depends on the available student aid (lowering the direct university cost) and implicit incentives in the student aid scheme. The 
study aid scheme works like an earned income tax credit (or income tax) giving students a work disincentive if their income exceeds the maximum income threshold. Thus working may also reduce the amount of aid received and hereby reduce current consumption. The aid scheme thus implies that working increases consumption at a rate decreasing in labor income (if labor income exceeded the maximum income threshold).

Second, working may reduce the consumption value of university enrollment if it implies increased effort in learning or if it inhibits participation in study-related activities. The size of this effect also depends on past work choices and whether the student has adjusted to the joint study-work activity.

Third, working may reduce the cost of the university-to-work transition by reducing job finding costs or the utility cost of getting a feel of the labor market as well as increasing starting salaries.

Fourth, working may increase future consumption through higher future wages caused by the accumulated work experience. Since higher (non-graduate) wages increase the opportunity cost of university attendance, this will make students more likely to drop-out of university earlier.

Fifth, working may also lower future consumption through lower future wages to the extent that working is detrimental to course credit production and ultimately graduation. This will make individuals more likely to stay enrolled longer in order to obtain a given degree. Note that individuals therefore both face the trade-off between the time opportunity cost of university enrollment and the future degree premium, as well as the trade-off that working while enrolled may affect both the opportunity cost (through experience) and the degree premium (through graduation probabilities) since being enrolled without graduating is very costly.

All in all, working lowers current opportunity costs, but increases future opportunity costs of education through increased labor market experience. Working can also increase the direct costs by lowering study aid, as well as affect the consumption value and decrease future opportunity costs of enrollment to the extent that there are adverse effects on academic achievement. These effects further depend on the direct effects of student work on wages and course credit accumulation.

Taking up a student loan is an alternative mean to finance consumption while studying. However, it introduces a trade-off between current and future consumption: the loan needs to be repaid once the student graduates and starts working, lowering future consumption. Different repayment schemes have different incentives attached to them. Income contingent loans may 
decrease incentives of graduating and taking a high-paid job, because lower earnings means a lower repayment rate. Annuity based loans may instead incentivize students to work during enrollment in order to start in the labor market with higher wages, and for the same reason they may increase effort in academic production.

\section{Estimation}

Our goal is to estimate the parameters of the law of motions of the course credit production function $(\gamma)$ and the earnings equation $(\alpha)$, as well as the utility function parameters $(\nu)$. Moreover, individuals enter university with different characteristics that make it unlikely for them to have the same preferences for education, unobserved abilities with respect to course credit production, and labor market productivity. Understanding this unobserved heterogeneity allows us to study which initial traits explain the propensity to drop out or to spend long excess time in college, as well as how these traits relate to family background. To account for unobserved heterogeneity and dynamic selection and to relax the i.i.d. assumption of the unobservable shocks, we introduce an additional state that is unobserved and persistent over time. Following Heckman and Singer (1984), the standard approach in the literature is to treat these initial traits as unmeasured and drawn from a mixture distribution (Keane and Wolpin, 1997; Eckstein and Wolpin, 1999; Arcidiacono, 2004; Keane et al., 2011). This way of accounting for unobserved heterogeneity allows for flexible correlation of the errors across the various alternatives as well as correlation over time and dynamic selection.

We assume there is a finite mixture of $m=1, \ldots, M$ discrete types of individuals who differ in the parameters that describe their preferences, their academic ability and motivation, and their labor market ability. Each type comprises a fixed proportion of the population. To reduce the number of parameters and avoid identification issues, we only allow for first-order heterogeneity effects. $^{18}$

We use a maximum-likelihood based estimation strategy. We estimate the model with unobserved heterogeneity using the algorithm described in Arcidiacono and Miller (2011). They extend the class of CCP estimators by adapting the application of the EM algorithm to sequential likelihood developed in Arcidiacono and Jones (2003) to CCP estimators developed in Hotz et al. (1994). Details of the estimation strategy and algorithm can be found in Appendix A.

\footnotetext{
${ }^{18}$ This approach is common in the literature; see e.g. Eckstein and Wolpin (1999) or Keane et al. (2011) for a discussion.
} 
We deal with the initial conditions problem Heckman (1981) by observing all high school graduates' abilities, skills, and labor market experience. We assume their value of college enrollment is given by the same model and parameters as those who enroll, but they optimally choose non-enrollment at $t=0$.

\subsection{Identification}

The endogenous variables in the model include the choices: university enrollment, whether and when to work, and student loan take-up, as well as the outcomes: accumulated course credits, labor market experience, and student debt accumulation. Labor market experience and student debt accumulation evolve deterministically conditional on the choices, while course credit production is probabilistic.

We control for endogeneity using all the restrictions implied by our economic model of the entire university enrollment period as a sequence of endogenous choices that drive subsequent outcomes. Importantly, our identification strategy also incorporates exogenous variation stemming from a major change of the study aid scheme. Identification of the course credit production and earnings functions rests on variation in earnings, employment, enrollment, and course credit data.

The problem of identification can be viewed as a sample selection problem, since wages are only observed for individuals who choose to work and course credits are only observed for those who are enrolled. The exclusion restrictions, the functional form, and distributional assumptions embedded in the model serve the same purpose as would a sample selection correction in a two-step or full information estimation procedure. We impose the exclusion restriction that ability only affects course credit production, $g_{t}$, and does not directly affect earnings, $y_{t}$, other than through accumulated course credits, $G_{t}$, and accumulated labor market experience, $H_{t}$, which they affect indirectly through affecting course credit production (through $\gamma_{1}$ ) and the consumption value of university attendance, $\nu$, and how this value is affected by student employment, $\nu^{h}$.

Our approach to incorporate unobserved heterogeneity identifies the type distribution through the principle of revealed preferences: the idea is to allow individuals to differ in permanent ways unobserved to the econometrician and estimate the distribution of types to fit the persistence of choices and outcomes of the individual. If two individuals with identical observable characteristics persistently make different choices and have different outcomes, they are 
assumed to have different unobservable characteristics. The data could be fit perfectly if the number of types approached the number of observations and were allowed to vary over time, but discipline is imposed by fixing a small number of types and requiring unobserved heterogeneity to be permanent.

The $\alpha$ parameter vector is identified from earnings data and the state variables: accumulated course credits, $G_{t}$, highest completed academic degree, $E_{t}$, and accumulated labor market experience, $H_{t}$. Unobserved heterogeneity, $\alpha_{0 m}$, is identified by cross-sectional variation in wages conditional on these state variables at each $t$.

The $\gamma$ parameter vector is identified from course credit data and the state variables: ability, $A$, accumulated course credits, $G_{t}$, and work status, $h_{t}$, and the unobserved heterogeneity parameters, $\gamma_{0 m}$, are identified by cross-sectional variation in acquired course credits conditional on these state variables. The remaining utility function parameters in the $\nu$ vector are identified based on the principle of revealed preferences. If the model were static, then identification of the utility function parameters would come from observing their college-work-loan choices and outcomes. The dynamic optimization problem resembles a static multinomial logit model with the future component of the value function treated as a known quantity based on the estimated earnings parameter vector, $\alpha$, and the course credit production parameter vector, $\gamma$, that controls the expectation of next period's state variable for a given discount factor, and the CCPs that are treated as nuisance parameters.

Finally, identification of the study aid effect on college-work-loan choices incorporates exogenous variation stemming from the major changes to the Swedish study aid scheme in 2001. These changes are detailed in Section 2.1 and their immediate impacts shown in Section 2.2. The policy parameters shocked by the reform affected different dimensions of choice in the behavioral model. First, the increase in the maximum base grant amount, $\bar{b}_{\text {post }}>\bar{b}_{\text {pre }}$, directly loosens the current budget constraint. This means that fewer students may take up the loan if the higher grant amount gives them sufficient credit. Figure B.1 illustrates this change. This increase may also affect student labor supply. A student working $h^{*}$ hours gets a higher total income $Y_{t}\left(h^{*}\right)+\bar{b}_{\text {post }}>Y_{t}\left(h^{*}\right)+\bar{b}_{\text {pre }}$ post-reform, and could have received the same total income working fewer hours, $Y_{t}\left(h^{* *}\right)+\bar{b}_{\text {post }}=Y_{t}\left(h^{*}\right)+\bar{b}_{\text {pre }}$, where $h^{*}>h^{* *}$. Depending on the income and substitution effects, students may simply work the same amount at a higher total income or work less at the same income. The increased weight on grants both affects the extensive and the intensive margin of student labor supply. Second, the slacker means testing meant 
that the maximum student income threshold increased, $\bar{Y}_{\text {post }}>\bar{Y}_{\text {pre }}$, and the implicit tax rate, $\tau_{B_{\text {post }}}<\tau_{B_{\text {pre }}}$, decreased. The immediate impact of the increase in $\bar{Y}$ is that more students are eligible for the maximum aid amount, $\bar{B}$, and fewer students are facing the implicit tax rate, $\tau_{B}$. The decrease in the tax rate further lowers work disincentives. Figure B.2 illustrates the potential labor supply effects of this change. There is no effect on the intensive margin and no effect on students working fewer than $h^{\prime}$ hours, $h<h^{\prime}$, where $Y\left(h^{\prime}\right)=\bar{Y}_{\text {pre }}$. A student working many hours, $h>h^{\prime \prime}$, where $Y\left(h^{\prime \prime}\right)=\bar{Y}_{\text {post }}+\frac{\bar{B}}{\tau_{B_{\text {post }}}}$, who was far from being eligible for the grant before the reform may work fewer hours and receive the same utility because of becoming eligible post-reform. Students working an intermediate amount of hours, $h^{\prime}<h<h^{\prime \prime}$, may either work more or less after slacker means testing. The overall effect of the means testing on the extensive margin is thus an empirical question as it depends on the relative strengths of the income and substitution effects on student labor supply. Third, the lower merit eligibility requirement in terms of course credits produced the period before, $\underline{g}_{t-1, \text { post }}<\underline{g}_{t-1, \text { pre }}$, affects the trade-off between studying and working. To the extent that student work-hours have a detrimental (beneficial) effect on course credit production, the lowering of merit requirements may increase (decrease) student labor supply. Fourth, the loan repayment scheme directly affects the expected future value of working, since it depends on accumulated student debt and before the reform - also on future income, $Y_{\widetilde{T}+t}$, where $\widetilde{T}$ is year of college exit. Because of the dynamics of the model, the law of motion for debt means that the loan repayment scheme has an indirect effect on current loan take-up decisions. The reform meant that this intertemporal trade-off became stronger for low earners and weaker for high earners as the installments were a proportional $4 \%$ income tax before the reform and a 25 -year annuity after the reform. Conditional on accumulated student debt, this meant a differential change depending future expected income. Figure B.3 illustrates this scenario for a starting salary one standard deviation below, $Y_{\widetilde{T}}^{\text {low }}$, and above, $Y_{\widetilde{T}}^{h i g h}$, the average starting salary. The reform meant higher installments for the low earner, $\widehat{I}_{\text {post }}>\widehat{I}\left(Y_{\widetilde{T}+15}^{\text {low }}\right)_{\text {pre }}$, and lower installments, $\widehat{I}_{\text {post }}<\widehat{I}\left(Y_{\widetilde{T}+15}^{\text {high }}\right)_{\text {pre }}$, for the high earner. The relative risk aversion parameter is identified from the intertemporal trade-off in total income as students choose between three sources of income to finance their college education: labor income, grants, and loans. Grants only increase current income (and less so if labor income is too high) while loans also lower future income as long as there is remaining student debt. The change in the loan repayment scheme thus implies an exogenous change in this intertemporal trade-off and the IES (and consequently the RRA) parameter is thus also 
identified from exogenous reform variation.

\section{The Data}

We use register based individual panel data of the Swedish population hosted by the Institute for Evaluation of Labour Market and Education Policy (IFAU). The dataset contains the cohorts of students who graduated from high school in the years 1990-2004. We have complete educational event histories for this population, including 9th grade and high school GPA and course choices for those who enroll in higher education. For every college enrollment spell we observe the duration, level and field of study, and targeted and actually acquired course credits (ECTS) every semester - both in the program they are enrolled in and their additional courses. ${ }^{19}$ We also have study aid accumulated each year. Labor market histories include official employment status (part-time and full-time), employment spells with relative earnings and total yearly earnings. Finally, we observe a range of demographic characteristics and background variables. We measure parental and family background variables in the year before college enrollment. We observe parental yearly income, field and level of education, employment and civil status. We also have information on number of siblings, birth order, and the age distribution of siblings both registered with the same mother and with the same father.

We restrict our enrollment sample to high school graduates who enroll in a program in college in the years between 1994 and 2002 and are younger than 23 years by the end of their initial enrollment year. This amounts to 192,366 individuals and 2,221,740 yearly observations on their education and labor market choices and outcomes until 2009. To conduct out of sample tests we add 48,236 students enrolled in 2003 and 2004, i.e. 311,921 observations. To account for initial conditions, we also include all high school graduates from the 1993-2002 cohorts who are not older than 20 when graduating from high school and have not enrolled in college by the time they are 23 years old. In total, our sample includes 734,802 individuals and a total of $8,187,710$ yearly observations. ${ }^{20}$

\footnotetext{
${ }^{19}$ Students are allowed to attend courses outside the educational program they are enrolled in and earn credits that can be merited towards their degree.

${ }^{20}$ Out of 1,202,062 students who graduate from high school in 1990-2004, 575,506 (48\%) enroll in a college program at some point. Of those who enrol in a college program, 392,169 individuals enrol in 1994-2004, of which 309,339 in 1994-2002. 285,662 are 22 years old or younger at initial enrollment. Out of 285,662 individuals who enroll in a college program between 1994 and 2004 and are younger than 23 at enrolment we drop additional 39,919 students that enroll in a college program after having already completed some coursework at university (and having received study aid), 85 students that either are reported to graduate the same year as enrolment or to enrol before having graduated high school, and 86 students that have missing ability information. Out of the 494,196 individuals in our sample who graduate from high school in 1993-2002 and do not enter in our enrolment
} 
Table 1: Descriptives

\begin{tabular}{|c|c|c|c|c|c|c|c|}
\hline Individual Characteristics & $\begin{array}{l}\text { Not En- } \\
\text { rolling }\end{array}$ & $\begin{array}{l}\text { All Stu- } \\
\text { dents }\end{array}$ & Dropouts & $\begin{array}{l}\text { 2-year } \\
\text { degree }\end{array}$ & $\begin{array}{l}\text { 3-year } \\
\text { degree }\end{array}$ & $\begin{array}{l}\text { 4-year } \\
\text { degree }\end{array}$ & $\begin{array}{l}\text { 5-year } \\
\text { degree }\end{array}$ \\
\hline \multicolumn{8}{|l|}{ At University Entry } \\
\hline Age & - & $\begin{array}{l}20.15 \\
(1.01)\end{array}$ & $\begin{array}{l}20.20 \\
(1.04)\end{array}$ & $\begin{array}{l}20.31 \\
(1.10)\end{array}$ & $\begin{array}{l}20.28 \\
(1.04)\end{array}$ & $\begin{array}{l}20.01 \\
(0.94)\end{array}$ & $\begin{array}{l}20.07 \\
(0.96)\end{array}$ \\
\hline $\begin{array}{l}\text { Age at high school } \\
\text { graduation }\end{array}$ & $\begin{array}{l}19.02 \\
(0.49)\end{array}$ & $\begin{array}{l}19.06 \\
(0.40)\end{array}$ & $\begin{array}{l}19.08 \\
(0.43)\end{array}$ & $\begin{array}{l}19.03 \\
(0.51)\end{array}$ & $\begin{array}{l}19.03 \\
(0.39)\end{array}$ & $\begin{array}{l}19.07 \\
(0.36)\end{array}$ & $\begin{array}{l}19.10 \\
(0.41)\end{array}$ \\
\hline Female & 0.45 & 0.52 & 0.40 & 0.52 & 0.68 & 0.47 & 0.63 \\
\hline Work Experience (years) & - & $\begin{array}{l}2.20 \\
(1.26)\end{array}$ & $\begin{array}{l}2.14 \\
(1.28)\end{array}$ & $\begin{array}{l}2.31 \\
(1.29)\end{array}$ & $\begin{array}{l}2.46 \\
(1.27)\end{array}$ & $\begin{array}{l}2.08 \\
(1.20)\end{array}$ & $\begin{array}{l}2.01 \\
(1.21)\end{array}$ \\
\hline High school GPA $(\geq P 75)$ & 0.10 & 0.48 & 0.36 & 0.34 & 0.40 & 0.66 & 0.85 \\
\hline High school GPA $(\geq P 90)$ & 0.02 & 0.21 & 0.13 & 0.10 & 0.12 & 0.35 & 0.64 \\
\hline High school GPA & $\begin{array}{l}2.76 \\
(0.63)\end{array}$ & $\begin{array}{l}3.40 \\
(0.57)\end{array}$ & $\begin{array}{l}3.25 \\
(0.57)\end{array}$ & $\begin{array}{l}3.21 \\
(0.54)\end{array}$ & $\begin{array}{l}3.30 \\
(0.55)\end{array}$ & $\begin{array}{l}3.60 \\
(0.52)\end{array}$ & $\begin{array}{l}3.86 \\
(0.43)\end{array}$ \\
\hline Math-Science track & 0.04 & 0.39 & 0.36 & 0.18 & 0.25 & 0.51 & 0.79 \\
\hline \multicolumn{8}{|l|}{ During enrollment } \\
\hline Part-time employed & - & 0.49 & 0.49 & 0.45 & 0.48 & 0.51 & 0.54 \\
\hline Full-time employed & - & 0.34 & 0.31 & 0.40 & 0.41 & 0.33 & 0.31 \\
\hline Course Credits (per year) & - & $\begin{array}{l}4.19 \\
(2.08)\end{array}$ & $\begin{array}{l}3.49 \\
(2.12)\end{array}$ & $\begin{array}{l}3.87 \\
(2.05)\end{array}$ & $\begin{array}{l}4.37 \\
(2.02)\end{array}$ & $\begin{array}{l}4.50 \\
(1.99)\end{array}$ & $\begin{array}{l}4.70 \\
(1.95)\end{array}$ \\
\hline Loan (per year) & - & $\begin{array}{l}25,826 \\
(20,516)\end{array}$ & $\begin{array}{l}26,004 \\
(19,873)\end{array}$ & $\begin{array}{l}20,268 \\
(18,722)\end{array}$ & $\begin{array}{l}24,441 \\
(19,773)\end{array}$ & $\begin{array}{l}26,519 \\
(21,342)\end{array}$ & $\begin{array}{l}27,441 \\
(20,512)\end{array}$ \\
\hline \multicolumn{8}{|l|}{ At University Exit } \\
\hline Total Course Credits & - & $\begin{array}{l}21.64 \\
(9.08)\end{array}$ & $\begin{array}{l}14.38 \\
(9.00)\end{array}$ & $\begin{array}{l}15.58 \\
(4.88)\end{array}$ & $\begin{array}{l}21.20 \\
(3.81)\end{array}$ & $\begin{array}{l}29.22 \\
(4.25)\end{array}$ & $\begin{array}{l}34.36 \\
(5.58)\end{array}$ \\
\hline Debt & - & $\begin{array}{l}140,049 \\
(90,263)\end{array}$ & $\begin{array}{l}119,770 \\
(85,583)\end{array}$ & $\begin{array}{l}85,029 \\
(68,836)\end{array}$ & $\begin{array}{l}121,093 \\
(73,989)\end{array}$ & $\begin{array}{l}175,952 \\
(93,581)\end{array}$ & $\begin{array}{l}204,843 \\
(99,747)\end{array}$ \\
\hline Work Experience (years) & - & $\begin{array}{l}5.57 \\
(2.16)\end{array}$ & $\begin{array}{l}4.68 \\
(2.18)\end{array}$ & $\begin{array}{l}5.16 \\
(1.85)\end{array}$ & $\begin{array}{l}5.92 \\
(1.88)\end{array}$ & $\begin{array}{l}6.19 \\
(2.04)\end{array}$ & $\begin{array}{l}6.62 \\
(2.07)\end{array}$ \\
\hline \multicolumn{8}{|l|}{ After University Exit } \\
\hline Employed & 0.87 & 0.94 & 0.90 & 0.95 & 0.97 & 0.96 & 0.96 \\
\hline Yearly Earnings & $\begin{array}{l}144,776 \\
(104,433)\end{array}$ & $\begin{array}{l}235,064 \\
(135,978)\end{array}$ & $\begin{array}{l}212,092 \\
(132,944)\end{array}$ & $\begin{array}{l}242,307 \\
(117,974)\end{array}$ & $\begin{array}{l}215,873 \\
(108,963)\end{array}$ & $\begin{array}{l}292,622 \\
(152,180)\end{array}$ & $\begin{array}{l}317,536 \\
(139,938)\end{array}$ \\
\hline $\mathrm{N}$ individuals & 374,120 & 192,328 & 67,810 & 2,068 & 48,954 & 62,222 & 5,719 \\
\hline Fraction of Sample & $67.23 \%$ & $34.56 \%$ & $12.19 \%$ & $0.37 \%$ & $8.80 \%$ & $11.18 \%$ & $1.03 \%$ \\
\hline Fraction of Students & - & $100 \%$ & $35.26 \%$ & $1.07 \%$ & $25.45 \%$ & $32.35 \%$ & $2.97 \%$ \\
\hline
\end{tabular}

Sample averages, standard deviations in parenthesis. One year of full-time studies corresponds to 60 ECTS. All amounts are in real SEK 2000. The exchange rate ultimo December 2000 was 9.3955 SEK/USD and $8.8263 \mathrm{SEK} / \mathrm{EUR}$.

Descriptives are shown in Table 1. Individuals are around 20 years old at initial college enrollment and $54 \%$ are females. The college dropout rate is $27 \%$, the majority (38\%) of the students graduate with a 4-year degree, almost $30 \%$ graduate with a 3 -year degree, and the

sample, 113,499 enrol in a college program when they are older than 22 years old and an additional 7,528 enrol in years outside the 1994-2002 restriction. 
remaining graduate with 2-year (1\%) and 5-year degrees $(4 \%) .{ }^{21}$ Fewer females drop out (39\%) and more females get a 3-year college degree (70\%). Approximately two thirds of high school graduates enrolling in college have a higher than average GPA of 3.41 (on a 1-5 scale), half of them are in the top quartile, and $23 \%$ of them are in the top decile of their respective high school cohorts. Dropouts and those with a 2-year or 3-year degree are not significantly different, but those with a 4-year or 5-year degrees are even more positively selected on GPA. A large fraction $(76 \%)$ of students are employed. Students accumulate around two thirds of mandates course credits each enrollment year and those eventually acquiring a longer college degree also tend to be more productive at accumulating course credits in each enrollment year. Dropouts only produce 34 ECTS on average per enrollment year, while those graduating with a shorter (longer) degree produce 39 (46) ECTS. Students tend to accumulated more than the required course credits at university exit. This could reflect switching between fields, a high consumption value of university attendance, or simply a high return to course taking. Those with longer degrees also accumulate more student debt, while dropouts actually have accumulated more debt than those with a shorter college degree at university exit. There only seems to be a substantial degree premium to acquiring a longer college degree, but not to a shorter degree. There does, however, seem to be a benefit in terms of a higher employment probability after university exit as $95 \%$ of those with a college degree are employed and only $91 \%$ of dropouts.

The period by period choice transitions are displayed in Table 2 which reveals a lot of persistence in most choices. Our absorbing state assumption is reasonable, since most of those not enrolled in college and working full-time at $t-1$ are also doing so at $t .{ }^{22}$ Though we observe transitions between all the feasible choices, which is important for identification of the model parameters. The only two choices that are not persistent are those involving no loan with no or part-time work $\left(k_{t}=1,4\right)$ and the partial loan with no work $\left(k_{t}=2\right)$. Individuals are very likely to transition from first taking up a partial and then a full student loan. This could indicate that students are debt averse and the partial loan option is a stepping stone for them to eventually taking up a full student loan. This is consistent with Stinebrickner and Stinebrickner (2008) who take a direct approach of assessing borrowing constraints for low-income students at Berea college. Their survey data reveals that the vast majority of students would not take

\footnotetext{
${ }^{21}$ The 1,995 (0.9\%) with right censored college enrollment spells who are still enrolled at the end of our sample period are not included in the last three columns of Table 1.

${ }^{22}$ Note that this observation is after we assume that students who stop out of college for less than a year are continuously enrolled.
} 
up a loan if offered to them at the market interest rate. Stinebrickner and Stinebrickner (2008) conclude that borrowing constraints are likely only an important reason for dropping out for some students, but not for the vast majority - even if among the half of students dropping out, two thirds cite the lack of money being part of the reason. Johnson (2013) also finds that students are reluctant to borrow. Our model incorporates two possible factors underlying this observation: Uncertainty about graduation and being able to comfortably pay back the loan, as well as a utility cost of having debt (loan aversion).

Table 2: Choice transition.

\begin{tabular}{|c|c|c|c|c|c|c|c|c|c|c|}
\hline \multirow[b]{2}{*}{$k_{t-1}$} & \multicolumn{10}{|c|}{$k_{t}$} \\
\hline & 0 & 1 & 2 & 3 & 4 & 5 & 6 & 7 & 8 & 9 \\
\hline 0 & 99.94 & 0.00 & 0.00 & 0.01 & 0.00 & 0.00 & 0.01 & 0.01 & 0.00 & 0.03 \\
\hline 1 & 12.92 & 10.26 & 6.77 & 14.35 & 3.29 & 8.22 & 13.31 & 7.88 & 7.00 & 16.00 \\
\hline 2 & 4.60 & 4.79 & 9.95 & 17.40 & 2.44 & 7.63 & 18.01 & 7.45 & 7.45 & 20.28 \\
\hline 3 & 7.67 & 2.66 & 1.07 & 27.57 & 1.00 & 0.82 & 23.52 & 4.49 & 1.27 & 29.95 \\
\hline 4 & 19.74 & 4.51 & 1.87 & 5.67 & 5.31 & 6.11 & 12.92 & 15.20 & 8.29 & 20.39 \\
\hline 5 & 5.33 & 1.92 & 3.86 & 4.87 & 3.89 & 15.53 & 16.18 & 13.38 & 13.36 & 21.67 \\
\hline 6 & 7.38 & 0.79 & 0.44 & 9.65 & 1.11 & 1.37 & 30.04 & 6.64 & 2.07 & 40.51 \\
\hline 7 & 45.60 & 0.90 & 0.37 & 1.24 & 0.71 & 0.75 & 2.02 & 27.84 & 4.43 & 16.13 \\
\hline 8 & 11.00 & 0.68 & 1.12 & 2.3 & 0.95 & 2.9 & 5.02 & 15.98 & 21.6 & 38.44 \\
\hline 9 & 17.12 & 0.37 & 0.15 & 3.51 & 0.35 & 0.31 & 7.44 & 11.58 & 2.58 & 56.59 \\
\hline
\end{tabular}

Figure 7 shows college-to-work transitions by employment and loan status. These are the ten discrete choices $k \in 0, \ldots, 10$ we model. The figure reveals how students gradually flow from college enrollment to working full time on the labor market $(k=0)$. $70 \%$ have entered the labor market full-time after six years and almost $100 \%$ ten years after initial enrollment. The most common choice during the first college years is to study and work during the academic year while taking up the full available loan $(\mathrm{k}=9)$. This is followed by studying without working or working part-time in the summer and taking up the full student loan $(\mathrm{k}=3,6)$. This choices become less popular with time since enrollment, while being a working student and taking up no loan $(k=7)$ becomes increasing popular and is the most common choice in the fifth enrollment year. Most students thus take up the full loan during their eligibility period - initially $80 \%$ working and the rest not working. ${ }^{23}$ Conforming with eligibility requirements, loan take-up rates fall sharply after six years after initial enrollment when being a working student with no

\footnotetext{
${ }^{23}$ This change is not driven by partial enrollment, which we do not model. Partial enrollment is in principle an option, but according to the data not a popular one among Swedish students. Part time enrollment increases slightly with time since initial enrollment, but never exceeds $1 \%$ of the student population.
} 
Figure 7: College-to-Work Transition.

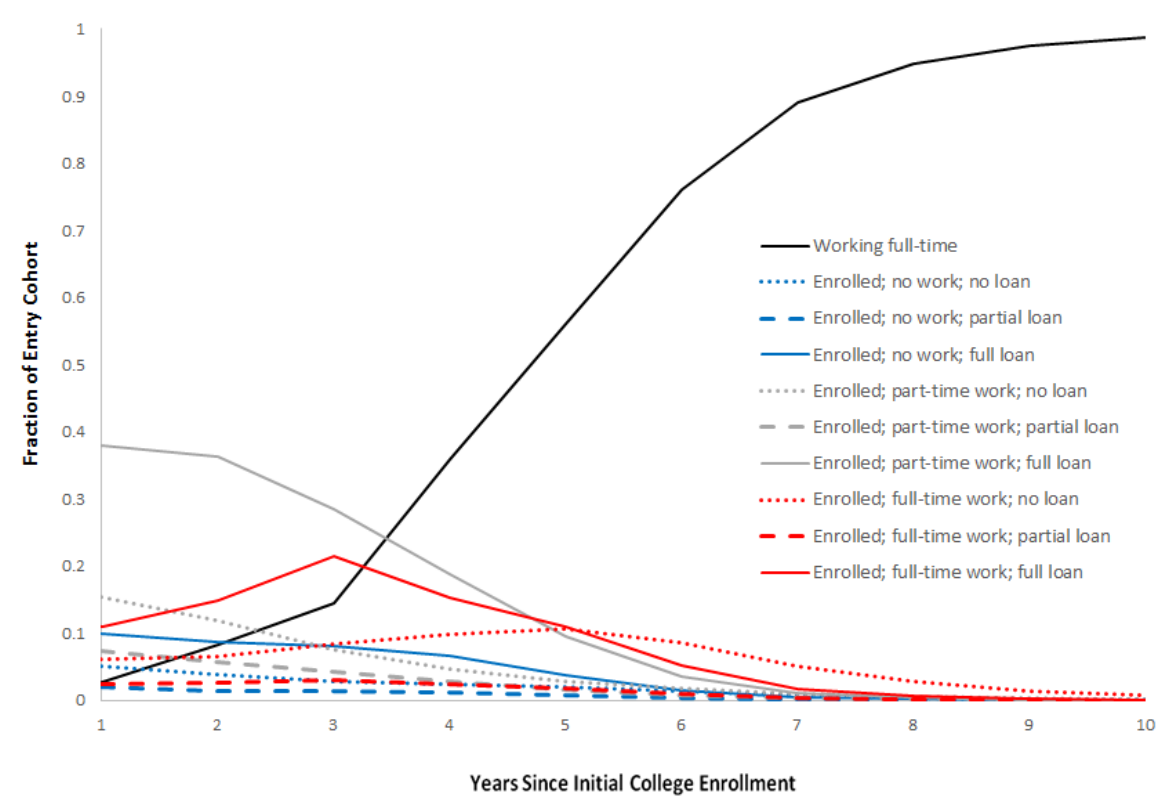

The Figure displays the college-to-work transition over the years since initial enrollment (on the x-axis). The fraction of individuals making each feasible model choice of college enrollment, employment and loan status, $k=0, \ldots, 6$, is displayed separately.

loan $(k=7)$ becomes the most common choice.

Figure 8 shows course credit production over time for the model choices. Students, working or not working, who take up no loan persistently produce fewer course credits (around 30-40 ECTS per year). This can indicate that students with higher ability or higher motivation to study expect a high wage and borrow more because they expect being able to repay their students debt swiftly after graduation. This mechanism should be more important after the reform and the switch from the income contingent to the annuity based repayment scheme. Whether this is the case will be quantified in our cost neutral policy simulations. Lastly, the decreasing production of course credits over time since enrollment - especially the steep decline around normal graduation years - indicates the importance of accounting for dynamic selection when estimating the model, since students who are more productive will graduate faster. 
Figure 8: Course Credit Production over time since initial enrollment.

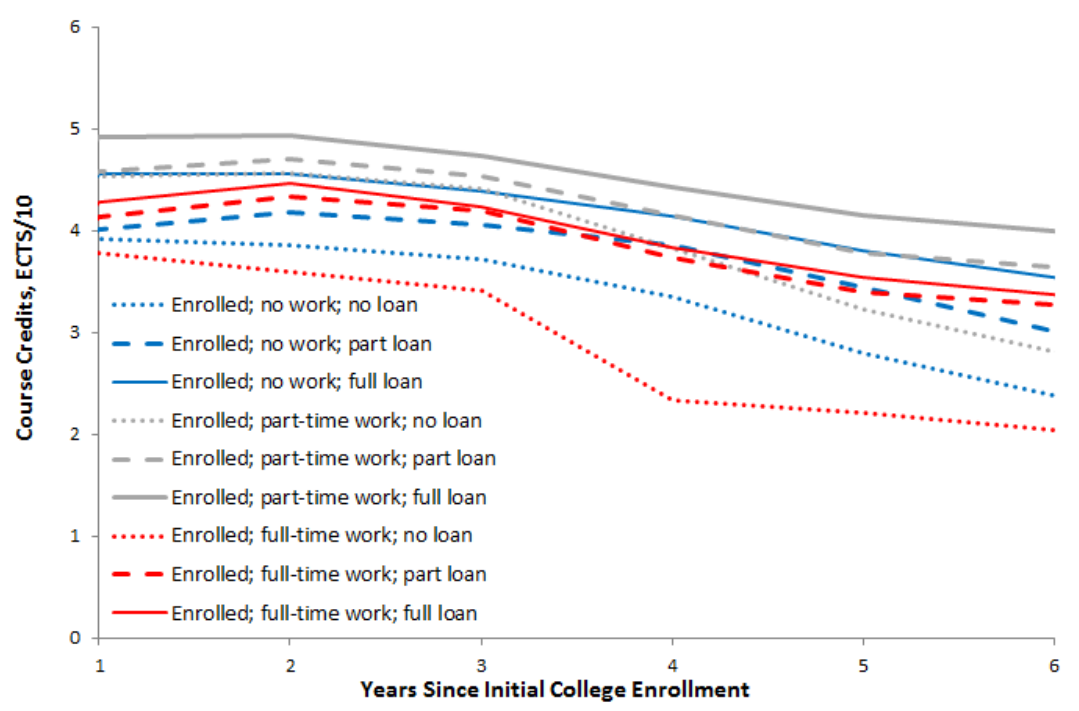

The Figure displays actual course credit production per year since initial enrollment (on the $\mathrm{x}$-axis). Average course credit production is displayed separately by the model choices; i.e. by student employment and loan status. One year of full-time studies corresponds to 60 ECTS (on the y-axis).

\section{$7 \quad$ Estimation Results}

The parameter estimates are presented in Table 6 and 7in Appendix C.1. The earnings equation parameters, $\alpha$, reveal that there is a positive degree premium, which is larger the more advanced the degree. There is a positive earnings effect of accumulated course credits on earnings, which is smaller the more advanced the degree. This indicates that knowledge accumulation through course taking is valued on the labor market, but less so for higher degrees for which the degree premium is higher. Experience has a positive linear effect on wages earned by students. Students working earn significantly lower wages than full-time workers, and students working part-time earn even less. This effect in part captures the differences in hours worked and the likely fact that students work fewer hours. The returns to labor market experience is higher in the early career and steeper for college graduates who also have higher starting salaries. Having accumulated labor market experience through college is valuable through increasing starting salaries, but the returns to student experience are insignificant after five years of post-college experience.

The parameters of the course credit production function, reveal that both ability and skills have a positive effect on course credit production. Having already acquired a degree has an increasingly negative effect, which probably reflects that courses at the Master level are more 
challenging on average and students progress more slowly. Similarly, there is a negative effect of time since first enrollment, capturing both the increasing difficulty of courses as the degree progresses, and students possibly being tired and less motivated with time. The positive effect of cumulated course credits captures the self-productivity of academic skills, as already accumulated academic knowledge enhances future academic learning. Working full-time while studying has a negative effect on course credit production, but working during the summer and maximum two months during the year has a positive effect. This result highlights that the timing of work during the year is crucial. This result is also in line with Joensen (2013b) who finds that the effect of hours worked on academic productivity follows an inverse-U shape, with few hours of work being beneficial and many hours being detrimental.

Finally, from the utility function parameters we learn that there is a positive cost of entering the labor market, $\nu_{1}$, for students. Time since initial enrollment has a negative effect on utility, indicating that the psychological cost of studying increases with time spent in college. This is capturing both the fact that courses can become increasingly challenging towards the end of a degree (both because of the curricula or because the student leave the most difficult exams last), the fact that the more time passes the higher is the graduation pressure, and it becomes increasingly likely that ones' peers have already graduated or dropped out and campus networks are evaporating. Ability and Skill have positive effects on utility for all students, and the effect is lower for students who work part-time. The effect of the stock of cumulated debt is positive for all loan choices, and higher for students taking up full and partial loan.

\subsection{Model Fit}

[Note: THE RESULTS IN THIS SECTION ARE FROM AN OLD VERSION OF THE MODEL]

This section assess model fit in order to increase the credibility of our policy simulations. First, we assess how well the model fits the key aspects of our data described in Section 6 . Second, we assess whether our model also fits well out of sample. This is done by looking at two important dimensions of heterogeneity in choices and outcomes that we do not explicitly model: college field and parental background.

Table 8 in Appendix C.2 presents actual and predicted choices and outcomes. Looking at academic achievement, our model perfectly predicts the probabilities of producing each feasible amount of course credits. However, we slightly underpredict productivity for students taking 
up the full loan and slightly overpredict productivity of students making the other choices. Our model does not capture the fact that those taking up the full loan perform better than those taking up the partial loan, but it does capture the other patterns - including that students who work produce fewer credits. The model slightly overpredicts accumulated course credits and overpredicts graduation rates by a large margin. Accumulated debt at university exit is predicted quite accurately, while earnings are overpredictd at all levels of education. Overall the model fits the fractions making each choice and their rankings quite well, but does not predict other time patterns as well. Slightly more (fewer) students are predicted to work (not work). There is a slight underprediction of the no work and full loan choice $(\mathrm{k}=2)$ in earlier time periods $(t=1, \ldots, 4)$ and a slight overprediction in later enrollment years $(t>5)$. The reverse is true for the work and no loan $(\mathrm{k}=4)$ and work and full loan $(\mathrm{k}=5)$ options. To get all the time transitions between choices right we thus need to incorporate a more flexible dependence on time. It is noteworthy that our model predicts the timing of university exit very accurately. This is pivotal as the timing of university exit is a margin of key policy interest. In the simulations in Section 8 we quantify how study aid policies affect the timing of both dropout and graduation.

Note that we here assess model fit of the most parsimonious one type model. There are several obvious ways we could improve model fit: First, we are estimating models with unobserved heterogeneity. Second, we are incorporating differences in initial skills proxied by level of mathematics from high school. This will likely introduce heterogenity making the model better able to fit some of the magnitudes of effects and differences in profiles. ${ }^{24}$ Third, we are getting more detailed data on employment in each month. This will also allow us to use the course credit data on the semester level, whereas we now need to aggregate to yearly observations as employment information is only available for November each year. This will further allow us to distinguish between the effects of working during the semester and working during the summer break.

Tables 9 and 10 reveal that dropout rates, timing of graduation, and wages differ substantially across college fields. We aggregate into six broad fields of education. Ranked from highest to lowest paying fields: (i) Technical Sciences, Engineering; (ii) Social Sciences, Law, Business, Services; (iii) Math, Natural, Life and Computer Sciences; (iv) Health Sciences, Health and

\footnotetext{
${ }^{24}$ Joensen and Nielsen (2009) and Joensen and Nielsen (2014) document a large causal effect of advanced high school math courses on academic achievement and earnings.
} 
Social Care; (v) Humanities and Arts; (vi) Education. 4-year college and MA/MSc graduation rates are clearly highest for the three highest paying fields (44-48\%). Two fields stand out with high 2-year-college and BA/BSc graduation rates: Health Sciences, Health and Social Care (55\%) and Education (50\%). The highest dropout rates are in Humanities and Arts (51\%) and the lowest in Health Sciences, Health and Social Care (12\%). Study effectiveness seems to be highest in Social Sciences, Law, Business, Services - despite the high MA/MSc graduation rates, individuals initially starting in this field transition to full-time labor market work faster and $87 \%$ are working full-time 10 years after enrolling. Study effectiveness seems to be lowest in Humanities and Arts, where only $77 \%$ are working full-time 10 years after enrolling. Overall, our model captures these differences quite well and the prediction errors mirror the ones we already laid out above. Not surprisingly, our model does not yet have sufficient individual heterogeneity to capture the large magnitudes of some of the differences by field of education particularly with respect to highest acquired degree.

Finally, Tables 11 and 12 show differences across parental income and education. Tables 11 shows that both course credit production and earnings are generally increasing in both maternal and paternal education. Dropout rates are quite similar (35-36\% if parents have no more than high school education and $30 \%$ if parents have postgraduate education), while MA/MSc graduation rates are strongly increasing with parental education (31-32\% if no more than high school education, $37-39 \%$ if 2 -year or some college education, $44-45 \%$ if at least a BA/BSc degree, and $56-59 \%$ if postgraduate). Children whose parents have a postgraduate education are more likely to be enrolled and more likely to be a student not working and not taking up the loan $(\mathrm{k}=1)$. Distinguishing between mother's and father's education does not seem crucial for choices and outcomes, as they are remarkably similar for the same level of parental education. All these patters are captured by the model. Tables 13 and 14 presents differences between individuals whose parents are in the bottom and top decile of the income distribution in the year before college enrollment. All numbers are shown separately by mother's, father's and total household income. The differences by parental income are not as stark as the differences by parental education. Course credit production is only weakly increasing in parental income. Dropout rates are similar, but MA/MSc graduation rates are much higher for children of high income parents (48-51\% compared to $32-34 \%$ for low income). Children of high income parents are more likely to take up the full loan $(\mathrm{k}=2$ and $\mathrm{k}=5)$. Again, all these differences are captured by our model - with the same misfits on some of the magnitudes as for the overall model fit. 
On the one hand, we want as parsimonious a model as possible to avoid the curse of dimensionality and enable solution of the stochastic dynamic programming problem for the policy simulations. On the other hand, we want a rich enough model to capture the relevant margins of behavior that are affected by the student aid policies. Having assessed model fit along important dimensions of heterogeneity that our model is not tailored to fit, gives us more confidence in making more precise ex-ante policy predictions.

\subsection{Initial Conditions and Heterogeneity}

[NOTE: THIS EX-POST ANALYSIS IS FROM AN OLD VERSION OF THE MODEL]

We will further explore how unobserved heterogeneity relates to other individual initial conditions, not incorporated into the model and estimation, but observed in the data. Individuals in our model are heterogeneous along three dimensions when they first enroll in college: high school GPA, employment experience, and their type. The type embodies unobserved genetic differences and early childhood investments. Parental and family background could thus be related to initial conditions through both nature and nurture; i.e. both through intergenerational genetic correlations, the upbringing environment, intellectual and monetary resources for earlier investments in child and youth human capital. ${ }^{25}$

How does the unobserved type interact with parental background in predicting academic outcomes? ${ }^{26}$ First, we will analyze if the types have different parental and family background in the year prior to initial college enrollment and the interrelation between initial conditions. Second, we will study how parental and family background are correlated with all educational achievement measures, as well as debt accumulation. Table 15 shows significant correlations between background characteristics and academic outcomes: dropout and graduation rates, timing of university exit for dropouts and graduates, as well as cumulated debt at university exit for both dropouts and graduates. Parental and family background are thus strong predictors of academic success. Next, we will analyze how sensitive these correlations are to controlling

\footnotetext{
${ }^{25}$ The dynamic effects of parental influences on skill formation have been well documented in a large literature growing out of Todd and Wolpin (2003), Cunha and Heckman (2007), Cunha and Heckman (2008), Cunha et al. (2010). The extensive literature on intergenerational mobility, reviewed in Black and Devereux (2011), is also lately focusing on the causes of intergenerational mobility, and on the various channels underlying the correlation of parental and child outcomes: these channels can be genetic, suggesting a limited role for policy, or due to parental education and income (e.g. through investment in education and social networks), that instead leave room for education policies among others.

${ }^{26}$ We will extend the analysis to better answer this question in the model with $M$ type unobserved heterogeneity.
} 
for type probabilities, since types may embody some of the same predictive power as parental and family background - through genes, childhood and youth social environmental, as well as intellectual and financial investments in abilities and skills. This relationship has been tested extensively, but how much is nature and how much is nurture is still an open and much debated question. Some papers do not find significant effects of parental income once controlling for ability; see e.g. Carneiro and Heckman (2002) and Johnson (2013). However, recently Belley and Lochner (2007) have challenged this result showing significant correlations - even after controlling for ability. They attribute this reversal to increased tuition costs leading college success to depend more strongly on parental income to finance tuition costs. Reassessing this issue with more comprehensive data and better methods allows us to relate this puzzle directly to study aid policies.

\section{Policy Simulations}

[NOTE: THE SIMULATIONS IN THIS SECTION ARE BASED ON AN OLD VERSION OF THE MODEL]

We perform three sets of policy simulations: First, we separately assess the impacts of changing means testing of study aid and time eligibility requirements. Second, we examine the impacts of changing the mix of loans and grants in study aid packages. Finally, we simulate how changing the loan repayment schemes would affect student behavior, academic success, and debt accumulation.

Given the state $X_{t}=\left(A, G_{t}, D_{t}, H_{t}, h_{t-1}, t\right)$, we solve the model for a state grid with $N_{\text {grid }}=$ $2 \times 2 \times 32 \times 45 \times 21 \times 10=1,209,600$ grid-points. We allow the grids for cumulated course credits and experience to comprise all possible states while we simplify the cumulated loan grid to take values between zero and the maximum available cumulated loan amount with linear steps equal to a quarter of the maximum loan amount available per year. First, we solve for the probabilities of achieving $g_{t}=0, \ldots, 7$ course credits every year conditional on the choices $k=0, \ldots, 6$. Second, we use course credit production probabilities and the parameter estimates to calculate the value functions for every choice, $k$. Third, we use the choice-specific value functions to calculate the CCPs of choosing $k=0, \ldots, 6$. Finally, we simulate different sets of policies in the following way: we start with a cohort of students at $t=1$ with zero cumulated course credits, $G_{0}=0$, zero cumulated student loan, $D_{0}=0$, but different initial abilities, 
$A_{0} \in\{0,1\}$, and work experience, $H_{0} \in\{0,1,2\}$. Initial conditions are thus distributed to mirror our sample. We then simulate the choices and state progression of this cohort using the course credit production probabilities and CCPs for each study aid policy.

Tables 3, 4, and 5 show the simulated impacts of the study aid policies. The first column in each table shows the benchmark outcomes, choices, and policy parameters. Appendix B.2 contains a set of figures to further illustrate the results in this section.

Table 3 shows the effects of changing time eligibility requirements and restrictiveness of means testing. The first two simulations change the time eligibility requirements by one year, such that in (Sim1) students are eligible for 5 years of aid and in (Sim2) they are eligible for 7 years. Dropout rates increase by 1.5 (decrease by 0.6) percentage points when the eligibility period is decreased (increased) by one year. This asymmetry in effects would be interesting to explore further, and is probably reflecting students with bad graduation and labor market prospects staying enrolled if they can receive student aid for longer - this is corroborated by the timing of dropping out being very close to the 5 year eligibility limit. Reversely, graduation rates decrease by 1.7 (increase by 1.5) percentage points when the eligibility period is decreased (increased) by one year. Decreasing the time eligibility to 5 years increases the time to graduation by a full semester, while increasing it to 7 years decreases time to graduation by almost a semester. This last result is surprising, and could be due to the fact that students are working more when receiving aid for a shorter time period and not taking up the loan to the same extent. We plan to explore these underlying mechanisms further in the future.

The last three simulations in Table 3 reveal the effects of changing the means testing which directly changes the work disincentive in the study aid scheme. (Sim3) increases the work disincentive by reducing the threshold from 0.75 to 0.50 of the base year amount, while (Sim4) reduces the work disincentive by increasing the threshold for allowable earnings from 0.75 to 1 . Dropout rates increase by 1.9 (decrease by 0.9 ) percentage points when lowering (increasing) the threshold. Timing of university exit is not affected much by means testing. It seems immediately puzzling that fewer students become employed when the work is made less attractive, but the means testing does not have any effect on the extensive margin of student labor supply. The simulations also reveal that students are just taking the cut in the aid, work more (or at higher wages) and accumulating less debt. (Sim5) changes the means testing of the benchmark to the post-reform one, i.e. allowing students to earn almost double what they earned before (the reform switched the threshold from 0.75 to 1.25 of the base year amount). As a consequence, 
students work more, and accumulate more debt. Dropout rates are lowered by 1.2 percentage points while graduation rates also are slightly lowered by 0.4 percentage points.

Table 3: Policy Simulations, Time Eligibility and Means Testing.

\begin{tabular}{|c|c|c|c|c|c|c|}
\hline & \multirow[b]{2}{*}{ Benchmark } & \multicolumn{2}{|c|}{ Time Eligibility } & \multirow[b]{2}{*}{ (Sim3) } & \multirow{2}{*}{$\begin{array}{l}\text { Means } \\
(\operatorname{Sim} 4)\end{array}$} & \multirow[b]{2}{*}{ (Sim5) } \\
\hline & & (Sim1) & $(\operatorname{Sim} 2)$ & & & \\
\hline \multicolumn{7}{|l|}{ Academic outcome: } \\
\hline Dropout rate & 0.306 & 0.319 & 0.300 & 0.325 & 0.297 & 0.294 \\
\hline $\mathrm{MA} / \mathrm{MSc}$ & 0.247 & 0.23 & 0.262 & 0.254 & 0.244 & 0.243 \\
\hline Time of dropout & 4.934 & 4.899 & 4.947 & 4.756 & 5.001 & 5.021 \\
\hline Time of MA/MSc & 6.104 & 6.796 & 5.652 & 6.103 & 6.078 & 6.061 \\
\hline Debt at exit: & 180,308 & 168,461 & 185,436 & 150,554 & 193,375 & 198,353 \\
\hline \multicolumn{7}{|l|}{ Choices: } \\
\hline Employed & 0.639 & 0.648 & 0.634 & 0.602 & 0.567 & 0.663 \\
\hline Full Loan & 0.800 & 0.793 & 0.803 & 0.783 & 0.806 & 0.809 \\
\hline Partial Loan & 0.098 & 0.1 & 0.096 & 0.116 & 0.097 & 0.096 \\
\hline \multicolumn{7}{|l|}{ Aid over Choice: } \\
\hline $\mathrm{k}=1$ & 16,987 & 15,408 & 17,647 & 17,115 & 16,911 & 16,879 \\
\hline $\mathrm{k}=2$ & 62,822 & 60,003 & 63,901 & 62,985 & 62,699 & 62,645 \\
\hline $\mathrm{k}=3$ & 40,631 & 39,854 & 40,945 & 40,666 & 40,603 & 40,592 \\
\hline $\mathrm{k}=4$ & 13,605 & 12,649 & 13,912 & 9,133 & 15,456 & 16,071 \\
\hline $\mathrm{k}=5$ & 53,768 & 52,110 & 54,183 & 40,200 & 58,993 & 60,834 \\
\hline $\mathrm{k}=6$ & 38,726 & 38,334 & 38,831 & 34,128 & 39,948 & 40,284 \\
\hline Average Aid amount & 51,059 & 48,950 & 51,770 & 43,958 & 54,032 & 55,115 \\
\hline \multicolumn{7}{|l|}{ Aid amounts: } \\
\hline grant & 17,856 & 17,856 & 17856 & 17,856 & 17,856 & 17,856 \\
\hline total & 64,232 & 64,232 & 64232 & 64,232 & 64,232 & 64,232 \\
\hline \multicolumn{7}{|l|}{ Time Eligible: } \\
\hline $\mathrm{t}=6$ & + & & & + & + & + \\
\hline $\mathrm{t}=5$ & & + & & & & \\
\hline $\mathrm{t}=7$ & & & + & & & \\
\hline \multicolumn{7}{|l|}{ Means Testing: } \\
\hline $0.50 *$ prisbasbelopp & & & & + & & \\
\hline $0.75^{*}$ prisbasbelopp & + & + & + & & & \\
\hline $1.00 *$ prisbasbelopp & & & & & + & \\
\hline $1.25^{*}$ prisbasbelopp & & & & & & + \\
\hline \multicolumn{7}{|l|}{ Grant-Loan Mix: } \\
\hline $28 \%$ grant, $72 \%$ loan & + & + & + & + & + & + \\
\hline \multicolumn{7}{|l|}{ Loan Repayment: } \\
\hline income contingent & 0.04 & 0.04 & 0.04 & 0.04 & 0.04 & 0.04 \\
\hline
\end{tabular}

The Table displays policy simulations of the effects on student choices and outcomes of changing time eligibility and means testing. All amounts are in real SEK 2000. The exchange rate ultimo December 2000 was 9.3955 SEK/USD and 8.8263 SEK/EUR.

Table 4 first shows the impacts of implementing all the 2001 reform changes, which align up well with the variation presented in Section 3. Then simulations from policies only changing the mix of grant and loan amounts in study aid are shown. (Sim6) increases the weight put on loans by almost 15 percentage points, such that $15 \%$ of aid is grant and $85 \%$ is loan. ( $\operatorname{Sim} 7$ ) decreases the weight put on loans by 15 percentage points relative to the post reform, such that 
grants and loans have equal weight in the total aid amount. There are no significant impacts on dropout and graduation by changing the weights of grants and loans in this range. The only substantial impact is on student debt accumulation, where students cumulate over SEK100,000 more debt when there is a 35 percentage point higher weight on the loan. Hence, whether the weight on loans is in the range of $50-85 \%$ does not matter for student choices and outcomes other than student debt. This is interesting from a policy makers perspective, since they can decide whether to privately (by the individual student) or publicly (by the government) fund college education - without altering educational outcomes. If even less weight is put on the loan, however, this is not true anymore. (Sim8) reveals the impacts of reversing the weights put on grants and loans relative to the benchmark, such that only $25 \%$ is loan. This implies that dropout rates decrease by 1.3 percentage points, but the time that dropouts are enrolled is also slightly increased. Graduation rates increase by 1.4 percentage points and times to graduation by almost a semester. Cumulated student debt now becomes only a third of the benchmark. Hence when only $25 \%$ of aid is in the form of a loan there is a social trade-off as the substantially improved educational outcomes are considered socially desirable, but most of the cost is also born publicly. What is socially optimal requires quantification of these social welfare costs and benefits. ${ }^{27}$

Finally, Table 5 shows the results of changing the repayment scheme for the loan. (Sim9) increases the repayment from $4 \%$ to $5 \%$ of income, (Sim10) implements the reform mix repayment scheme implemented with the 2001 reform, 25 years-annuity with the possibility of switching to an income contingent repayment of $5 \%$ of income, and then going back to a new 25 years-annuity calculated on the remaining debt. Finally, (Sim11) implements a scheme only with the 25-years annuity. We find that increasing the income contingent repayment rate by one percentage point has small effects overall: decreasing the student debt by a mere SEK1,000 and increasing the time to master graduation by a month and a half. Implementing the annuity schemes has, however, a larger impact: student debt at exit decreases by around SEK10,000, the dropout (graduation) rate increases by $2.1(0.5)$ percentage points, while the timing of dropout (graduation) decreases by a month. Fewer people take the full loan in favour of no loan. The three schemes do not significantly change the repayment installments with respect to the benchmark, as shown in Section 3, for the average earner. However, students expecting

\footnotetext{
${ }^{27}$ These normative assessments are beyond the scope of this paper, but would be interesting to explore in a future extension.
} 
Table 4: Policy Simulations, Grant-Loan Mix.

\begin{tabular}{|c|c|c|c|c|c|}
\hline & \multirow[b]{2}{*}{ Benchmark } & \multirow[b]{2}{*}{ Post-reform } & \multicolumn{3}{|c|}{ Grant-Loan Mix } \\
\hline & & & (Sim6) & $(\operatorname{Sim} 7)$ & (Sim8) \\
\hline \multicolumn{6}{|l|}{ Academic outcome: } \\
\hline Dropout rate & 0.306 & 0.315 & 0.306 & 0.306 & 0.293 \\
\hline $\mathrm{MA} / \mathrm{MSc}$ & 0.247 & 0.252 & 0.247 & 0.248 & 0.261 \\
\hline Time of dropout & 4.934 & 4.89 & 4.931 & 4.929 & 5.008 \\
\hline Time of MA/MSc & 6.104 & 6.113 & 6.122 & 6,087 & 5.618 \\
\hline Debt at exit: & 180,308 & 168,788 & 215,711 & 120,617 & 58,566 \\
\hline \multicolumn{6}{|l|}{ Student choices: } \\
\hline Employed & 0.639 & 0.661 & 0.639 & 0.639 & 0.635 \\
\hline Full Loan & 0.800 & 0.764 & 0.816 & 0.769 & 0.732 \\
\hline Partial Loan & 0.098 & 0,107 & 0.091 & 0.106 & 0.114 \\
\hline \multicolumn{6}{|l|}{ Aid over Choice: } \\
\hline $\mathrm{k}=1$ & 16,987 & 21,117 & 9,098 & 30,880 & 46,561 \\
\hline $\mathrm{k}=2$ & 62,822 & 62,290 & 62,851 & 62,758 & 62,531 \\
\hline $\mathrm{k}=3$ & 40,631 & 42,708 & 36,541 & 47,731 & 55,685 \\
\hline $\mathrm{k}=4$ & 13,605 & 20,246 & 7,177 & 25,317 & 38,941 \\
\hline $\mathrm{k}=5$ & 53,768 & 60,285 & 53,890 & 53,516 & 52,825 \\
\hline $\mathrm{k}=6$ & 38,726 & 42,388 & 34,804 & 45,528 & 53,151 \\
\hline Average Aid amount & 51,059 & 53,805 & 50,682 & 52,076 & 53,891 \\
\hline \multicolumn{6}{|l|}{ Aid amounts: } \\
\hline grant & 17,856 & 22,160 & 9,635 & 32,116 & 48,174 \\
\hline total & 64,232 & 64,232 & 64,232 & 64,232 & 64,232 \\
\hline \multicolumn{6}{|l|}{ Time Eligible: } \\
\hline $\mathrm{t}=6$ & + & + & + & + & + \\
\hline \multicolumn{6}{|l|}{ Means Testing: } \\
\hline $0.75^{*}$ prisbasbelopp & + & & + & + & + \\
\hline $1.25^{*}$ prisbasbelopp & & + & & & \\
\hline \multicolumn{6}{|l|}{ Grant-Loan Mix: } \\
\hline $15 \%$ grant, $85 \%$ loan & & & + & & \\
\hline $28 \%$ grant, $72 \%$ loan & + & & & & \\
\hline $35 \%$ grant, $65 \%$ loan & & + & & & \\
\hline $50 \%$ grant, $50 \%$ loan & & & & + & \\
\hline $75 \%$ grant, $25 \%$ loan & & & & & + \\
\hline \multicolumn{6}{|l|}{ Loan Repayment: } \\
\hline income contingent & + & - & + & + & + \\
\hline mixed & - & + & & & \\
\hline
\end{tabular}

The Table displays policy simulations of the effects on student choices and outcomes of changing the relative weight on grants and loans in study aid packages. All amounts are in real SEK 2000. The exchange rate ultimo December 2000 was 9.3955 SEK/USD and 8.8263 SEK/EUR. 
lower income (e.g. college dropouts) will face higher repayment rates and will be pushed to dropout earlier and with less debt. ${ }^{28}$

Table 5: Policy Simulations, Loan Repayment Schemes.

\begin{tabular}{|c|c|c|c|c|}
\hline & \multirow[b]{2}{*}{ Benchmark } & \multicolumn{3}{|c|}{ Loan Repayment } \\
\hline & & (Sim9) & $(\operatorname{Sim} 10)$ & (Sim11) \\
\hline \multicolumn{5}{|l|}{ Academic outcome: } \\
\hline Dropout rate & 0.306 & 0.309 & 0.327 & 0.325 \\
\hline Graduating with Master & 0.247 & 0.244 & 0.254 & 0.252 \\
\hline Time of dropout & 4.934 & 4.910 & 4.818 & 4.832 \\
\hline Time of Master graduation & 6.104 & 6.229 & 6.198 & 6.215 \\
\hline \multicolumn{5}{|l|}{ Accumulated debt at exit: } \\
\hline Cumulated loan & 180,308 & 179,327 & 170,494 & 171,724 \\
\hline Choices: & & & & \\
\hline Employed & 0.639 & 0.640 & 0.643 & 0.642 \\
\hline Full Loan & 0.800 & 0.799 & 0.765 & 0.770 \\
\hline Partial Loan & 0.098 & 0.103 & 0.107 & 0.106 \\
\hline \multicolumn{5}{|l|}{ Aid over Choice: } \\
\hline $\mathrm{k}=1$ & 16,987 & 17,019 & 17,049 & 17,046 \\
\hline $\mathrm{k}=2$ & 62,822 & 62,852 & 62,465 & 62,526 \\
\hline $\mathrm{k}=3$ & 40,631 & 40,641 & 40,602 & 40,609 \\
\hline $\mathrm{k}=4$ & 13,605 & 13,644 & 13,946 & 13,926 \\
\hline $\mathrm{k}=5$ & 53,768 & 53,856 & 52,994 & 53,144 \\
\hline $\mathrm{k}=6$ & 38,726 & 38,717 & 38,724 & 38,743 \\
\hline Average Aid amount & 51,059 & 51,048 & 49,332 & 49,598 \\
\hline \multicolumn{5}{|l|}{ Aid amounts: } \\
\hline grant & 17,856 & 17,856 & 17,856 & 17,856 \\
\hline total & 64,232 & 64,232 & 64,232 & 64,232 \\
\hline \multicolumn{5}{|l|}{ Time Eligible: } \\
\hline $\mathrm{t}=6$ & + & + & + & + \\
\hline Means Testing: & & & & \\
\hline $0.75^{*}$ prisbasbelopp & + & + & + & + \\
\hline Grant-Loan Mix: & & & & \\
\hline $28 \%$ grant, $72 \%$ loan & + & + & + & + \\
\hline $\begin{array}{r}\text { Loan Repayment: } \\
\text { income contingent } \\
\text { mix (reform) } \\
\text { annuity }\end{array}$ & $4 \%$ & $5 \%$ & + & + \\
\hline
\end{tabular}

The Table displays policy simulations of the effects on student choices and outcomes of changing loan repayment schemes. All amounts are in real SEK 2000. The exchange rate ultimo December 2000 was 9.3955 SEK/USD and 8.8263 SEK/EUR.

Overall, the policy simulations show many asymmetries and non-linearities where increasing or decreasing the same policy instrument in isolation has very different effects on student choices and outcomes. Detecting and quantifying these differences would not be possible without detailed panel data and a carefully specified and estimated dynamic model.

\footnotetext{
${ }^{28}$ Exploring how much these underlying mechanisms are driving the policy responses is high on our research agenda.
} 


\section{Conclusions}

The design of financial aid to students can have an impact on the incentives to study and work during college, as well as a substantial impact on their budget constraint - both during college and afterwards - as is the case when student loans are an important component of aid. In this paper, we shed light on these behavioral and economic effects of study aid policies. We model students' choices of enrollment, work, and student loan undertaking in a structural dynamic model with observed and unobserved heterogeneity.

We find that it is pivotal to have good estimates of how many students are at the relevant margins of change, as this reveals asymmetric effects of both time eligibility requirements, income means testing, and how much weight is put on loans and grants in financial aid packages. If the weight on loans is in the range of $50-85 \%$ it does not affect student behavior and outcomes other than student debt. Hence, policy makers can decide whether the individual student or the government should fund college education - without altering educational outcomes. However, if only $25 \%$ of the financial aid is in form of a loan this neutrality does not hold, as the increase of college graduates and the decrease in their cumulated student debt are substantial. The type of loan repayment scheme also has wide-ranging effects. Making an income contingent repayment stricter - basically increasing taxes on post-college labor income - does not have large impacts. However, moving from an income contingent to an annuity based schemes has beneficial effects, as both dropouts and graduates accumulate less student debt and enter the labor market earlier.

Our results are a step in the direction of better understanding the mechanisms driving student debt accumulation, study, and work behavior, and how they are affected by aid policies. More can be done starting from the setting in our paper, such as investigating more detailed work choices both during and after college, and heterogeneity along various skill dimensions and initial conditions. In particular, it will be very interesting to model student loans in a more realistic labor market setting to study the direct impacts of different repayment schemes on post-college labor market outcomes and careers; e.g. field of education, occupation, industry, search effort, and reservation wages. Another interesting result of our paper suggests that loan aversion depends on parental income, and even if credit constraints are loosened, students who do not have high-income parents prefer not to borrow. Especially in light of the borrowing constraint literature, it will be important to better understand the underlying mechanisms and their implications for optimal financial aid. 


\section{References}

Altonji, J. G. (1993, January). The demand for and return to education when education outcomes are uncertain. Journal of Labor Economics 11(1), 48-83.

Angrist, J., E. Bettinger, E. Bloom, E. King, and M. Kremer (2002). Vouchers for private schooling in colombia: Evidence from a randomized natural experiment. The American Economic Review 92(5), pp. 1535-1558.

Arcidiacono, P. (2004). Ability sorting and the returns to college major. Journal of Econometrics 121(1), 343-375.

Arcidiacono, P. and J. B. Jones (2003). Finite mixture distributions, sequential likelihood and the em algorithm. Econometrica 71(3), 933-946.

Arcidiacono, P. and R. A. Miller (2011). Conditional choice probability estimation of dynamic discrete choice models with unobserved heterogeneity. Econometrica 79(6), 1823-1867.

Attanasio, O. P., C. Meghir, and A. Santiago (2012). Education choices in mexico: using a structural model and a randomized experiment to evaluate progresa. The Review of Economic Studies 79(1), 37-66.

Avdic, D. and M. Gartell (2015). Working while studying? student aid design and socioeconomic achievement disparities in higher education. Labour Economics 33, 26-40.

Avery, C. and S. Turner (2012). Student loans: Do college students borrow too muchor not enough? The Journal of Economic Perspectives 26(1), 165-192.

Belley, P. and L. Lochner (2007). The changing role of family income and ability in determining educational achievement. Technical Report 1.

Bettinger, E. (2004). How financial aid affects persistence. In College choices: The economics of where to go, when to go, and how to pay for it, pp. 207-238. University of Chicago Press.

Black, S. and P. Devereux (2011). Recent developments in intergenerational mobility. Handbook of Labor Economics 4, 1487-1541.

Blundell, R. and A. Shephard (2012). Employment, hours of work and the optimal taxation of low-income families. The Review of Economic Studies 79(2), 481-510. 
Bound, J., M. Lovenheim, and S. Turner (2007). Understanding the decrease in college completion rates and the increased time to the baccalaureate degree. Ann Arbor, Mich.: Population Studies Center, University of Michigan Institute for Social Research.

Brown, M., J. K. Scholz, and A. Seshadri (2012). A new test of borrowing constraints for education. The Review of Economic Studies 79(2), 511-538.

Cameron, S. V. and C. Taber (2004, February). Estimation of educational borrowing constraints using returns to schooling. Journal of Political Economy 112(1), 132-182.

Card, D. and D. R. Hyslop (2005). Estimating the effects of a time-limited earnings subsidy for welfare-leavers. Econometrica 73(6), 1723-1770.

Carneiro, P. and J. J. Heckman (2002, October). The evidence on credit constraints in postsecondary schooling. Economic Journal 112(482), 705-734.

CSN (2002). Den första terminen med det nya studiestödet. Centrala Studiestödsnämnden.

CSNFS (2001). Centrala studiestödsnämndens föreskrifter och allmänna råd om beviljning av studiemedel. Centrala Studiestödsnämnden.

Cunha, F. and J. Heckman (2007). The technology of skill formation. The American Economic Review 97(2), 31-47.

Cunha, F. and J. J. Heckman (2008). Formulating, identifying and estimating the technology of cognitive and noncognitive skill formation. Journal of Human Resources 43(4), 738-782.

Cunha, F., J. J. Heckman, L. Lochner, and D. V. Masterov (2006). Interpreting the evidence on life cycle skill formation. Handbook of the Economics of Education 1, 697-812.

Cunha, F., J. J. Heckman, and S. M. Schennach (2010). Estimating the technology of cognitive and noncognitive skill formation. Econometrica 78(3), 883-931.

DesJardins, S. L. and B. P. McCall (2010). Simulating the effects of financial aid packages on college student stopout, reenrollment spells, and graduation chances. The Review of Higher Education 33(4), 513-541.

Dynarski, S. (2008). Building the stock of college-educated labor. Journal of human resources 43(3), 576-610. 
Dynarski, S. and J. Scott-Clayton (2013). Financial aid policy: Lessons from research. Technical report, National Bureau of Economic Research.

Dynarski, S. M. (2003). Does aid matter? measuring the effect of student aid on college attendance and completion. The American Economic Review 93(1), pp. 279-288.

Eckstein, Z. and K. I. Wolpin (1999). Why youths drop out of high school: The impact of preferences, opportunities, and abilities. Econometrica 67(6), 1295-1339.

Eurostat, E. E. (2009). Key Data on Education in Europe.

Friedman, M. (1962). Capitalism and freedom. University of Chicago press.

Garibaldi, P., F. Giavazzi, A. Ichino, and E. Rettore (2012). College cost and time to complete a degree: Evidence from tuition discontinuities. Review of Economics and Statistics 94(3), 699-711.

Gicheva, D. (2012). In debt and alone? examining the causal link between student loans and marriage.

Goodman, J. (2008). Who merits financial aid?: Massachusetts' adams scholarship. Journal of Public Economics 92(10), 2121-2131.

Heckman, J. and B. Singer (1984). A method for minimizing the impact of distributional assumptions in econometric models for duration data. Econometrica: Journal of the Econometric Society, 271-320.

Heckman, J. J. (1981). The incidental parameters problem and the problem of initial conditions in estimating a discrete time-discrete data stochastic process.

Heckman, J. J. (2010). Building bridges between structural and program evaluation approaches to evaluating policy. Journal of Economic Literature 48(2), pp. 356-398.

Heckman, J. J., L. J. Lochner, and P. E. Todd (2006). Earnings functions, rates of return and treatment effects: The mincer equation and beyond. Handbook of the Economics of Education 1, 307-458.

Hotz, V. J. and R. A. Miller (1993). Conditional choice probabilities and the estimation of dynamic models. The Review of Economic Studies 60(3), 497-529. 
Hotz, V. J., R. A. Miller, S. Sanders, and J. Smith (1994). A simulation estimator for dynamic models of discrete choice. The Review of Economic Studies 61(2), 265-289.

Joensen, J. (2013a). Academic and Labor Market Success: The Impact of Student Employment, Abilities, and Preferences. mimeo, Stockholm School of Economics.

Joensen, J. (2013b). Timing and Incentives: Impacts of Student Aid on Academic Achievement. mimeo, Stockholm School of Economics.

Joensen, J. S. and H. S. Nielsen (2009). Is there a causal effect of high school math on labor market outcomes? Journal of Human Resources 44(1), 171-198.

Joensen, J. S. and H. S. Nielsen (2014). Mathematics and gender: Heterogeneity in causes and consequences. The Economic Journal, n/a-n/a.

Johnson, M. T. (2013). Borrowing constraints, college enrollment, and delayed entry. Journal of Labor Economics 31(4), 669-725.

Kane, T. J. (2006). Public intervention in post-secondary education. Handbook of the Economics of Education 2, 1369-1401.

Keane, M. and K. Wolpin (1997). The career decisions of young men. Journal of Political Economy 105(3), 473-522.

Keane, M. and K. Wolpin (2001). The effect of parental transfers and borrowing constraints on educational attainment. International Economic Review 42(4), 1051-1103.

Keane, M. P., P. E. Todd, and K. I. Wolpin (2011). The structural estimation of behavioral models: Discrete choice dynamic programming methods and applications. Handbook of Labor Economics 4, 331-461.

Keane, M. P. and K. I. Wolpin (1994, November). The solution and estimation of discrete choice dynamic programming models by simulation and interpolation: Monte carlo evidence. The Review of Economics and Statistics 76(4), 648-72.

Leslie, L. L. (1984). Changing patterns in student financing of higher education. The Journal of Higher Education, 313-346. 
Leuven, E., H. Oosterbeek, and B. Klaauw (2010). The effect of financial rewards on students' achievement: Evidence from a randomized experiment. Journal of the European Economic Association 8(6), 1243-1265.

Lochner, L. and A. Monge-Naranjo (2011a, October). The nature of credit constraints and human capital. American Economic Review 101(6), 2487-2529.

Lochner, L. and A. A. Monge-Naranjo (2011b). Credit constraints in education. Technical report, National Bureau of Economic Research.

Mattana, E. (2013). Flying the Nest: Intergenerational Strategic Interaction, Co-residence, and Social Mobility. mimeo, Stockholm School of Economics.

McFadden, D. et al. (1978). Modelling the choice of residential location. Institute of Transportation Studies, University of California.

Nielsen, H. S., T. Sørensen, and C. Taber (2010, May). Estimating the effect of student aid on college enrollment: Evidence from a government grant policy reform. American Economic Journal: Economic Policy 2(2), 185-215.

OECD (2009). Education at a Glance 2009: OECD Indicators.

Oreopoulos, P., D. Lang, and J. Angrist (2009, January). Incentives and services for college achievement: Evidence from a randomized trial. American Economic Journal: Applied Economics 1(1), 136-63.

Rothstein, J. and C. E. Rouse (2011). Constrained after college: Student loans and early-career occupational choices. Journal of Public Economics 95(1), 149-163.

Rust, J. (1987). Optimal replacement of gmc bus engines: An empirical model of harold zurcher. Econometrica: Journal of the Econometric Society, 999-1033.

Scott-Clayton, J. (2011). On money and motivation a quasi-experimental analysis of financial incentives for college achievement. Journal of Human Resources 46(3), 614-646.

Solis, A. (2011). Credit access and college enrollment. Unpublished doctoral dissertation). University of California, Berkeley. 
Stinebrickner, R. and T. Stinebrickner (2008). The effect of credit constraints on the college drop-out decision: A direct approach using a new panel study. The American Economic Review 98(5), 2163-84.

Todd, P. and K. Wolpin (2006). Assessing the impact of a school subsidy program in mexico: Using a social experiment to validate a dynamic behavioral model of child schooling and fertility. The American Economic Review 96(5), 1384-1417.

Todd, P. E. and K. I. Wolpin (2003, February). On the specification and estimation of the production function for cognitive achievement. Economic Journal 113(485), F3-F33. 


\section{Appendices}

\section{A Solution and Estimation of the Model}

\section{A.1 CCP Estimation}

Our goal is to estimate the parameters of the law of motions of the course credit production function $(\gamma)$ and the earnings equation $(\alpha)$, as well as the utility function parameters $(\nu)$. We use a maximum-likelihood based estimation procedure. We assume conditional independence of the state variables and the unobservables as in Rust (1987). That is, we assume that, conditional on today's realization of the state $X_{t}$ and the choice $\delta_{t}$, next period's realization of the state $X_{t+1}$ is independent of the unobservable shocks $\epsilon_{t}$. This assumption is adopted in most dynamic discrete choice papers and implies separability between the choice probability and the transition for the observable state in the likelihood function. Denote the individuals observed in our data by $i=1, \ldots, N . \hat{\theta}=\{\nu, \gamma, \alpha\}$ denotes the parameters to be estimated. The likelihood function for every individual can be written as:

$$
\begin{aligned}
L_{t}\left(\delta_{i t}, X_{i t+1} \mid X_{i t} ; \theta\right) & =p_{t}\left(\delta_{i t} \mid X_{i t} ; \theta\right) P\left(X_{i t+1} \mid X_{i t}, \delta_{i t} ; \theta_{2}\right) \\
& =p_{t}\left(\delta_{i t} \mid X_{i t} ; \theta\right) P_{t}\left(G_{i t+1} \mid X_{i t}, \delta_{i t} ; \gamma\right) P_{t}\left(W_{i t} \mid X_{i t}, \delta_{i t} ; \alpha\right)
\end{aligned}
$$

The estimation problem is thus:

$$
\begin{aligned}
\hat{\theta}=\arg \max _{\theta} \sum_{i=1}^{N} \sum_{t=1}^{T}( & \ln \left[p_{t}\left(\delta_{i t} \mid X_{i t} ; \theta\right)\right]+\ln \left[P_{t}\left(G_{i t+1} \mid X_{i t}, \delta_{i t} ; \gamma\right)\right] \\
& \left.+\ln \left[P_{t}\left(W_{i t} \mid X_{i t}, \delta_{i t} ; \alpha\right)\right]\right)
\end{aligned}
$$

where $p_{t}\left(\delta_{i t} \mid X_{i t} ; \theta\right)$ is the conditional choice probability (CCP) of the choice $\delta_{i t}$. The entire set of model parameters enters in the likelihood component specific to the utility and the sets specific to course credit production and wages enter also separately in the likelihood components of the two states.

The separability of the likelihood function allows a sequential maximum likelihood approach. We can then first estimate the wage and the course credit law of motions separately and then 
use the parameter estimates for $\hat{\gamma}$ and $\hat{\alpha}$ to estimate the conditional choice probabilities.

$$
\ell(\theta)=\sum_{i=1}^{N}\left(\ell_{n}^{w}(\alpha)+\ell_{n}^{g}(\gamma)+\ell_{n}^{k}(\theta)\right)
$$

Hence, we need to derive and estimate the CCPs. This involves solving the model by backward recursion. Define the ex-ante (integrated) value function as the continuation value for an agent in state $X_{t}$ just before $\epsilon_{t}$ is revealed. This is the value function before the choice is made:

$$
\bar{V}_{t}\left(X_{t}\right)=\sum_{k} \underset{\epsilon_{t}}{\mathbb{E}} \mathbf{1}\left[\delta_{t}\left(X_{t}, \epsilon_{t}\right)=\delta^{k}\right]\left[U^{k}\left(X_{t}\right)+\epsilon_{t}^{k}+\beta \underset{G_{t+1}}{\mathbb{E}} \bar{V}_{t+1}\left(X_{t+1}\right)\right]
$$

where the future value of the agent is the future value of the choice $k$, given the realization of the shocks and given that choice $k$ is taken. Define then the conditional value function as the present discounted value (net of $\epsilon_{t}$ ) of choosing $\delta^{k}$ and behaving optimally from period $t+1$ onwards. This is the value function after the choice is made, conditional on the choice.

$$
v_{t}^{k}\left(X_{t}\right) \equiv u^{k}\left(X_{t}\right)+\beta \underset{G_{t+1}}{\mathbb{E}} \bar{V}_{t+1}\left(X_{t+1}\right)
$$

Hence the choice is defined as follows:

$$
\delta_{t}\left(X_{t}, \epsilon_{t}\right)=\arg \max _{k}\left\{v_{t}^{k}\left(X_{t}\right)+\epsilon_{t}^{k}\right\}
$$

The probability of observing the alternative $k$ conditional on $X_{t}$ is then found integrating out $\epsilon_{t}$ from $\delta_{t}\left(X_{t}, \epsilon_{t}\right)$ :

$$
\begin{aligned}
p\left(\delta^{k} \mid X_{t}\right) & =\underset{\epsilon_{t}}{\mathbb{E}} \mathbf{1}\left[\delta_{t}\left(X_{t}, \epsilon_{t}\right)=\delta^{k}\right] \\
& =\underset{\epsilon_{t}}{\mathbb{E}} \mathbf{1}\left[\arg \max _{k}\left(v_{t}^{k}\left(X_{t}\right)+\epsilon_{t}\right)=\delta^{k}\right]
\end{aligned}
$$

We assume that the $\epsilon_{t}^{k}$ 's follow a Type I Extreme Value distribution. The assumption of an extreme value distribution for the error term has been introduced in this literature by McFadden et al. (1978). It is computationally convenient as it guarantees closed form expressions for the 
CCPs and the ex-ante value functions. The CCP's become:

$$
p_{t}\left(\delta^{k} \mid X_{t}\right)=\frac{\exp \left[v_{t}^{k}\left(X_{t}\right)\right]}{\sum_{k^{\prime}=0}^{6} \exp \left[v_{t}^{k^{\prime}}\left(X_{t}\right)\right]}
$$

The ex-ante value function becomes:

$$
\bar{V}_{t}\left(X_{t}\right)=\ln \left\{\sum_{k^{\prime}=0}^{6} \exp \left[v_{t}^{k^{\prime}}\left(X_{t}\right)\right]\right\}+\gamma
$$

Where $\gamma$ is the Euler constant $(\gamma=0.57722)$.

Given the closed form solution of the CCPs we only need to estimate the conditional value functions. Hotz and Miller (1993) show that the conditional value can always be written as a function of current utilities and future CCPs. Generalized extreme value errors, together with the assumptions of (i) structural errors additively separable from the flow payoff, (ii) conditional independence of the state transitions, and (iii) independence of structural errors over time, guarantee that differences in conditional value functions can be expressed as functions of choice probabilities alone.

Divide and multiply the ex-ante value function $\bar{V}_{t}\left(X_{t}\right)$ in A.9 by $\exp \left[v_{t}^{0}\left(X_{t}\right)\right]$, where $k=0$ is full-time labor market work: ${ }^{29}$

$$
\begin{aligned}
\bar{V}_{t}\left(X_{t}\right) & =\ln \left(\left\{\frac{\sum_{k^{\prime}} \exp \left[v_{t}^{k^{\prime}}\left(X_{t}\right)\right]}{\exp \left[v_{t}^{k^{*}}\left(X_{t}\right)\right]}\right\} \exp \left[v_{t}^{k^{*}}\left(X_{t}\right)\right]\right)+\gamma \\
& =\ln \left\{\sum_{k^{\prime}} \exp \left[v_{t}^{k^{\prime}}\left(X_{t}\right) v_{t}^{0}\left(X_{t}\right)\right]\right\}+v_{t}^{0}\left(X_{t}\right)+\gamma \\
& =-\ln \left[p_{t}\left(\delta^{0} \mid X_{t}\right)\right]+v_{t}^{0}\left(X_{t}\right)+\gamma
\end{aligned}
$$

Where $p_{t}\left(\delta^{0} \mid X_{t}\right)$ is the CCP of choosing $k=0$.

Therefore, the conditional value function becomes:

$$
\begin{aligned}
v_{t}^{k}\left(x_{t}\right) & =U^{k}\left(X_{t}\right)+\beta \underset{G_{t+1}}{\mathbb{E}} \bar{V}_{t+1}\left(X_{t+1}\right) \\
& =U^{k}\left(X_{t}\right)+\beta \underset{G_{t+1}}{\mathbb{E}}\left(v_{t+1}^{0}\left(X_{t+1}\right)-\ln \left[p_{t+1}\left(\delta^{0} \mid X_{t+1}\right)\right]\right)+\beta \gamma
\end{aligned}
$$

Hence, we only need to know the law of motion of the course credits and the conditional

\footnotetext{
${ }^{29}$ Note that we could have normalized with respect to an arbitrary choice, but choosing the absorbing state is computationally more efficient.
} 
value function and CCP of exiting university and entering the labor market full-time. Choosing the absorbing state as the reference choice simplifies the solution as its continuation value is deterministic and does not dependent on possible future choices. This means that the $\mathbb{E} \max$ is particularly easy to compute as we only need to compute the one-period ahead value function for the absorbing state and the CCP of entering it: ${ }^{30}$

$$
v_{t}^{k}\left(x_{t}\right)=u^{k}\left(x_{t}\right)+\beta \underset{G_{t+1}}{\mathbb{E}}\left(v_{t+1}^{0}\left(X_{t+1}\right)-\ln \left[p_{t+1}\left(\delta_{t}^{0}=1 \mid X_{t+1}\right)\right]\right)+\beta \gamma
$$

\section{A.2 Unobserved Heterogeneity}

Individuals enter university with different characteristics that make it unlikely for them to have the same preferences for education, $\nu_{0}^{m}$, unobserved abilities with respect to course credit production, $\gamma_{0}^{m}$, and labor market productivity, $\alpha_{0}^{m}$. Understanding this unobserved heterogeneity also allows us to study which initial traits explain the propensity to drop out or to spend long excess time in college, as well as how they differ from the other individuals and how these characteristics relate to family background. To account for unobserved heterogeneity and dynamic selection and to relax the i.i.d. assumption of the unobservable shocks, we introduce an additional state that is unobserved and persistent over time. Following Heckman and Singer (1984), the standard approach in the literature is to treat these initial traits as unmeasured and drawn from a mixture distribution (Keane and Wolpin, 1997; Eckstein and Wolpin, 1999; Arcidiacono, 2004; Keane et al., 2011). This way of accounting for unobserved heterogeneity allows for flexible correlation of the errors across the various alternatives as well as correlation over time and dynamic selection.

We assume there is a finite mixture of $m=1, \ldots, M$ discrete types of individuals who differ in the parameters that describe their preferences, their academic ability and motivation, and their labor market ability. Each type comprises a fixed proportion of the population. To reduce the number of parameters and avoid identification issues, we only allow for first-order heterogeneity effects. $^{31}$

We estimate the model with unobserved heterogeneity using the algorithm described in Arcidiacono and Miller (2011). They extend the class of CCP estimators by adapting the

\footnotetext{
${ }^{30}$ In the terminology of Arcidiacono and Miller (2011), the model is said to exhibit the one period dependence (OPD) property, since the current value function only depends on the one-period ahead value of university exit and the probability of choosing to exit the university and start working full time on the labor market.

${ }^{31}$ This approach is common in the literature; see e.g. Eckstein and Wolpin (1999) or Keane et al. (2011) for a discussion.
} 
application of the EM algorithm to sequential likelihood developed in Arcidiacono and Jones (2003) to CCP estimators developed in Hotz et al. (1994).

The joint likelihood of the choice $\delta_{i t}$ and the state $X_{i t}$, with the addition of the types $m_{i t}$, becomes a finite mixture of the type-specific likelihood in equation (A.1):

$$
L_{t}\left(\delta_{i t}, X_{i t+1} \mid X_{i t} ; \theta\right)=\sum_{m=1}^{M} \pi\left(m \mid X_{i t}\right) L_{t}\left(\delta_{i t}, X_{i t+1} \mid X_{i t}, m ; \theta\right)
$$

The probability of being in unobserved state $m$ given the state at the first observed time period, $X_{n 1}$, is denote by $\pi\left(m \mid X_{n 1}\right)$. Note that since the state $m$ is here assumed to be time invariant, it is decided from time period 1 , but identification relies on all the available information in $X_{i t}$.

The problem is then augmented with the $\pi$ 's.

$$
(\hat{\theta}, \hat{\pi})=\arg \max _{\theta, \pi} \sum_{i=1}^{N} \ln \left[\sum_{m=1}^{m} \pi\left(m \mid X_{i t}\right) \prod_{t=1}^{T} L_{t}\left(\delta_{i t}, X_{i t+1} \mid X_{i t}, m ; \theta\right)\right]
$$

The log likelihood is now no longer additively separable, implying that maximization cannot be done sequentially. However, the expectation-maximization (EM) algorithm simplifies this optimization problem substantially by reintroducing additive separability in the log-likelihood functions through an iterative maximization approach. The EM algorithm splits the problem in two stages and yields a solution to the initial maximization problem upon convergence. It is an iterative process in which the outer loop (expectation step) solves the distribution of $m$ and the $\pi$ 's and the inner loop (maximization step) solves for the parameters, $\theta$. Arcidiacono and Miller (2011) show that the EM algorithm is easily adapted to CCP estimation.

Given values for $\theta^{(n)}$ and $\pi^{(n)}$, the $(n+1)$ iteration of the the EM-CCP algorithm is as follows. In the expectation step, we update the conditional probabilities of individual $n$ being unobserved type $m$ given the data and the model parameters:

$$
q^{(n+1)}\left(m \mid \delta_{n}, X_{n}\right)=\frac{\pi^{(n)}\left(m \mid X_{i t}\right) \prod_{t} P_{t}\left(X_{i t+1} \mid X_{i t}, \delta_{i t}, m ; \theta_{2}^{(n)}\right) p_{t}\left(\delta_{i t} \mid X_{i t}, m\right)}{\sum_{m^{\prime}} \pi^{(n)}\left(m^{\prime} \mid X_{i t}\right) \prod_{t} P_{t}\left(X_{i t+1} \mid X_{i t}, \delta_{i t}, m^{\prime} ; \theta_{2}^{(n)}\right) p_{t}\left(\delta_{i t} \mid X_{i t}, m^{\prime}\right)}
$$

The conditional probability of being in each unobserved state is linked to the probability of being in state $m$ given the data at the first observed time period (given time invariability). Hence we update the population type probabilities $\pi\left(m \mid X_{i t}\right)$ as:

$$
\pi^{(n+1)}\left(m \mid X_{t}\right)=\frac{\sum_{n} q^{(n+1)}\left(m \mid \delta_{n}, X_{n} t\right) \mathbf{1}\left(X_{t n}=X_{t}\right)}{\sum_{n} \mathbf{1}\left(X_{i t}=X_{t}\right)} .
$$


In the maximization step, we take $q^{(n+1)}\left(m \mid \delta_{n}, X_{n}\right)$ as given and obtain $\theta^{(n+1)}$ :

$$
\theta^{(n+1)}=\arg \max _{\theta} \sum_{m=1}^{M} \sum_{i=1}^{N} \sum_{t=1}^{T} q^{(n+1)}\left(m \mid \delta_{n}, X_{n}\right)\left(\ln \left[L_{t}\left(\delta_{i t}, X_{i t+1} \mid X_{i t}, m, p^{(n)} ; \theta^{(n)}\right)\right]\right)
$$

When the types are treated as observed, additive separability can be reintroduced, and the maximization step can be divided in two parts: first the law of motions of the states $G_{t}$ and $W_{t}$ are estimated given the type distribution estimated in the expectation step. Then we retrieve the parameters of the payoff functions according to the CCP method described in section A.1.

$$
\begin{aligned}
\theta^{(n+1)}= & \arg \max _{\theta} \sum_{m=1}^{M} \sum_{i=1}^{N} \sum_{t=1}^{T} q^{(n+1)}\left(m \mid \delta_{n}, X_{n}\right) \ln \left[p_{t}\left(\delta_{i t} \mid X_{i t} ; \theta\right)\right] \\
& +\ln \left[P\left(G_{i t+1} \mid X_{i t}, \delta_{i t} ; \gamma\right)\right]+\ln \left[P\left(W_{i t} \mid X_{i t}, \delta_{i t} ; \alpha\right)\right] .
\end{aligned}
$$

Finally, we update the CCPs of the choice of exit college - which is the only one we need for the CCP method described in section A.1 - augmented with the unobserved state $m$ from the likelihood:

$$
p_{0}^{(n+1)}\left(\delta_{t}^{0} \mid X_{t}, m\right)=L_{t}\left(\delta_{t}^{0} \mid X_{t}, m ; p^{(n)}, \theta^{(n+1)}\right) .
$$

Arcidiacono and Miller (2011) show that this algorithm converges to a fixed point and is computationally feasible for many problems with the finite time dependence property. 


\section{B Figures}

\section{B.1 Identification}

Figure 9: Total Student Income, Increasing weight on Grants.

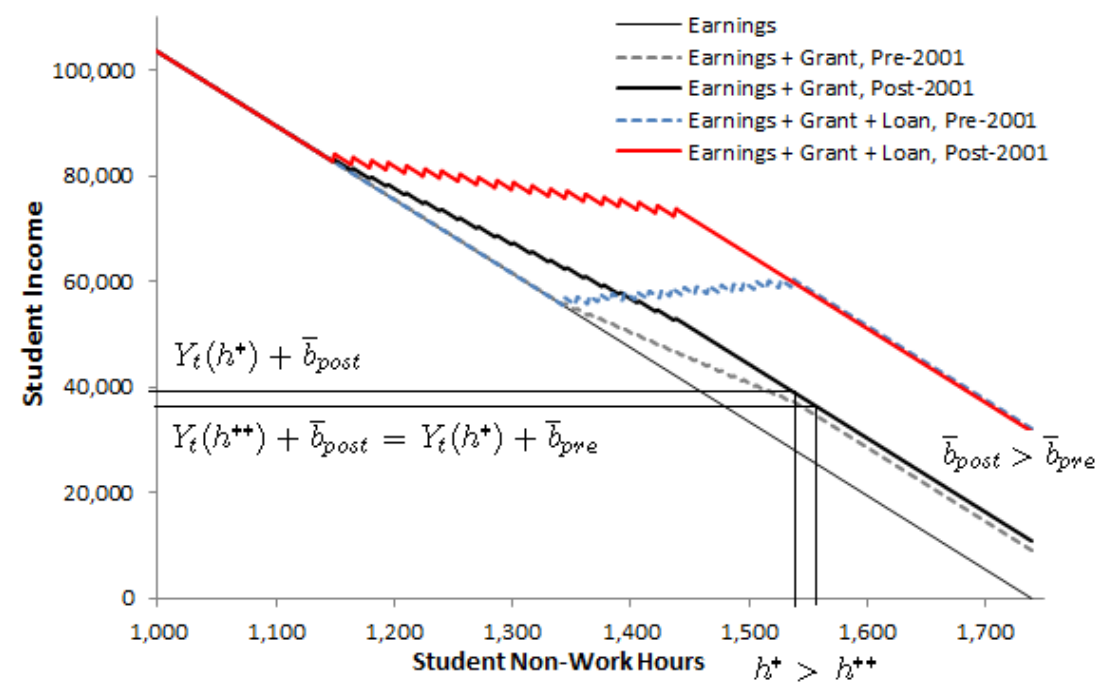

The Figure displays total student income - including the maximum student aid and grant amount - as a function of student leisure hours; i.e. yearly hours not worked. The figure is constructed assuming a non-working student has 1739 leisure hours a year and working students have an hourly wage of 140 SEK. All amounts are in real SEK 2000. The exchange rate ultimo December 2000 was 9.3955 SEK/USD and 8.8263 SEK/EUR. The figure illustrates the reform impact of increasing the weight on grants relative to loans in total study aid. 
Figure 10: Total Student Income, Less Stringent Means Testing.

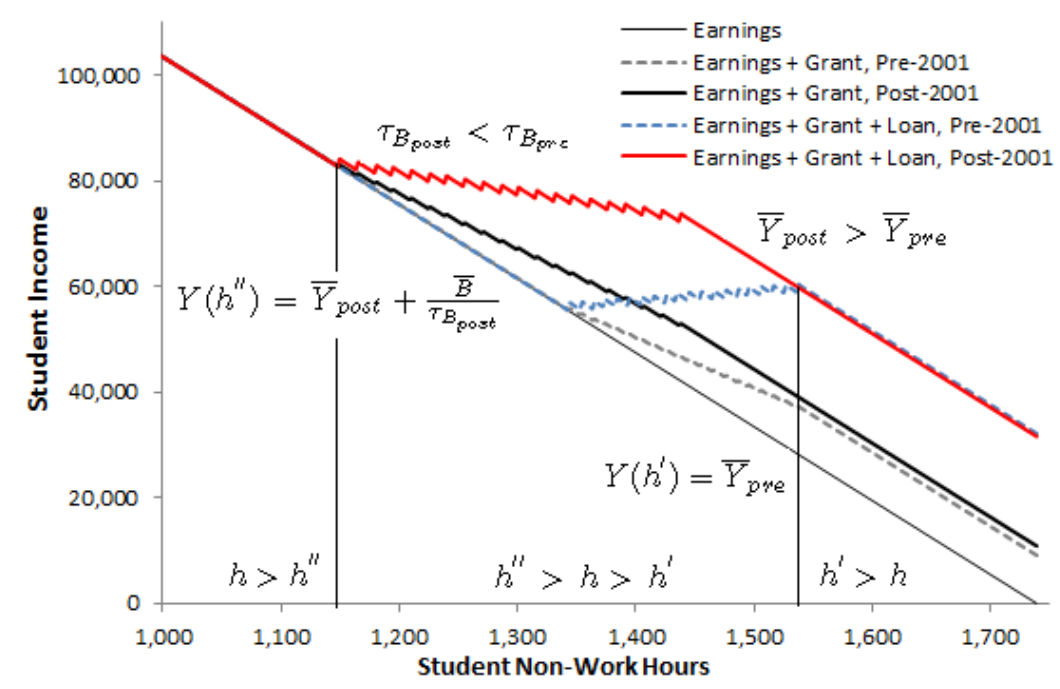

The Figure displays total student income - including the maximum student aid and grant amount - as a function of student leisure hours; i.e. yearly hours not worked. The figure is constructed assuming a non-working student has 1739 leisure hours a year and working students have an hourly wage of 140 SEK. All amounts are in real SEK 2000. The exchange rate ultimo December 2000 was 9.3955 SEK/USD and 8.8263 SEK/EUR. The figure illustrates the reform impact of less stringent means testing.

Figure 11: Expected Repayment Scheme, from Income-Contingent to Annuity.

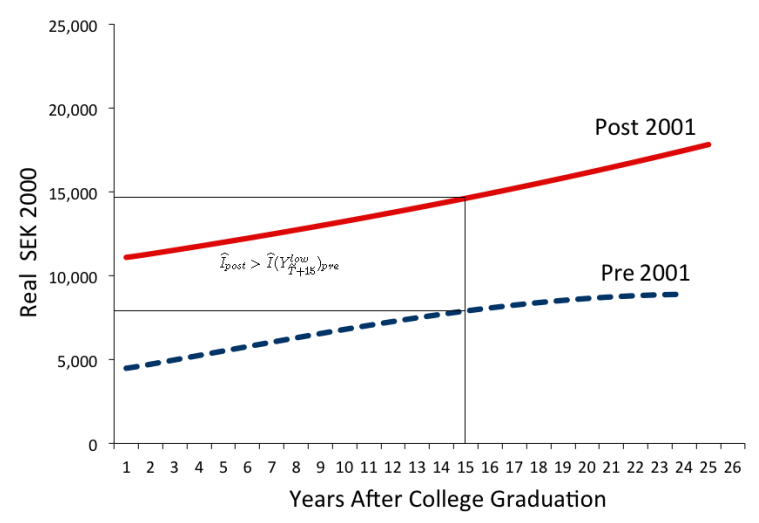

(a) Expected Repayment, low starting salary

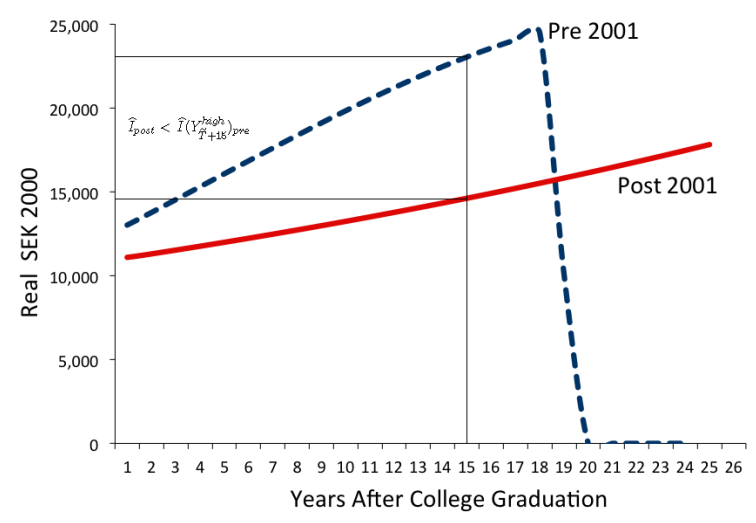

(b) Expected Repayment, high starting salary

The Figure displays the expected repayment scheme and evolution of cumulative debt for a full-time student with maximum loan (240 weeks), with starting low yearly income equal to the sample average minus one standard deviation (SEK 105,116) and high yearly income equal to the sample average plus one standard deviation (SEK 306,678). The income equation is assumed to be $\ln (w)=\ln \left(w_{0}\right)+0.06 H_{t}-0.0012 H_{t}^{2}$ and the loan interest rate $2.5 \%$. Pre reform figures are displayed with dashed lines and post reform figures with solid lines. The figure displays how installments are increased for low income individuals and decreased for high income individuals. 


\section{B.2 Simulations}

Figure 12: Loan-Grant Share: Completed Degrees and Timing of Graduation

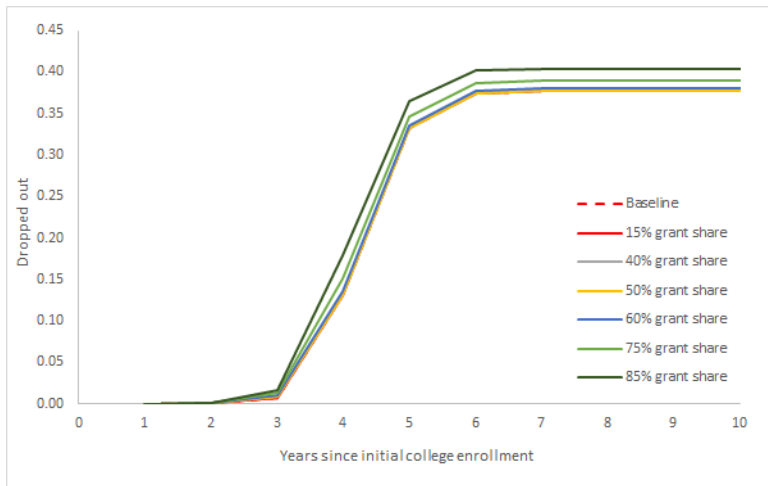

(a) Dropouts

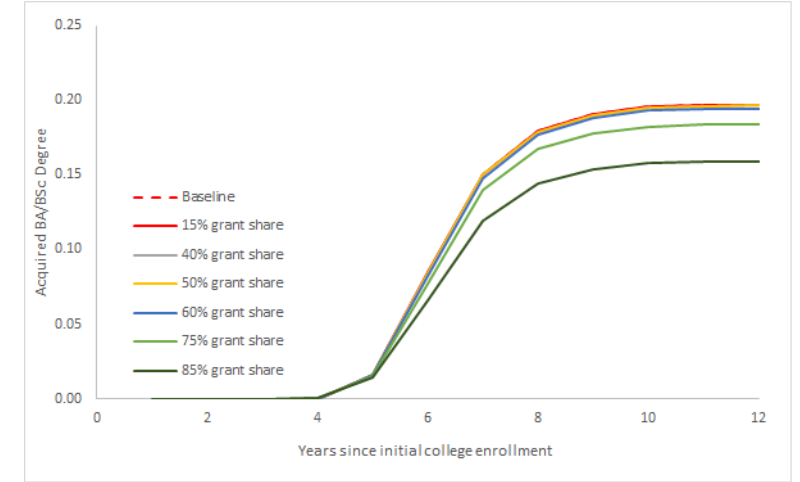

(b) 2-year college and BA/BSc Degree

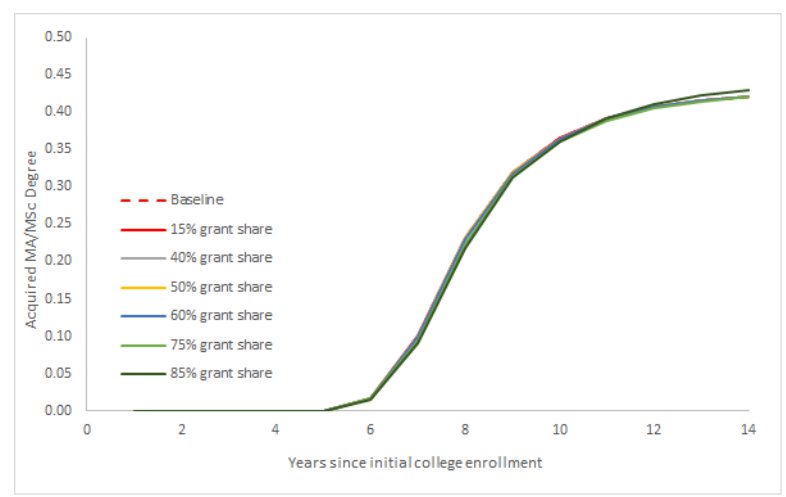

(c) 4-year college and MA/MSc Degree

The Figures displays the timing and type of college exit: dropouts, shorter degrees (2-year and BA/BSc), and longer college degrees (4-year and MA/MSc). The baseline simulation is run with $27.8 \%$ grant share, $0.75^{*}$ prisbasbelopp means testing, income contingent repayment at $4 \%, 6$ years of eligibility. The reform simulation is run with $34 \%$ grant share, $1.25^{*}$ prisbasbelopp means testing, annuity $\widehat{a}_{t}$ repayment plus twice possible leniency with income contingent repayment at 5\%, 6 years of eligibility. Grant shares: 15\%, 40\%, 50\%, $60 \%, 75 \%, 85 \%$. 
Figure 13: Loan-Grant Share: Cumulated Work Experience

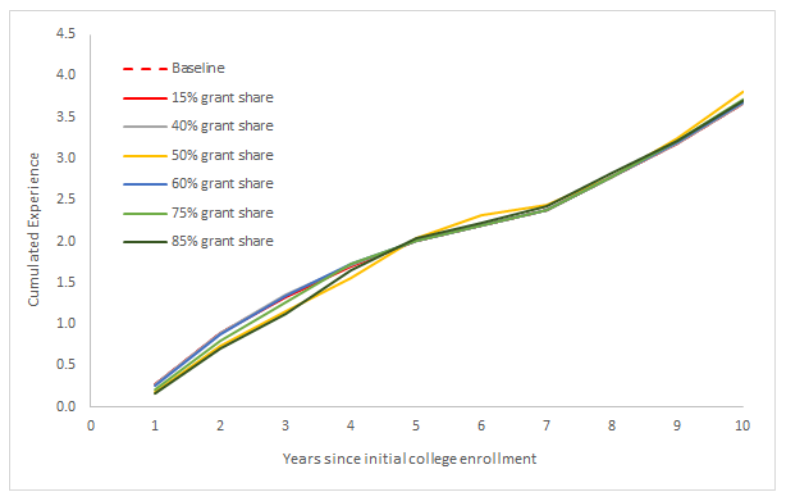

(a) All College Students

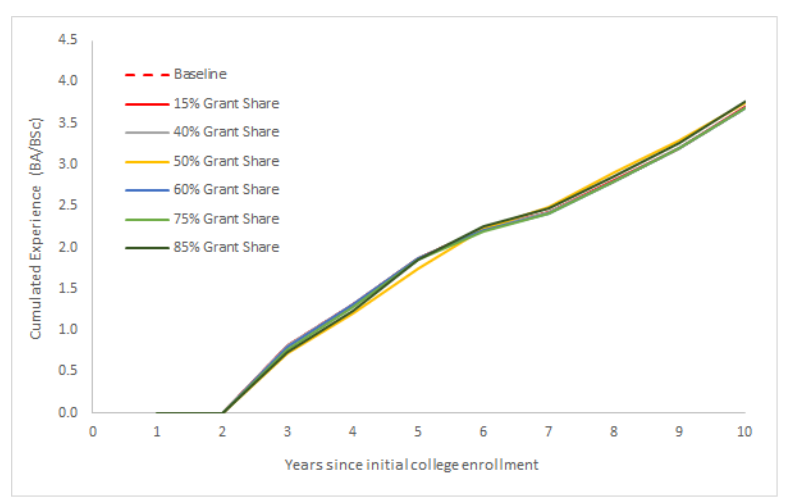

(c) 2-year college and BA/BSc Degree

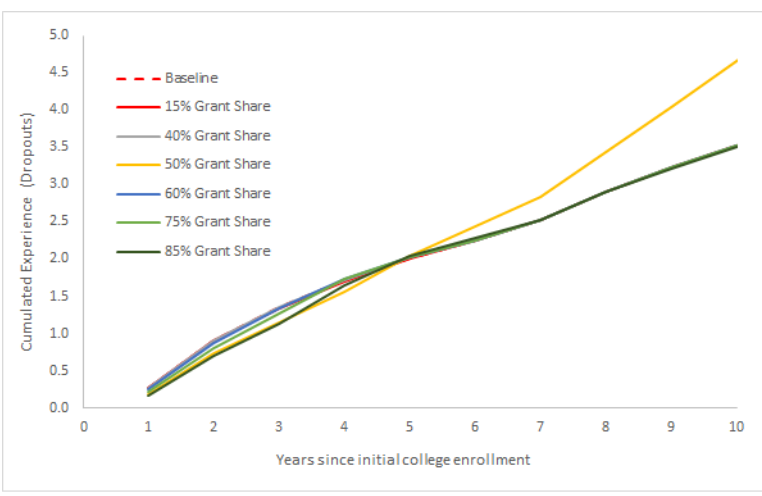

(b) Dropouts

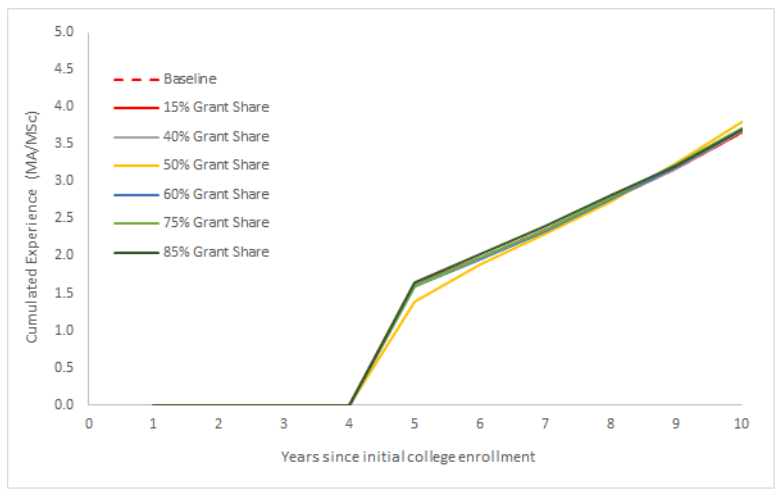

(d) 4-year college and MA/MSc Degree

The Figures display cumulated student labor market experience at college exit, by year of exit and highest acquired degree. The baseline simulation is run with $27.8 \%$ grant share, $0.75^{*}$ prisbasbelopp means testing, income contingent repayment at 4\%,6 years of eligibility. The reform simulation is run with $34 \%$ grant share, $1.25^{*}$ prisbasbelopp means testing, annuity $\widehat{a}_{t}$ repayment plus twice possible leniency with income contingent repayment at 5\%, 6 years of eligibility. Grant shares: $15 \%, 40 \%, 50 \%, 60 \%, 75 \%, 85 \%$. 
Figure 14: Loan-Grant Share: Cumulated Student Debt

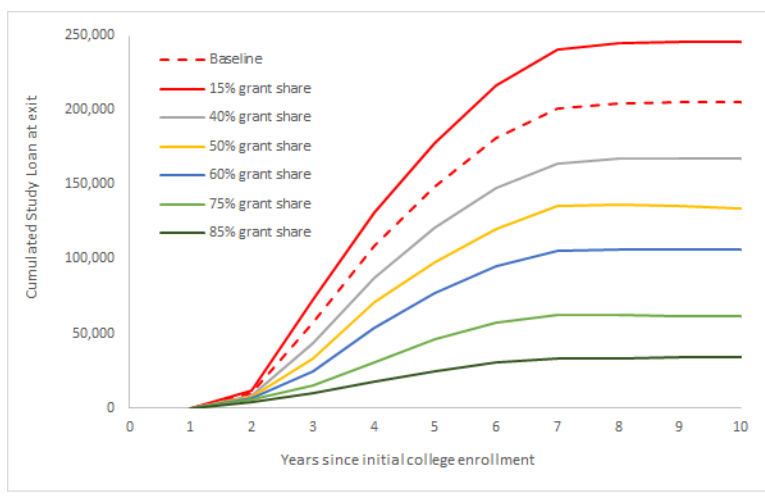

(a) All College Students

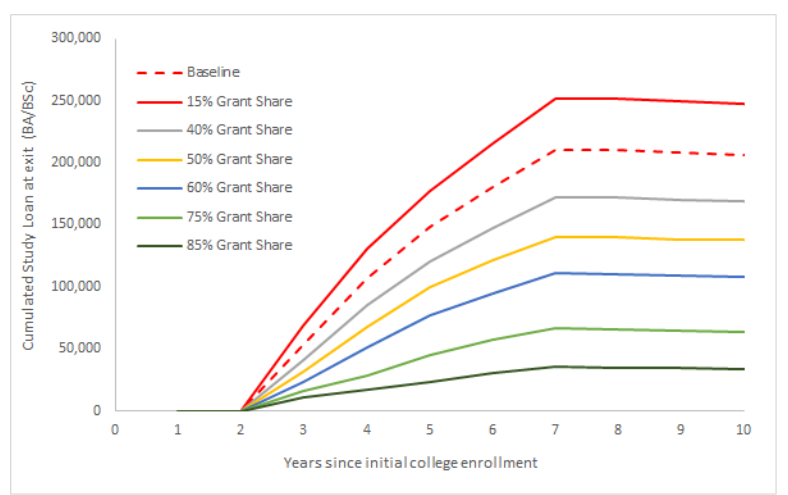

(c) 2-year college and BA/BSc Degree

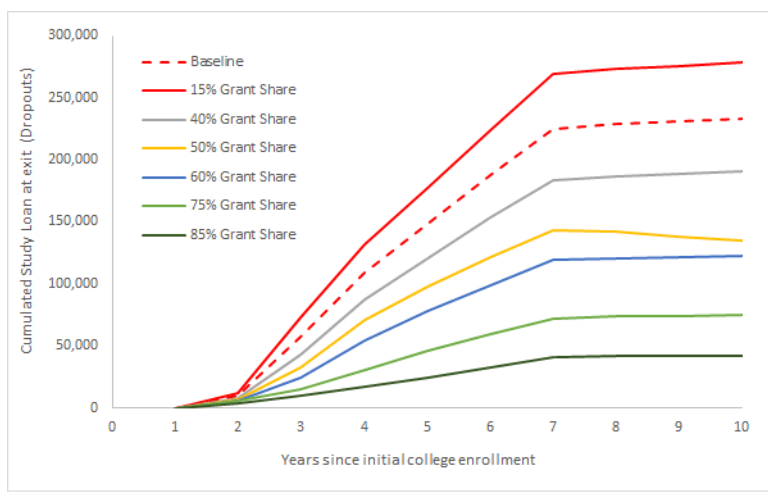

(b) Dropouts

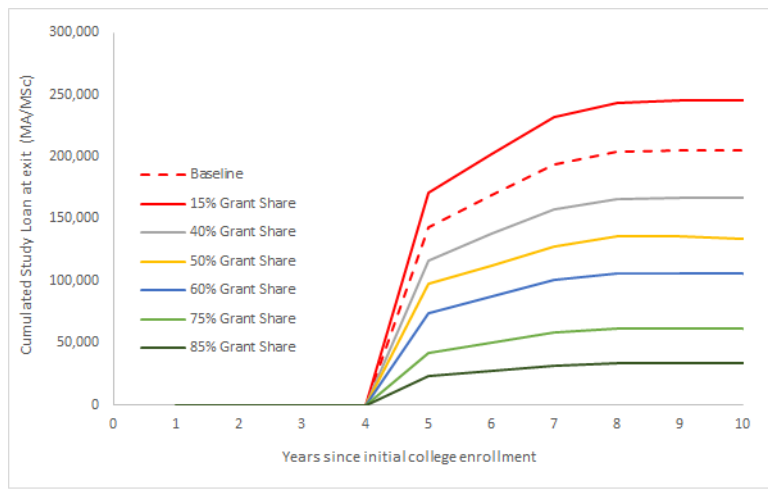

(d) 4-year college and MA/MSc Degree

The Figures display cumulated student debt at college exit, by year of exit and highest acquired degree. The baseline simulation is run with $27.8 \%$ grant share, $0.75^{*}$ prisbasbelopp means testing, income contingent repayment at $4 \%, 6$ years of eligibility. The reform simulation is run with $34 \%$ grant share, $1.25^{*}$ prisbasbelopp means testing, annuity $\widehat{a}_{t}$ repayment plus twice possible leniency with income contingent repayment at $5 \%, 6$ years of eligibility. Grant shares: $15 \%, 40 \%, 50 \%, 60 \%, 75 \%, 85 \%$. 
Figure 15: Means Testing: Completed Degrees and Timing of Graduation

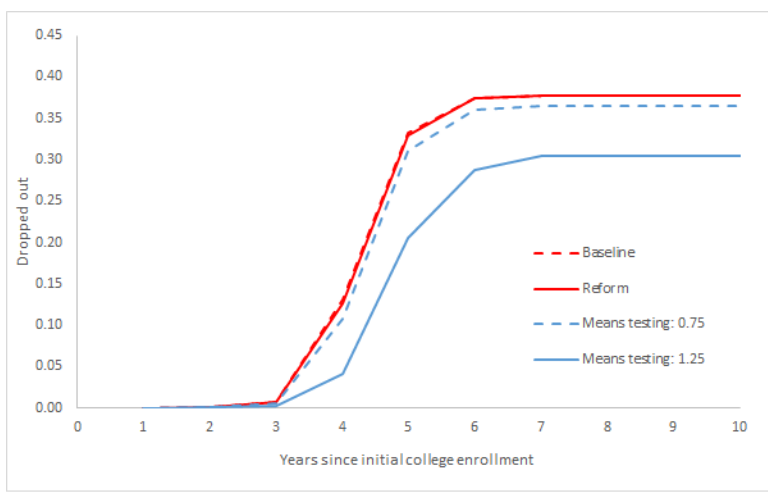

(a) Dropouts

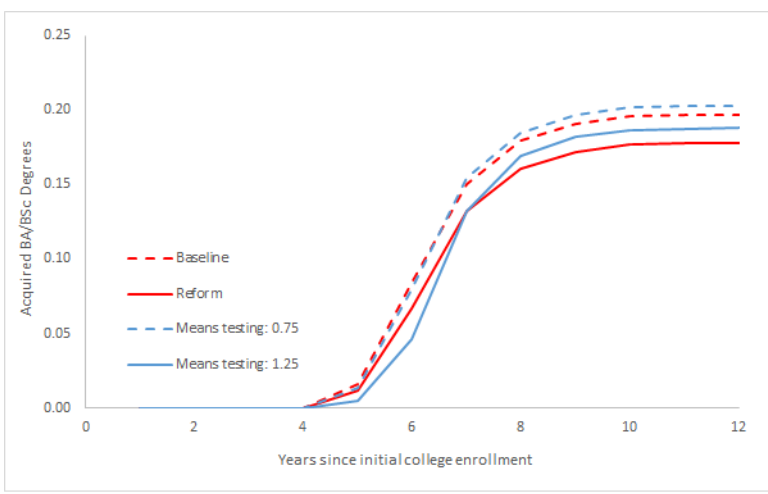

(b) 2-year college and BA/BSc Degree

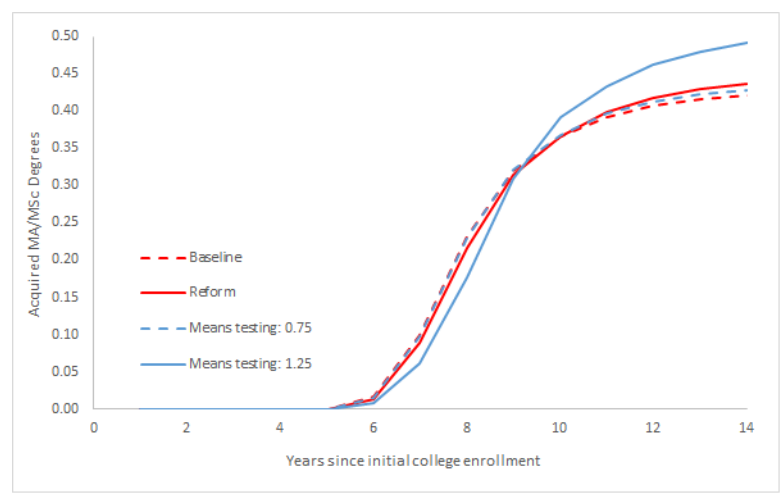

(c) 4-year college and MA/MSc Degree

The Figures displays the timing and type of college exit: dropouts, shorter degrees (2-year and BA/BSc), and longer college degrees (4-year and MA/MSc). The baseline simulation is run with $27.8 \%$ grant share, $0.75^{*}$ prisbasbelopp means testing, income contingent repayment at $4 \%, 6$ years of eligibility. The reform simulation is run with $34 \%$ grant share, $1.25^{*}$ prisbasbelopp means testing, annuity $\widehat{a}_{t}$ repayment plus twice possible leniency with income contingent repayment at $5 \%, 6$ years of eligibility. Means testing: $0.75^{*}$ prisbasbelopp and $1.25^{*}$ prisbasbelopp . 
Figure 16: Means Testing: Cumulated Work Experience

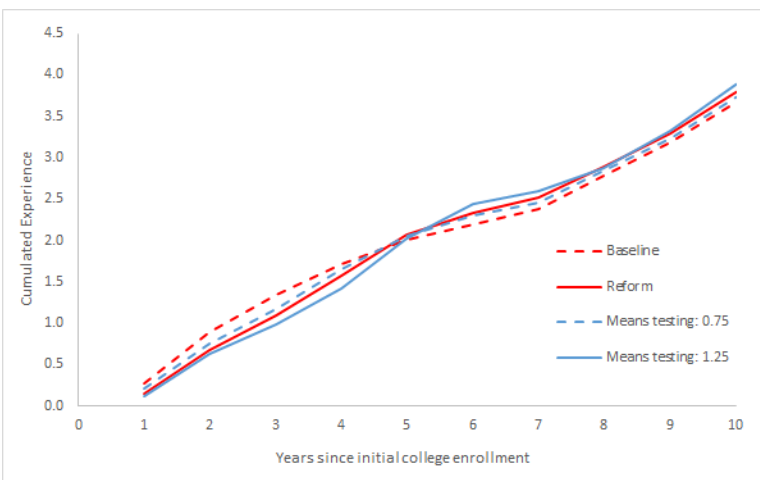

(a) All College Students

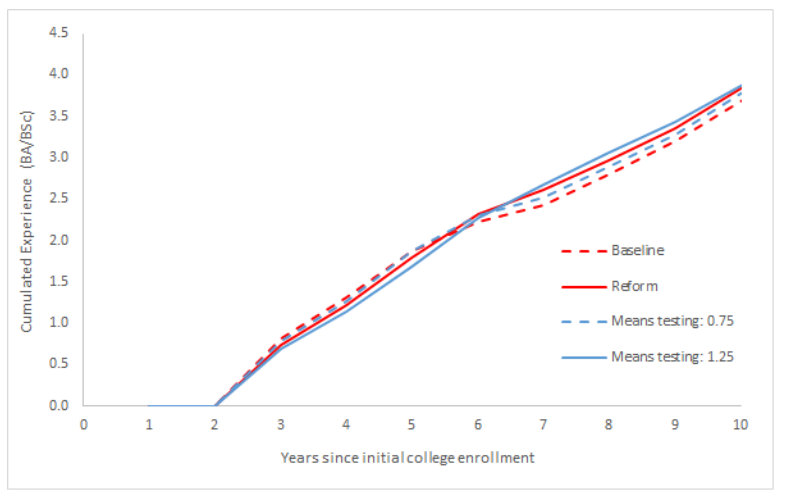

(c) 2-year college and BA/BSc Degree

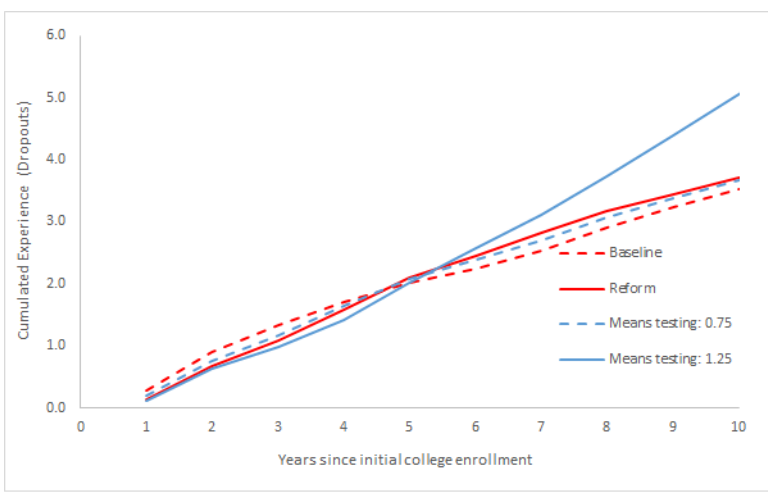

(b) Dropouts

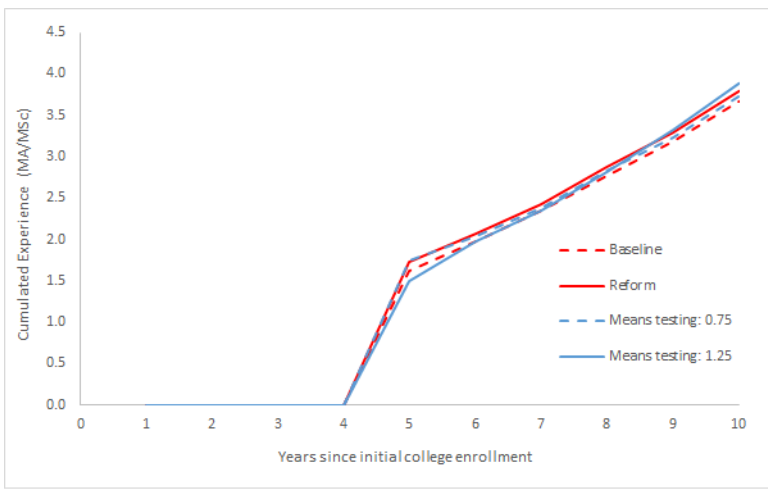

(d) 4-year college and MA/MSc Degree

The Figures display cumulated student labor market experience at college exit, by year of exit and highest acquired degree. The baseline simulation is run with $27.8 \%$ grant share, $0.75^{*}$ prisbasbelopp means testing, income contingent repayment at 4\%, 6 years of eligibility. The reform simulation is run with $34 \%$ grant share, $1.25^{*}$ prisbasbelopp means testing, annuity $\widehat{a}_{t}$ repayment plus twice possible leniency with income contingent repayment at 5\%,6 years of eligibility. Means testing: $0.75^{*}$ prisbasbelopp and $1.25^{*}$ prisbasbelopp . 
Figure 17: Means Testing: Cumulated Student Debt

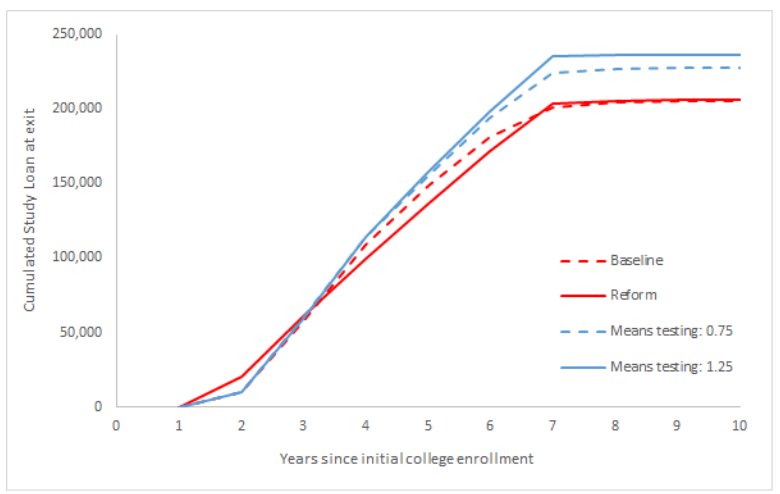

(a) All College Students

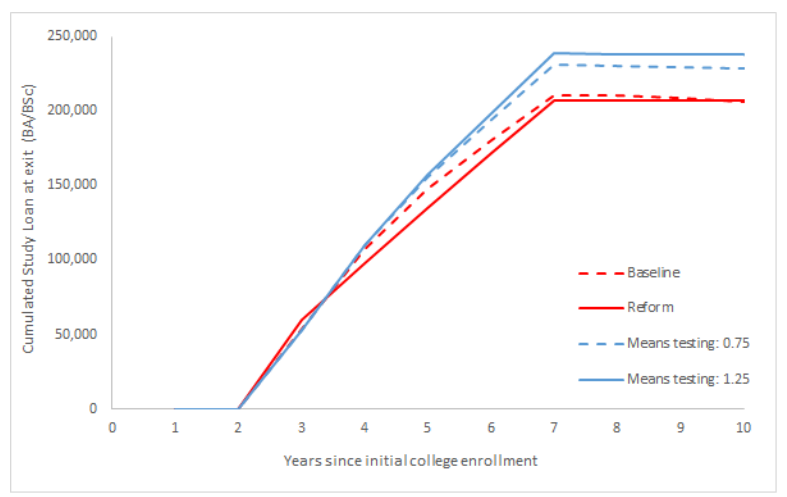

(c) 2-year college and BA/BSc Degree

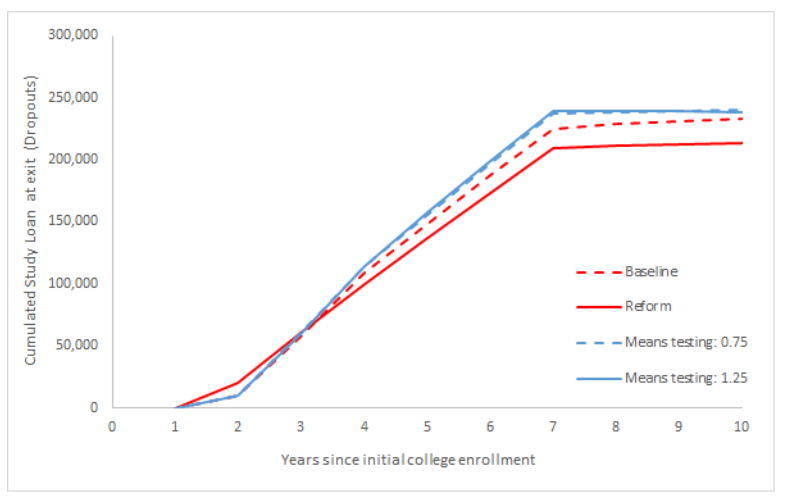

(b) Dropouts

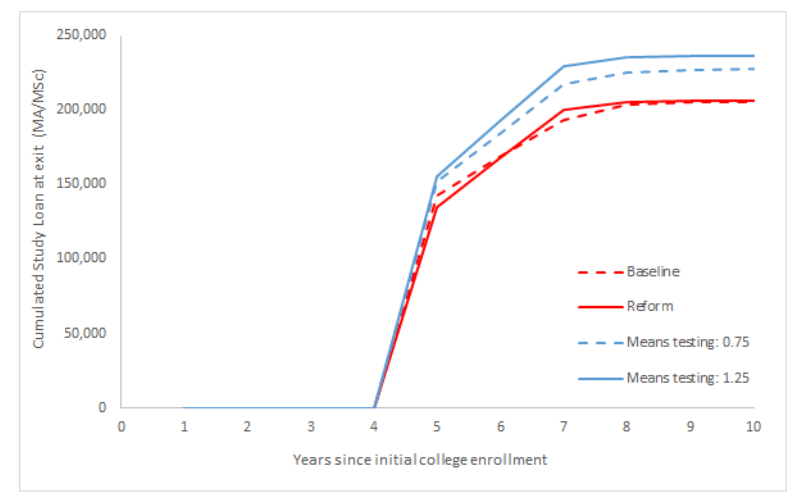

(d) 4-year college and MA/MSc Degree

The Figures display cumulated student debt at college exit, by year of exit and highest acquired degree. The baseline simulation is run with $27.8 \%$ grant share, $0.75^{*}$ prisbasbelopp means testing, income contingent repayment at 4\%, 6 years of eligibility. The reform simulation is run with $34 \%$ grant share, $1.25^{*}$ prisbasbelopp means testing, annuity $\widehat{a}_{t}$ repayment plus twice possible leniency with income contingent repayment at $5 \%, 6$ years of eligibility. Means testing: $0.75^{*}$ prisbasbelopp and $1.25^{*}$ prisbasbelopp . 
Figure 18: Repayment Schemes: Completed Degrees and Timing of Graduation

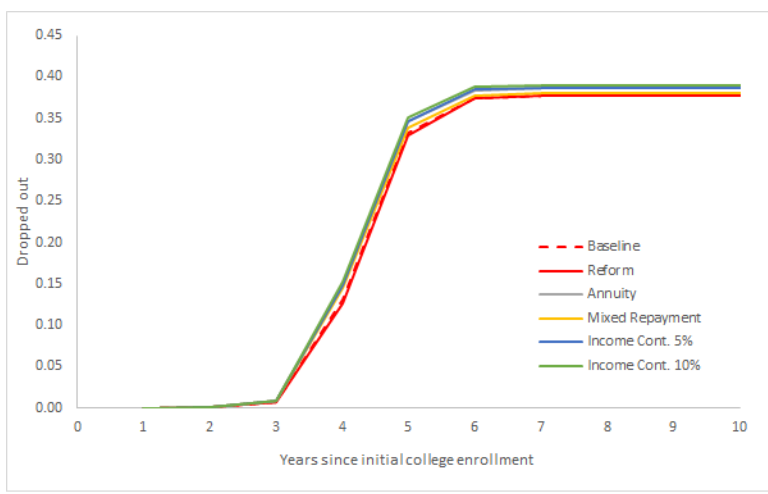

(a) Dropouts

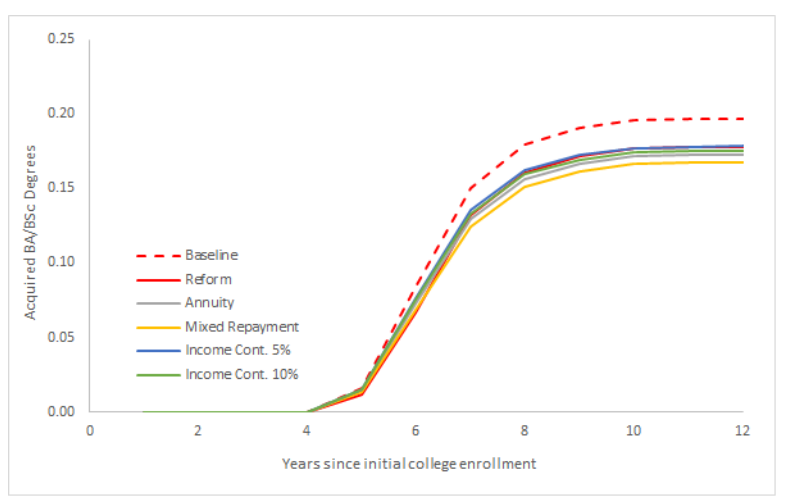

(b) 2-year college and BA/BSc Degree

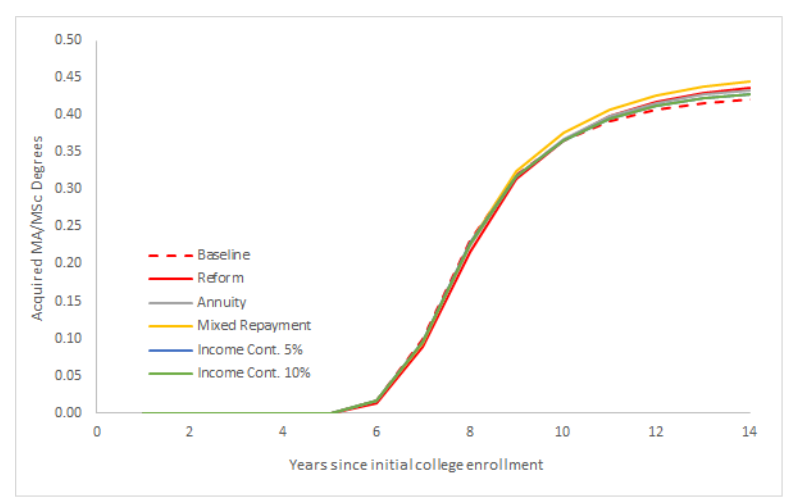

(c) 4-year college and MA/MSc Degree

The Figures displays the timing and type of college exit: dropouts, shorter degrees (2-year and BA/BSc), and longer college degrees (4-year and MA/MSc). The baseline simulation is run with $27.8 \%$ grant share, $0.75^{*}$ prisbasbelopp means testing, income contingent repayment at $4 \%$., 6 years of eligibility The reform simulation is run with $34 \%$ grant share, $1.25^{*}$ prisbasbelopp means testing, annuity $\widehat{a}_{t}$ repayment plus twice possible leniency with income contingent repayment at 5\%,6 years of eligibility. Repayment schemes: annuity $\widehat{a}_{t}$ and income contingent at $5 \%$ and $10 \%$. 
Figure 19: Repayment: Cumulated Work Experience

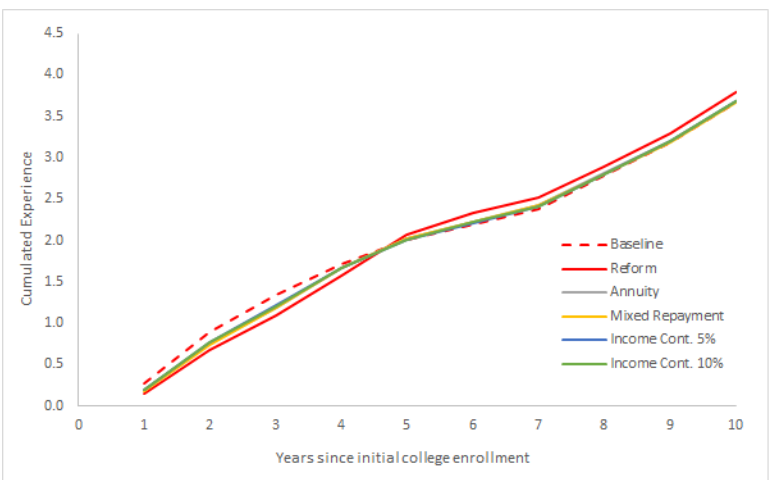

(a) All College Students

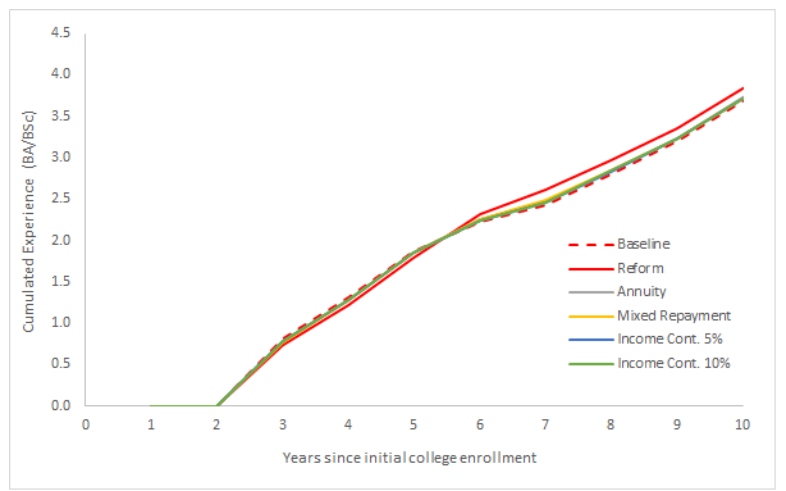

(c) 2-year college and BA/BSc Degree

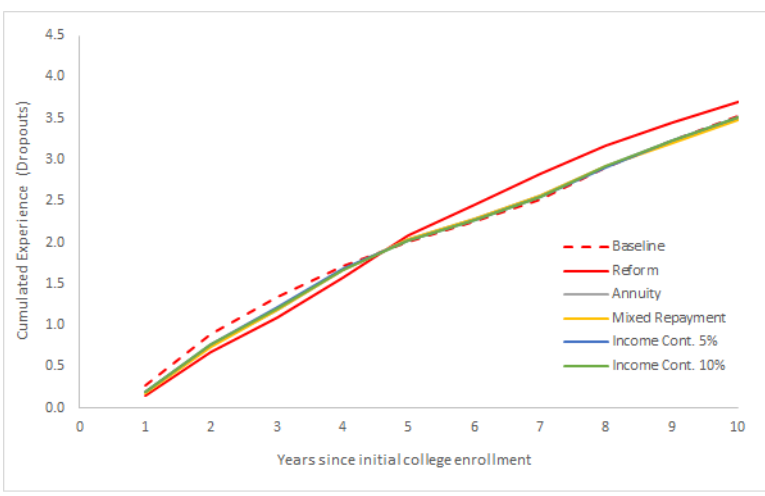

(b) Dropouts

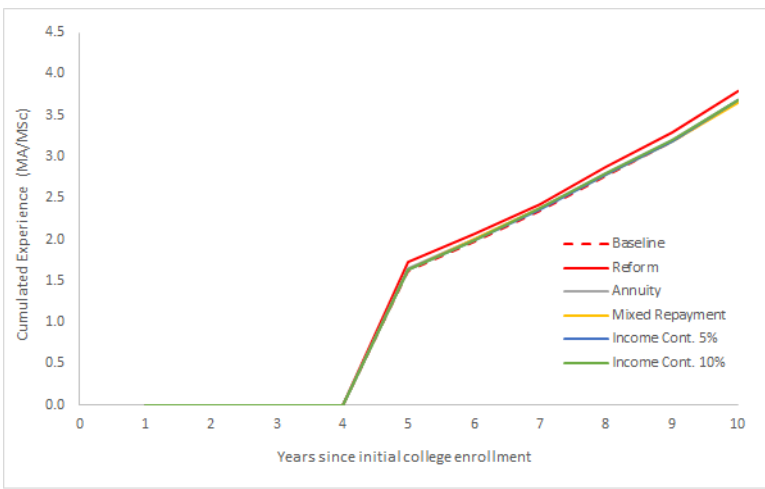

(d) 4-year college and MA/MSc Degree

The Figures display cumulated student labor market experience at college exit, by year of exit and highest acquired degree. The baseline simulation is run with $27.8 \%$ grant share, $0.75^{*}$ prisbasbelopp means testing, income contingent repayment at 4\%, 6 years of eligibility. The reform simulation is run with $34 \%$ grant share, $1.25^{*}$ prisbasbelopp means testing, annuity $\widehat{a}_{t}$ repayment plus twice possible leniency with income contingent repayment at 5\%,6 years of eligibility. Repayment schemes: annuity $\widehat{a}_{t}$ and income contingent at $5 \%$ and $10 \%$. 
Figure 20: Repayment Schemes: Cumulated Student Debt

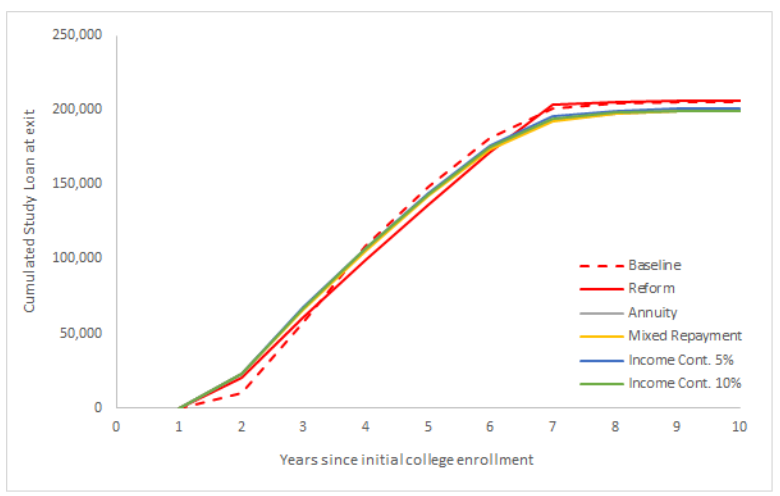

(a) All College Students

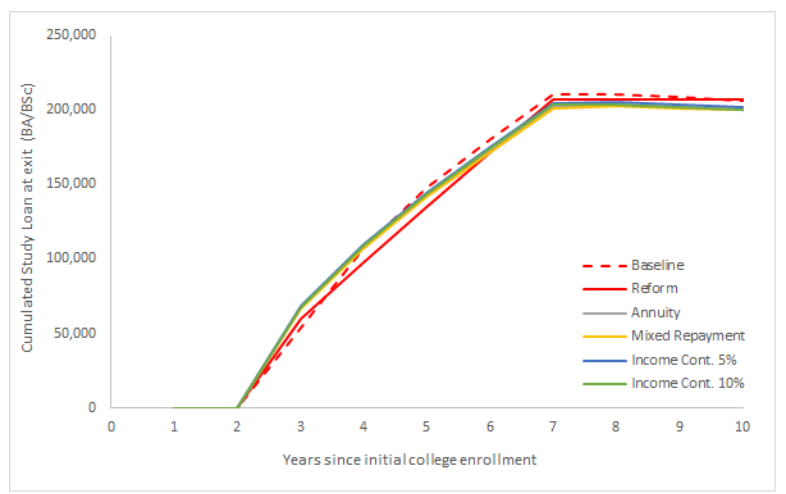

(c) 2-year college and BA/BSc Degree

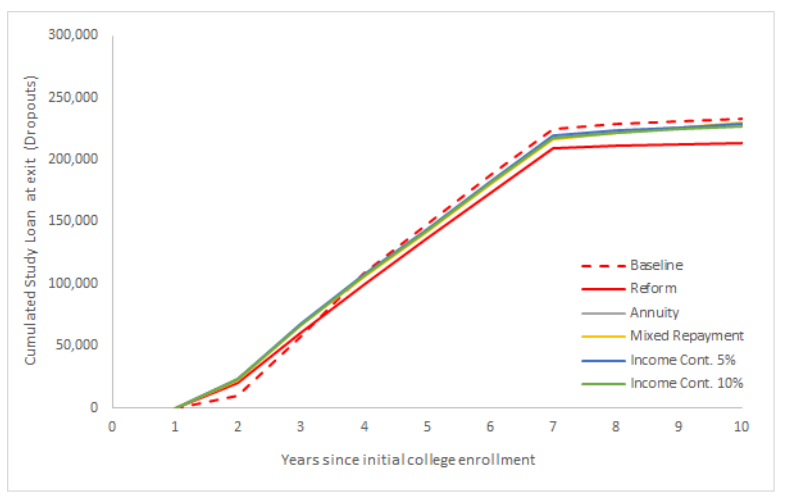

(b) Dropouts

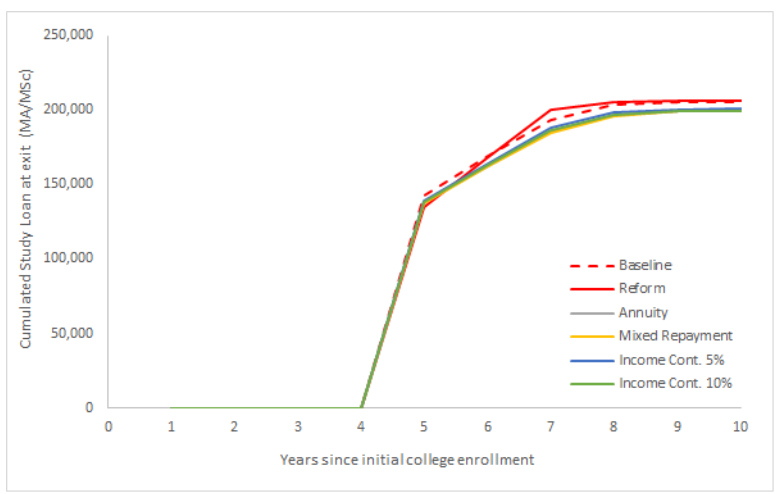

(d) 4-year college and MA/MSc Degree

The Figures display cumulated student debt at college exit, by year of exit and highest acquired degree. The baseline simulation is run with $27.8 \%$ grant share, $0.75^{*}$ prisbasbelopp means testing, income contingent repayment at 4\%, 6 years of eligibility. The reform simulation is run with $34 \%$ grant share, $1.25^{*}$ prisbasbelopp means testing, annuity $\widehat{a}_{t}$ repayment plus twice possible leniency with income contingent repayment at $5 \%, 6$ years of eligibility. Repayment schemes: annuity $\widehat{a}_{t}$ and income contingent at $5 \%$ and $10 \%$. 
Figure 21: Years of Eligibility: Completed Degrees and Timing of Graduation

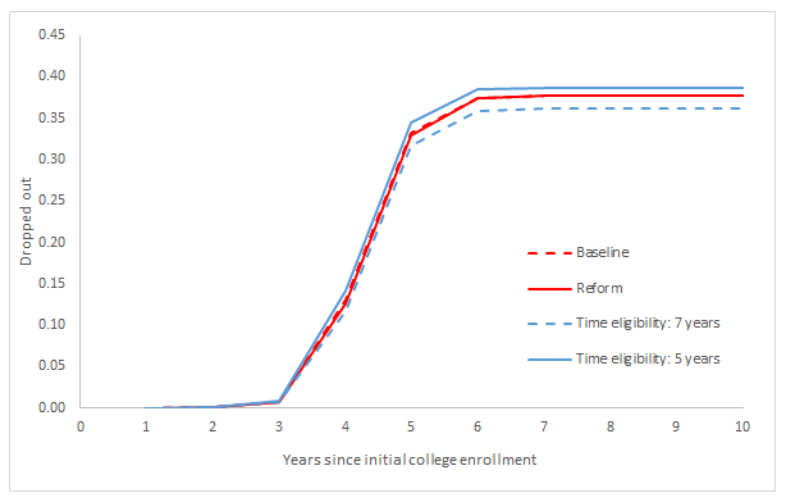

(a) Dropouts

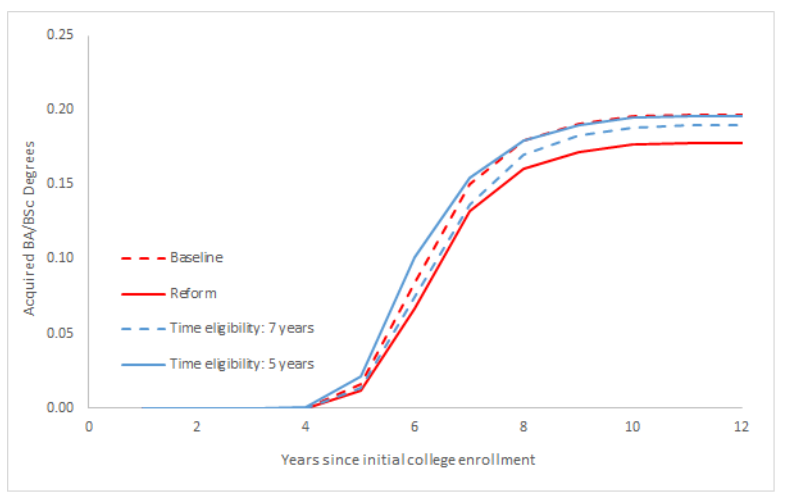

(b) 2-year college and BA/BSc Degree

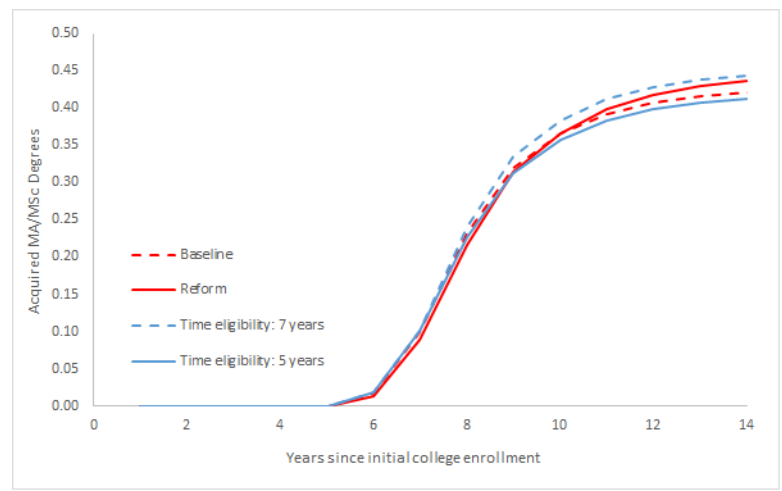

(c) 4-year college and MA/MSc Degree

The Figures displays the timing and type of college exit: dropouts, shorter degrees (2-year and BA/BSc), and longer college degrees (4-year and MA/MSc). The baseline simulation is run with $27.8 \%$ grant share, $0.75^{*}$ prisbasbelopp means testing, income contingent repayment at $4 \%, 6$ years of eligibility. The reform simulation is run with $34 \%$ grant share, $1.25^{*}$ prisbasbelopp means testing, annuity $\widehat{a}_{t}$ repayment plus twice possible leniency with income contingent repayment at $5 \% 6$ years of eligibility. Years of eligibility: 5 and 7 . 
Figure 22: Years of Eligibility: Cumulated Work Experience

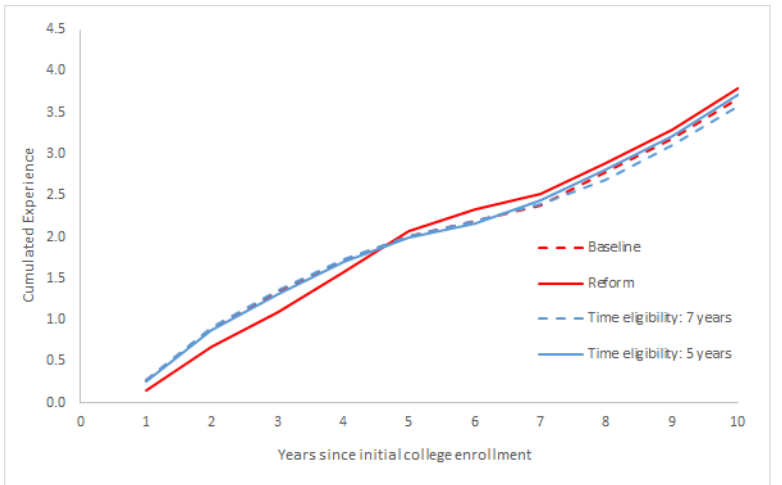

(a) All College Students

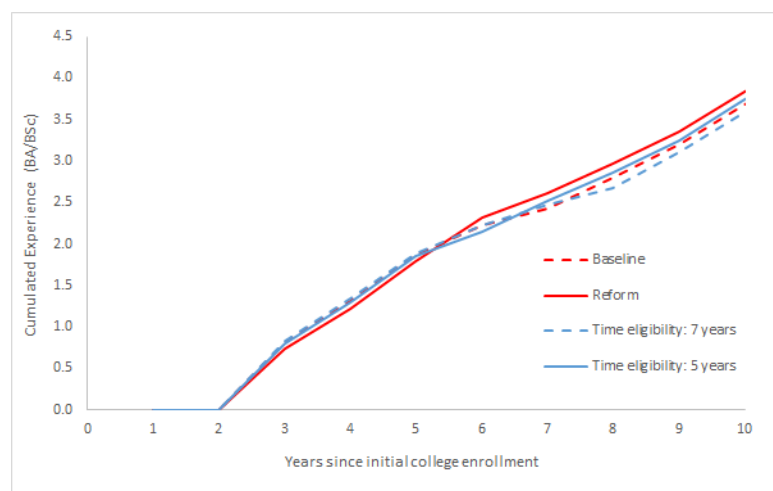

(c) 2-year college and BA/BSc Degree

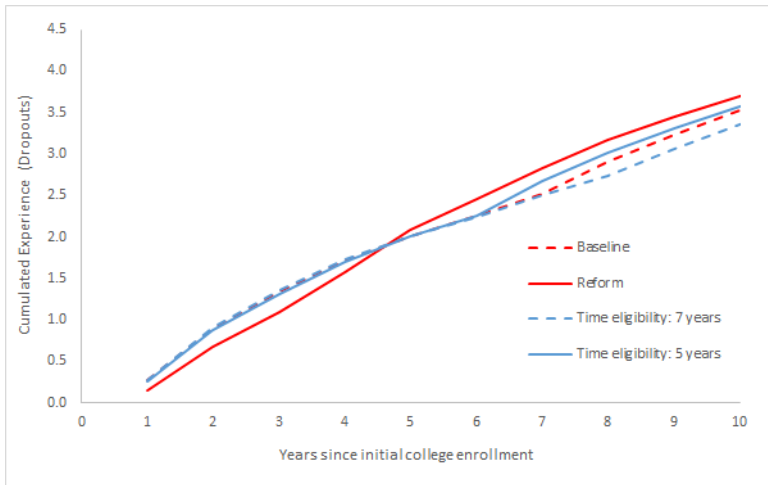

(b) Dropouts

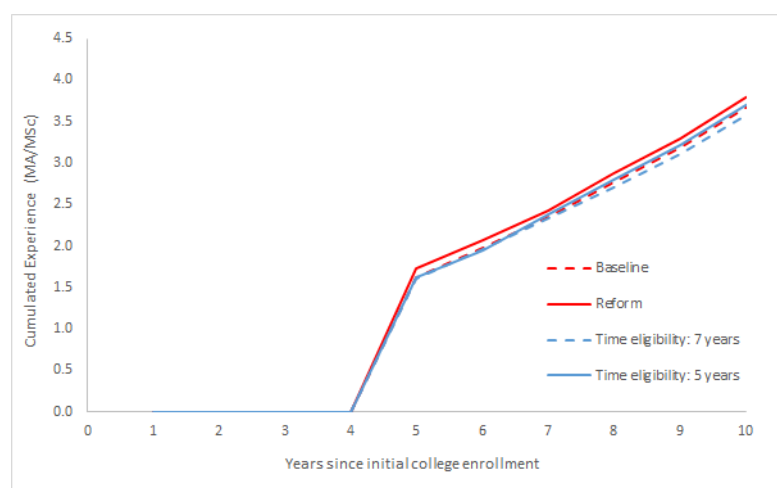

(d) 4-year college and MA/MSc Degree

The Figures display cumulated student labor market experience at college exit, by year of exit and highest acquired degree. The baseline simulation is run with $27.8 \%$ grant share, $0.75^{*}$ prisbasbelopp means testing, income contingent repayment at 4\%, 6 years of eligibility. The reform simulation is run with $34 \%$ grant share, $1.25^{*}$ prisbasbelopp means testing, annuity $\widehat{a}_{t}$ repayment plus twice possible leniency with income contingent repayment at $5 \% 6$ years of eligibility. Years of eligibility: 5 and 7 . 
Figure 23: Years of Eligibility: Cumulated Student Debt

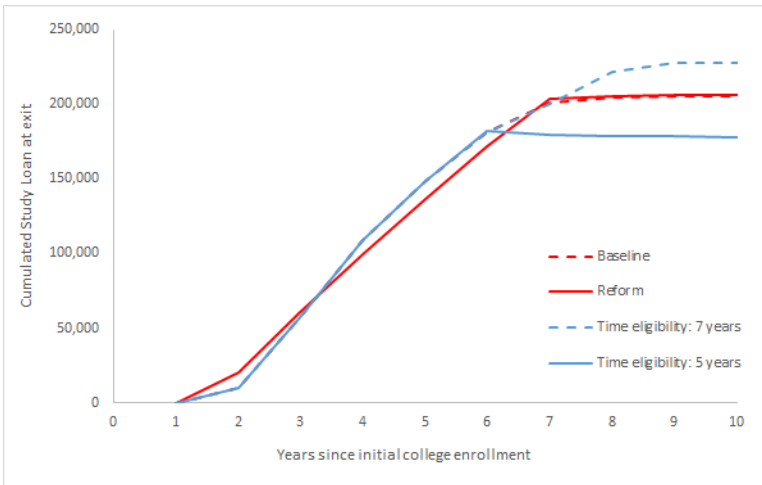

(a) All College Students

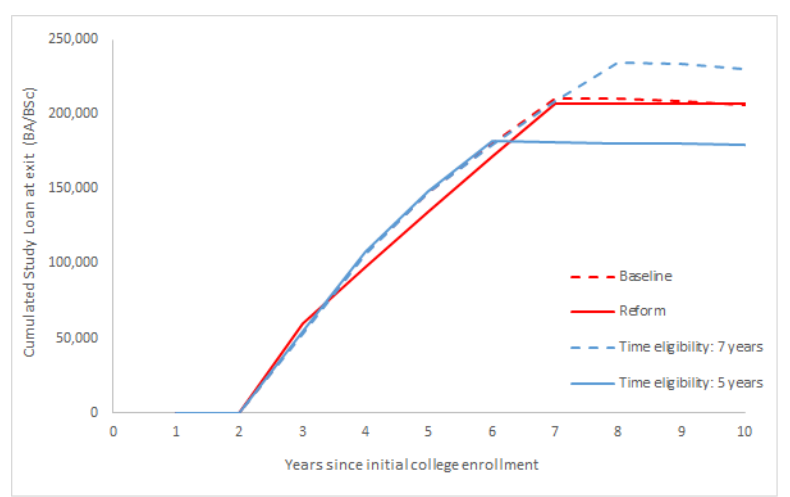

(c) 2-year college and BA/BSc Degree

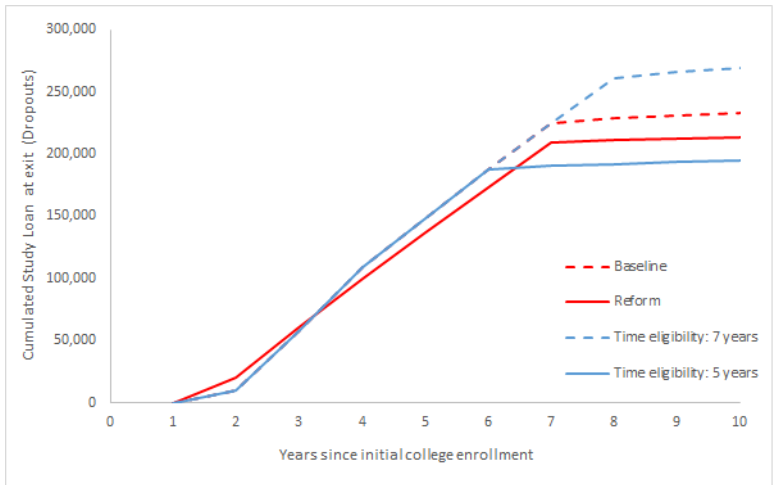

(b) Dropouts

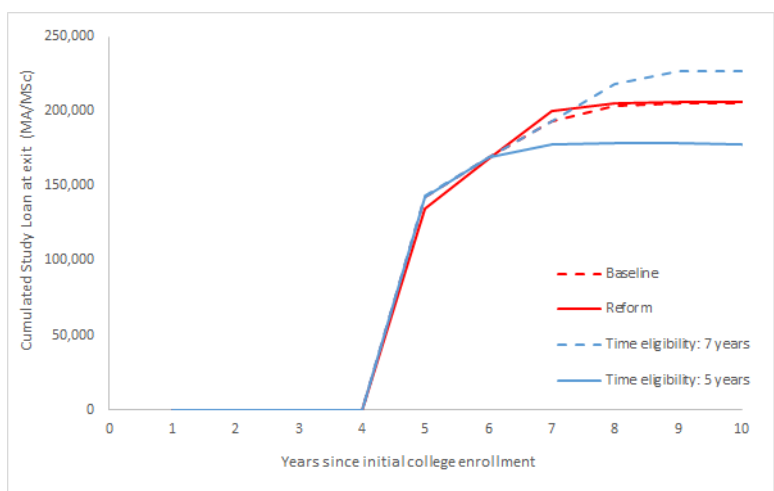

(d) 4-year college and MA/MSc Degree

The Figures display cumulated student debt at college exit, by year of exit and highest acquired degree. The baseline simulation is run with $27.8 \%$ grant share, $0.75^{*}$ prisbasbelopp means testing, income contingent repayment at 4\%, 6 years of eligibility. The reform simulation is run with $34 \%$ grant share, $1.25^{*}$ prisbasbelopp means testing, annuity $\widehat{a}_{t}$ repayment plus twice possible leniency with income contingent repayment at $5 \% 6$ years of eligibility. Years of eligibility: 5 and 7 . 


\section{Tables}

\section{C.1 Parameter Estimates}

Table 6: Estimates of Model Parameters: Wage Equation

\begin{tabular}{|c|c|c|}
\hline & & \\
\hline & & \\
\hline$\alpha_{0}$ & 9.991 & $(.0019)$ \\
\hline (2-years degree $\left.E_{1}\right) \alpha_{1}$ & .265 & $(.0259)$ \\
\hline$\left(3\right.$-years degree $\left.E_{2}\right) \alpha_{2}$ & .852 & $(.0083)$ \\
\hline (4-years degree $\left.E_{3}\right) \alpha_{3}$ & .836 & $(.0107)$ \\
\hline (5-years degree $\left.E_{4}\right) \alpha_{4}$ & 1.368 & $(.0408)$ \\
\hline$\left(\right.$ Course Credits $\left.G_{t}\right) \alpha_{5}$ & .0178 & $(.0001)$ \\
\hline$\left(G_{t} E_{1}\right) \alpha_{6}$ & .0025 & $(.0010)$ \\
\hline$\left(G_{t} E_{2}\right) \alpha_{7}$ & -.0090 & $(.0003)$ \\
\hline$\left(G_{t} E_{3}\right) \alpha_{8}$ & -.0078 & $(.0003)$ \\
\hline$\left(G_{t} E_{4}\right) \alpha_{9}$ & -.0106 & $(.0008)$ \\
\hline$\left(\right.$ Experience $\left.d_{0} \log (H+1)\right) \alpha_{10}$ & .983 & $(.0131)$ \\
\hline$\left(d_{0} \log (H+1) E_{1}\right) \alpha_{11}$ & -.210 & $(.0093)$ \\
\hline$\left(d_{0} \log (H+1) E_{2}\right) \alpha_{12}$ & -.448 & $(.0028)$ \\
\hline$\left(d_{0} \log (H+1) E_{3}\right) \alpha_{13}$ & -.308 & $(.0038)$ \\
\hline$\left(d_{0} \log (H+1) E_{4}\right) \alpha_{14}$ & -.475 & $(.0149)$ \\
\hline$\left(d_{0} \log (H+1)[\tilde{H}>0]\right) \alpha_{15}$ & .148 & $(.0132)$ \\
\hline$\left(d_{0} \log (H+1)[\tilde{H}>1]\right) \alpha_{16}$ & -.095 & $(.0023)$ \\
\hline$\left(d_{0} \log (H+1)[\tilde{H}>2]\right) \alpha_{17}$ & -.071 & $(.0013)$ \\
\hline$\left(d_{0} \log (H+1)[\tilde{H}>3]\right) \alpha_{18}$ & -.100 & $(.0010)$ \\
\hline (Unskilled Experience $\left.S_{t} \tilde{H}\right) \alpha_{19}$ & .173 & $(.0007)$ \\
\hline (Student employed $\left.S_{t}\right) \alpha_{20}$ & -.053 & $(.0028)$ \\
\hline (Student employed part-time $\left.\left[h_{t}=.5\right]\right) \alpha_{21}$ & -.565 & $(.00328)$ \\
\hline
\end{tabular}


Table 7: Estimates of Model Parameters: Course Credits and Preferences.

\begin{tabular}{|c|c|c|}
\hline & \multicolumn{2}{|c|}{ One type $(\mathrm{M}=1)$} \\
\hline & \multicolumn{2}{|c|}{$w_{t}$} \\
\hline & \multicolumn{2}{|c|}{$g^{*}$} \\
\hline (2-years degree $\left.E_{1}\right) \gamma_{1}$ & -.104 & $(.0335)$ \\
\hline (3-years degree $\left.E_{2}\right) \gamma_{2}$ & -.527 & $(.0122)$ \\
\hline (4-years degree $\left.E_{3}\right) \gamma_{3}$ & -.912 & $(.0225)$ \\
\hline$($ High school GPA $\geq \mathrm{P} 90 A) \gamma_{4}$ & .242 & $(.0037)$ \\
\hline (Advanced Math $K) \gamma_{5}$ & .016 & $(.0032)$ \\
\hline$\left(\right.$ Course Credits $\left.G_{t}\right) \gamma_{6}$ & .051 & $(.0004)$ \\
\hline (Time since enrollment $t$ ) $\gamma_{7}$ & -.471 & $(.0018)$ \\
\hline$([t=0]) \gamma_{8}$ & -1.944 & $(.0054)$ \\
\hline (work full-time $\left.\left[h_{t}=1\right]\right) \gamma_{9}$ & -.081 & $(.0045)$ \\
\hline \multirow[t]{2}{*}{ (work part-time $\left.\left[h_{t}=.5\right]\right) \gamma_{10}$} & .313 & $(.0057)$ \\
\hline & \multicolumn{2}{|c|}{$P\left(d_{t}^{k}=1\right)$} \\
\hline$\lambda$ & .245 & $(.0010)$ \\
\hline$\nu_{0}$ & .322 & $(.0334)$ \\
\hline$\left(\left[h_{t}=1\right]\left[h_{t-1}=0\right]\right) \nu_{1}^{k=1,2,3}$ & -19.612 & $(33.0024)$ \\
\hline$\left(\left[h_{t}=1\right]\left[h_{t-1}=0\right]\right) \nu_{1}^{k=4,5,6}$ & 1.730 & $(.0112)$ \\
\hline$\left(\left[h_{t}=1\right]\left[h_{t-1}=0\right]\right) \nu_{1}^{k=7,8,9}$ & .781 & $(.0334)$ \\
\hline$\left(\right.$ Cumulated Loan $\left.D_{t}\right) \nu_{2}^{k=1,4,7}$ & 1.045 & $(.0334)$ \\
\hline$\left(\right.$ Cumulated Loan $\left.D_{t}\right) \nu_{2}^{k=2,5,8}$ & .647 & $(.0335)$ \\
\hline (Cumulated Loan $\left.D_{t}\right) \nu_{2}^{k=3,6,9}$ & 2.271 & $(.0334)$ \\
\hline (High school GPA $\geq \mathrm{P} 90 A) \nu_{3}^{k=1,2,3}$ & .349 & $(.0072)$ \\
\hline (High school GPA $\geq \mathrm{P} 90 A) \nu_{3}^{k=4,5,6}$ & .178 & $(.0072)$ \\
\hline (High school GPA $\geq$ P90 A) $\nu_{3}^{k=7,8,9}$ & .540 & $(.0049)$ \\
\hline (Advanced Math $K) \nu_{4}^{k=1,2,3}$ & .691 & $(.0060)$ \\
\hline (Advanced Math $K) \nu_{4}^{k=4,5,6}$ & .269 & $(.0060)$ \\
\hline (Advanced Math $K) \nu_{4}^{k=7,8,9}$ & .616 & $(.0043)$ \\
\hline (Time since enrollment $t$ ) $\nu_{5}^{k=1,2,3}$ & -1.061 & $(.0016)$ \\
\hline (Time since enrollment $t$ ) $\nu_{5}^{k=4,5,6}$ & -1.006 & $(.0016)$ \\
\hline (Time since enrollment $t$ ) $\nu_{5}^{k=7,8,9}$ & -.587 & $(.0011)$ \\
\hline Log Likelihood & -2997769.4 & \\
\hline
\end{tabular}

Standard errors in parenthesis. All parameters are significant at a 1\% level of significance. 


\section{C.2 Model Fit}

Table 8: Observed and Predicted Academic and Labor Market Outcomes, Choices and Transitions (a).

\begin{tabular}{|c|c|c|}
\hline & Observed & Predicted \\
\hline \multicolumn{3}{|l|}{ Course Credits } \\
\hline$P\left(g_{t}=0\right)$ & 0,49 & 0,49 \\
\hline$P\left(g_{t}=1\right)$ & 0,05 & 0,05 \\
\hline$P\left(g_{t}=2\right)$ & 0,09 & 0,09 \\
\hline$P\left(g_{t}=3\right)$ & 0,06 & 0,06 \\
\hline$P\left(g_{t}=4\right)$ & 0,05 & 0,05 \\
\hline$P\left(g_{t}=5\right)$ & 0,10 & 0,10 \\
\hline$P\left(g_{t}=6\right)$ & 0,09 & 0,09 \\
\hline$P\left(g_{t}=7\right)$ & 0,07 & 0,07 \\
\hline \multicolumn{3}{|l|}{ Across alternatives: } \\
\hline$g_{t}$ given $d_{t}^{1}=1$ & 3,59 & 4,31 \\
\hline$g_{t}$ given $d_{t}^{2}=1$ & 5,01 & 4,39 \\
\hline$g_{t}$ given $d_{t}^{3}=1$ & 3,66 & 4,41 \\
\hline$g_{t}$ given $d_{t}^{4}=1$ & 1,73 & 2,90 \\
\hline$g_{t}$ given $d_{t}^{5}=1$ & 4,13 & 3,32 \\
\hline$g_{t}$ given $d_{t}^{6}=1$ & 3,58 & 3,36 \\
\hline \multicolumn{3}{|l|}{ Each time period: } \\
\hline$g_{1}$ & 4,67 & 4,05 \\
\hline$g_{2}$ & 4,71 & 3,84 \\
\hline$g_{3}$ & 4,26 & 3,63 \\
\hline$g_{4}$ & 3,16 & 2,97 \\
\hline$g_{5}$ & 2,07 & 2,15 \\
\hline$g_{6}$ & 1,15 & 1,35 \\
\hline$g_{7}$ & 0,64 & 0,83 \\
\hline$g_{8}$ & 0,43 & 0,56 \\
\hline$g_{9}$ & 0,31 & 0,41 \\
\hline$g_{10}$ & 0,24 & 0,30 \\
\hline \multicolumn{3}{|c|}{ Total in last time period: } \\
\hline$G_{11}$ & 23,79 & 24,05 \\
\hline \multicolumn{3}{|c|}{ Highest acquired degree: } \\
\hline$E_{11}=0$ & 0,34 & 0,05 \\
\hline$E_{11}=1$ & 0,28 & 0,44 \\
\hline$E_{11}=2$ & 0,38 & 0,50 \\
\hline
\end{tabular}


Observed and Predicted Academic and Labor Market Outcomes, Choices and Transitions (b).

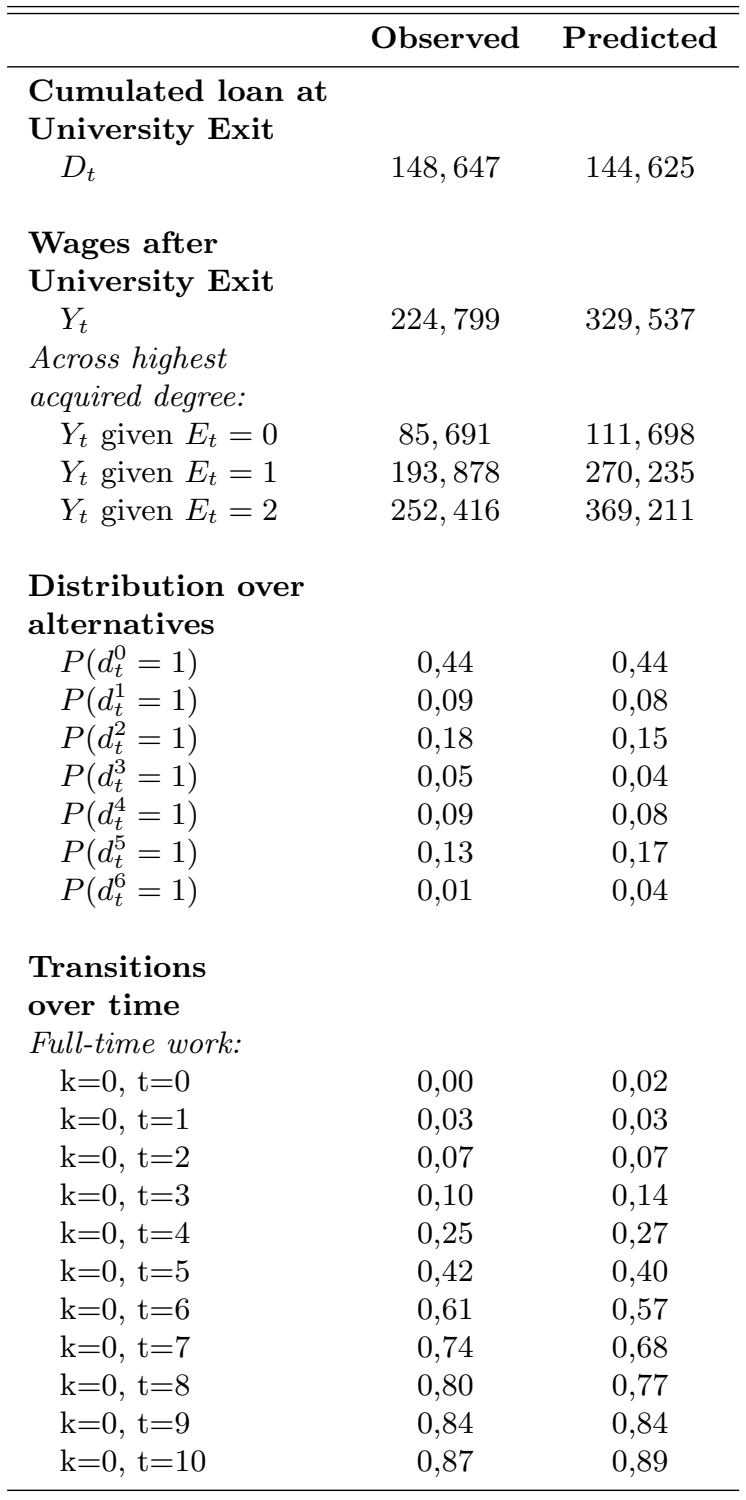


Observed and Predicted Academic and Labor Market Outcomes, Choices and Transitions (c).

\begin{tabular}{|c|c|c|}
\hline & Observed & Predicted \\
\hline \multicolumn{3}{|l|}{$\begin{array}{l}\text { Transitions } \\
\text { over time }\end{array}$} \\
\hline \multicolumn{3}{|c|}{ Enrolled full-time; no work; no loan: } \\
\hline $\mathrm{k}=1, \mathrm{t}=0$ & 0,24 & 0,16 \\
\hline $\mathrm{k}=1, \mathrm{t}=1$ & 0,17 & 0,15 \\
\hline $\mathrm{k}=1, \mathrm{t}=2$ & 0,15 & 0,14 \\
\hline $\mathrm{k}=1, \mathrm{t}=3$ & 0,13 & 0,12 \\
\hline $\mathrm{k}=1, \mathrm{t}=4$ & 0,10 & 0,10 \\
\hline $\mathrm{k}=1, \mathrm{t}=5$ & 0,08 & 0,08 \\
\hline $\mathrm{k}=1, \mathrm{t}=6$ & 0,06 & 0,05 \\
\hline $\mathrm{k}=1, \mathrm{t}=7$ & 0,04 & 0,04 \\
\hline $\mathrm{k}=1, \mathrm{t}=8$ & 0,03 & 0,03 \\
\hline $\mathrm{k}=1, \mathrm{t}=9$ & 0,02 & 0,02 \\
\hline $\mathrm{k}=1, \mathrm{t}=10$ & 0,02 & 0,01 \\
\hline \multicolumn{3}{|c|}{ Enrolled full-time; no work; full loan: } \\
\hline $\mathrm{k}=2, \mathrm{t}=0$ & 0,23 & 0,29 \\
\hline $\mathrm{k}=2, \mathrm{t}=1$ & 0,49 & 0,29 \\
\hline $\mathrm{k}=2, \mathrm{t}=2$ & 0,45 & 0,27 \\
\hline $\mathrm{k}=2, \mathrm{t}=3$ & 0,36 & 0,24 \\
\hline $\mathrm{k}=2, \mathrm{t}=4$ & 0,25 & 0,20 \\
\hline $\mathrm{k}=2, \mathrm{t}=5$ & 0,13 & 0,16 \\
\hline $\mathrm{k}=2, \mathrm{t}=6$ & 0,05 & 0,11 \\
\hline $\mathrm{k}=2, \mathrm{t}=7$ & 0,03 & 0,08 \\
\hline $\mathrm{k}=2, \mathrm{t}=8$ & 0,02 & 0,05 \\
\hline $\mathrm{k}=2, \mathrm{t}=9$ & 0,01 & 0,04 \\
\hline $\mathrm{k}=2, \mathrm{t}=10$ & 0,01 & 0,02 \\
\hline \multicolumn{3}{|c|}{ Enrolled full-time; no work; partial loan: } \\
\hline $\mathrm{k}=3, \mathrm{t}=0$ & 0,25 & 0,09 \\
\hline $\mathrm{k}=3, \mathrm{t}=1$ & 0,10 & 0,07 \\
\hline $\mathrm{k}=3, \mathrm{t}=2$ & 0,08 & 0,06 \\
\hline $\mathrm{k}=3, \mathrm{t}=3$ & 0,06 & 0,05 \\
\hline $\mathrm{k}=3, \mathrm{t}=4$ & 0,05 & 0,04 \\
\hline $\mathrm{k}=3, \mathrm{t}=5$ & 0,03 & 0,03 \\
\hline $\mathrm{k}=3, \mathrm{t}=6$ & 0,02 & 0,02 \\
\hline $\mathrm{k}=3, \mathrm{t}=7$ & 0,01 & 0,02 \\
\hline $\mathrm{k}=3, \mathrm{t}=8$ & 0,00 & 0,01 \\
\hline $\mathrm{k}=3, \mathrm{t}=9$ & 0,00 & 0,01 \\
\hline $\mathrm{k}=3, \mathrm{t}=10$ & 0,00 & 0,00 \\
\hline
\end{tabular}


Observed and Predicted Academic and Labor Market Outcomes, Choices and Transitions (d).

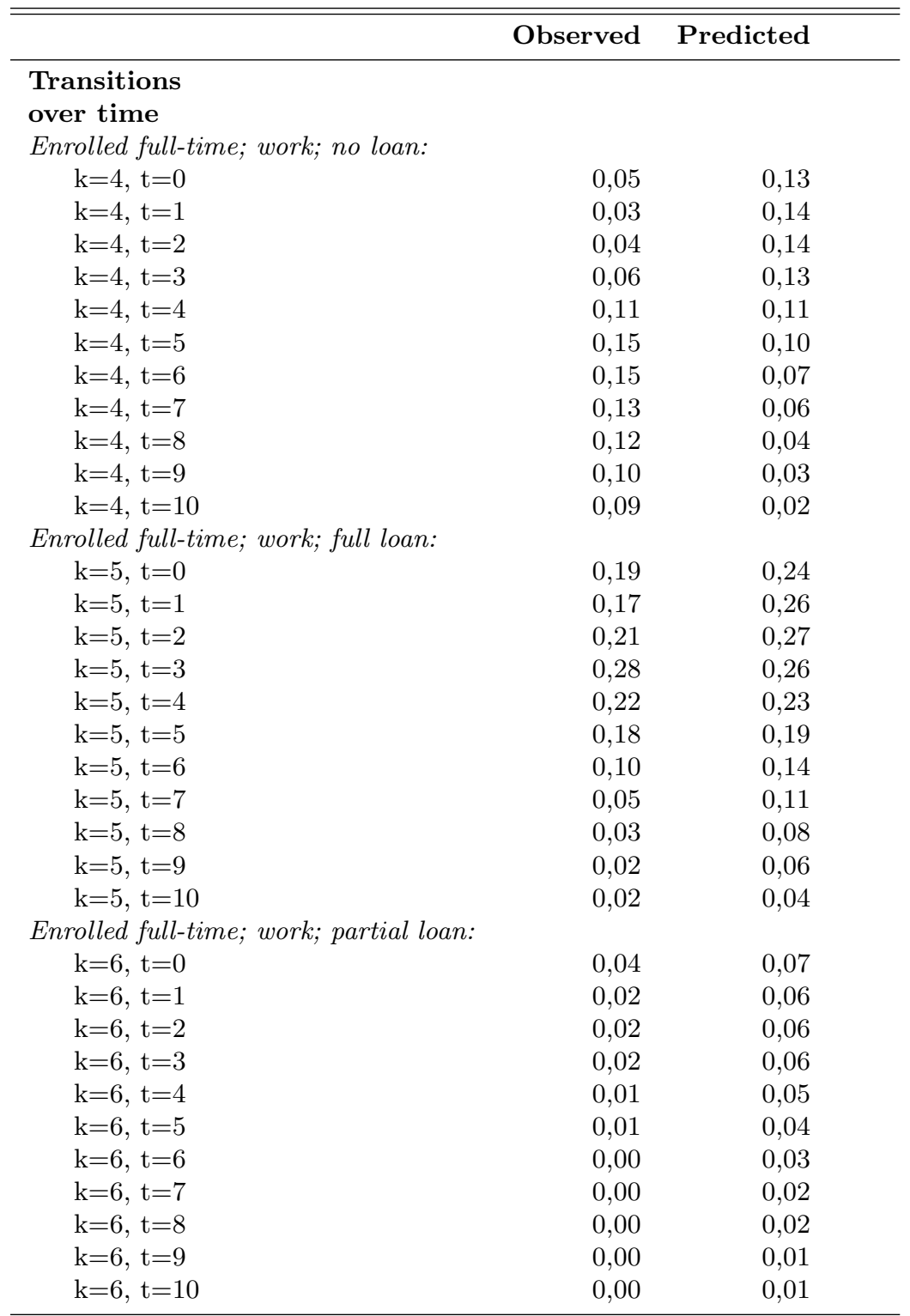




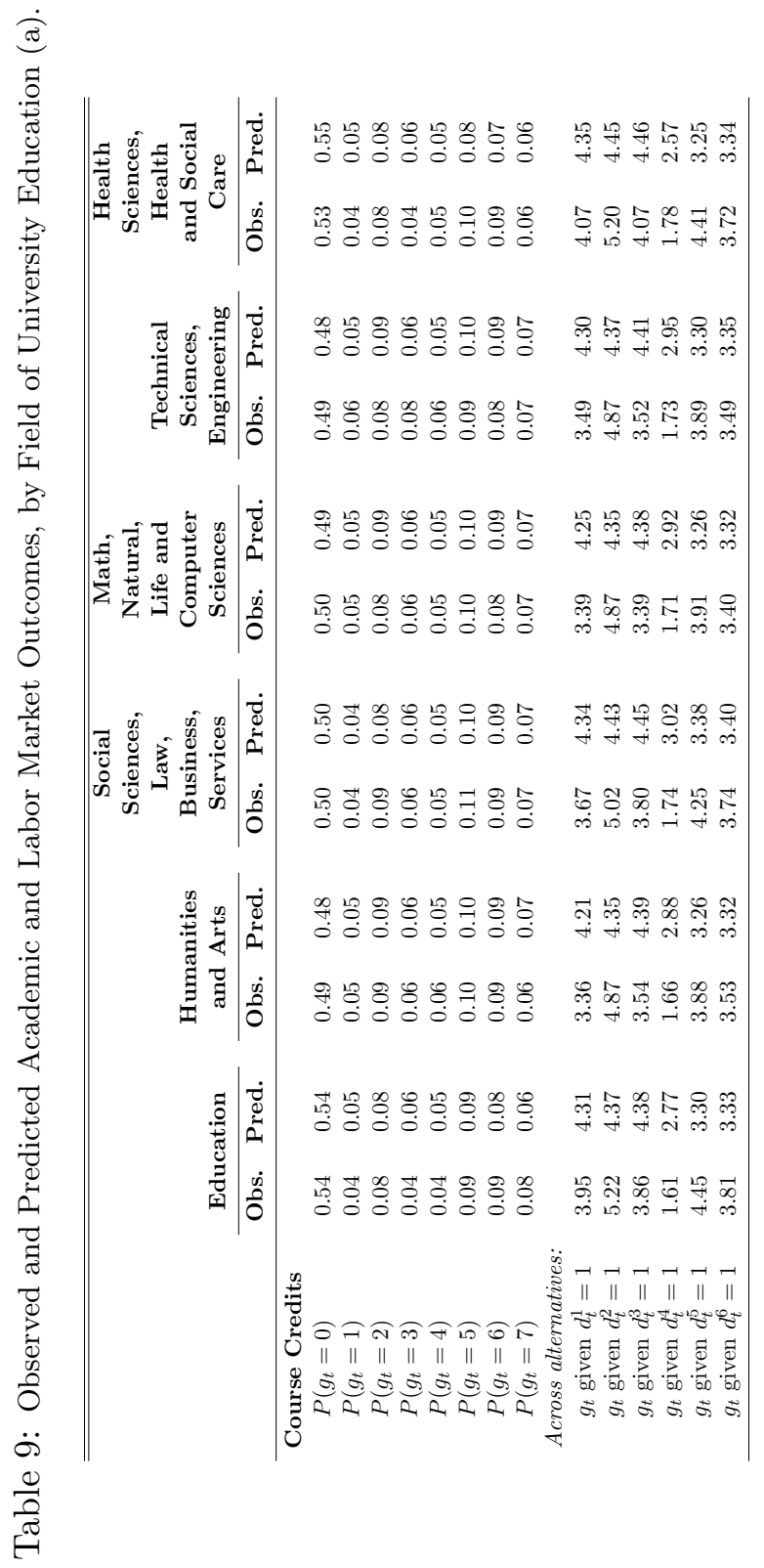




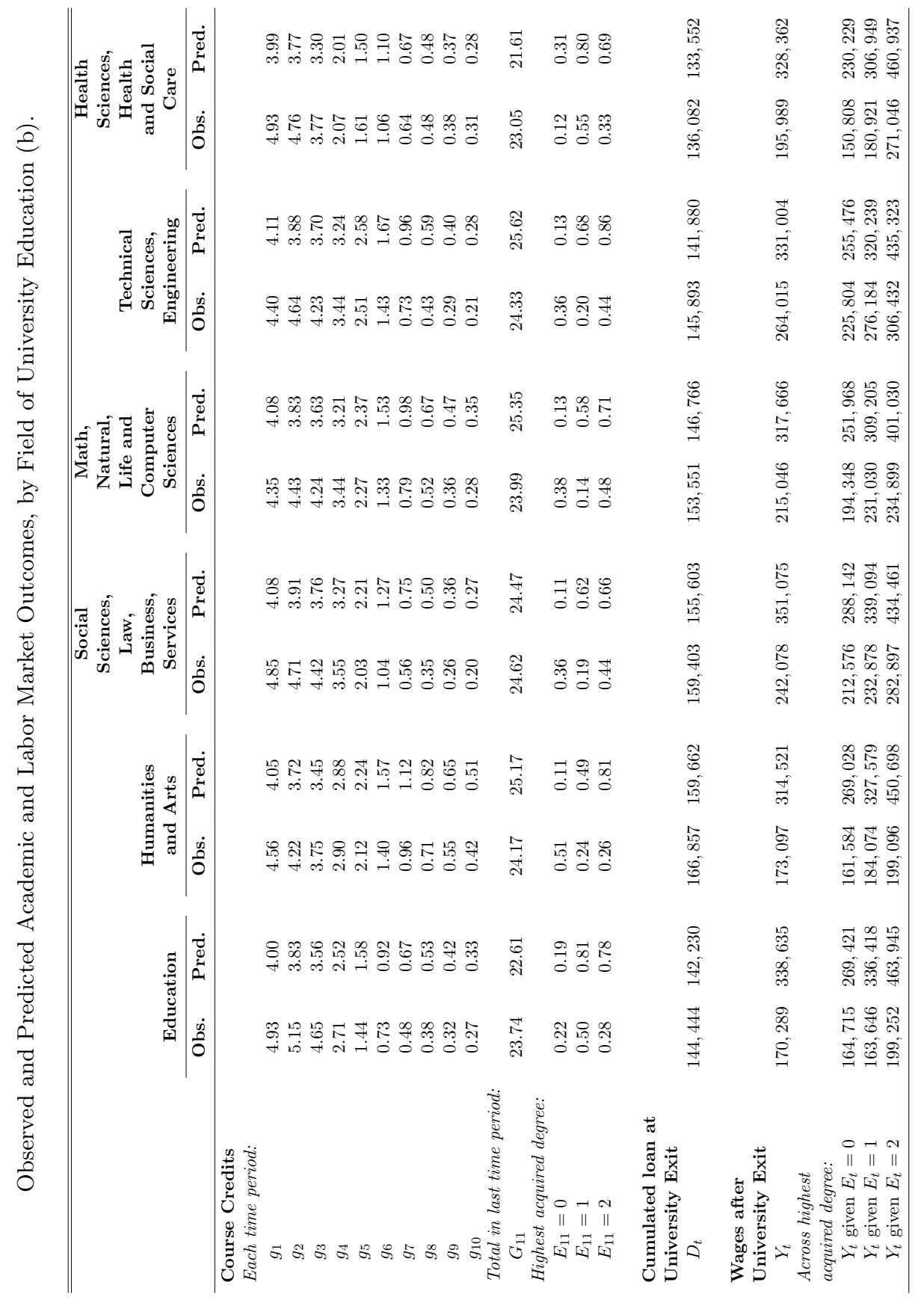




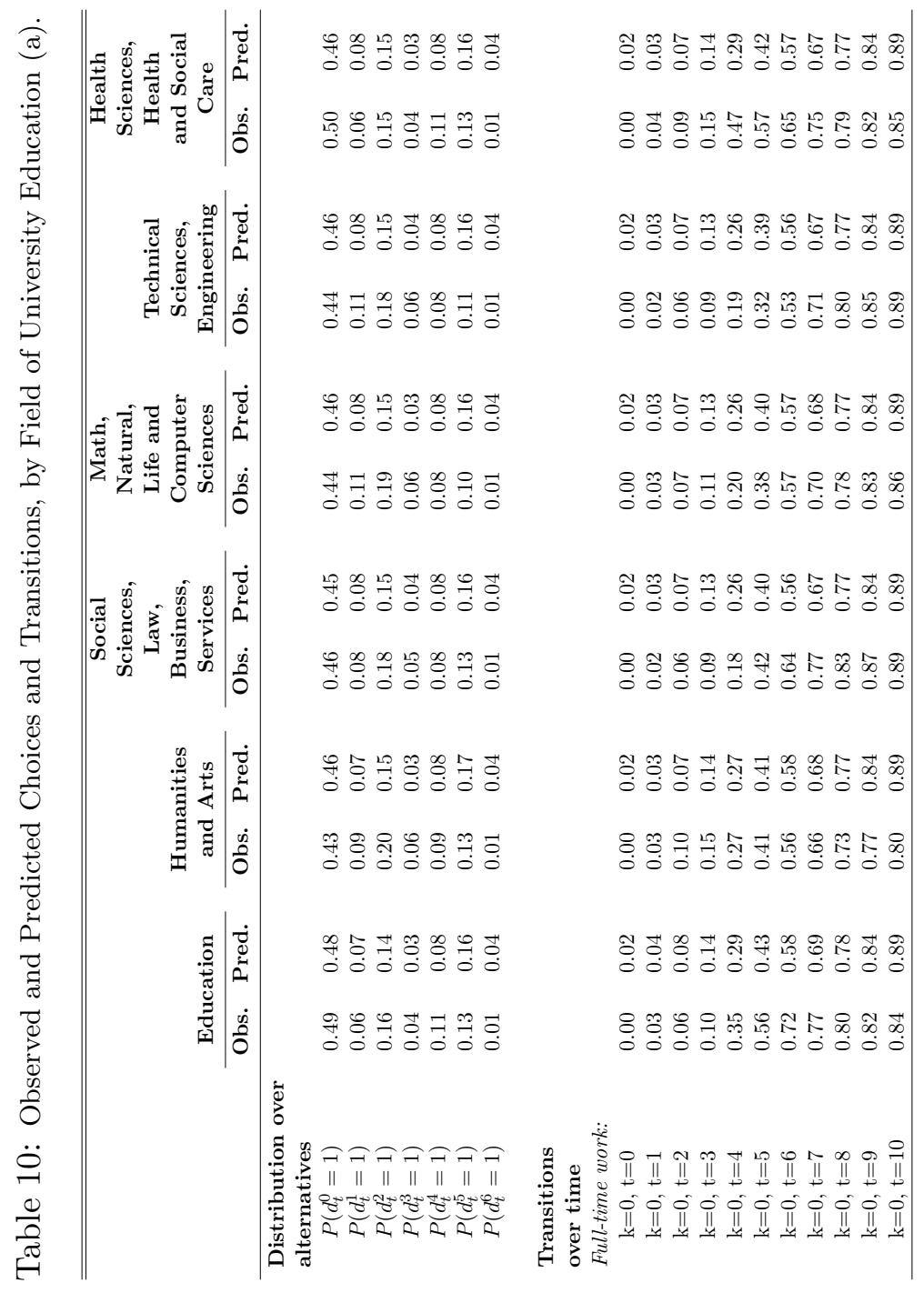




\begin{tabular}{|c|c|c|}
\hline 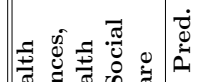 & 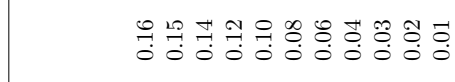 & 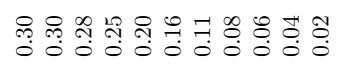 \\
\hline 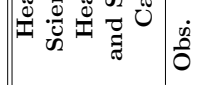 & 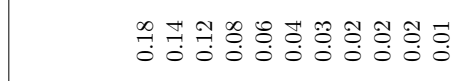 & 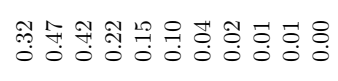 \\
\hline 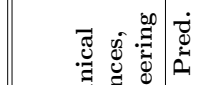 & 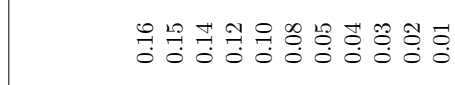 & 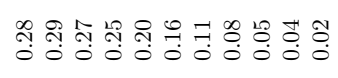 \\
\hline 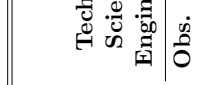 & 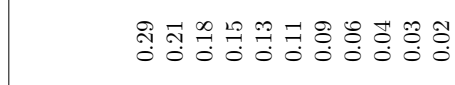 & 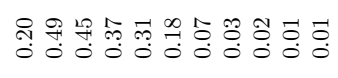 \\
\hline 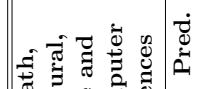 & 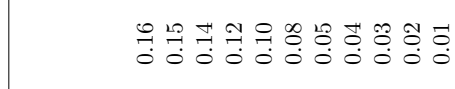 & 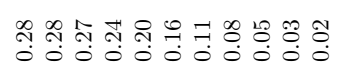 \\
\hline 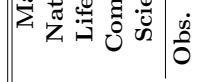 & 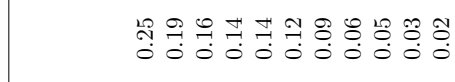 & 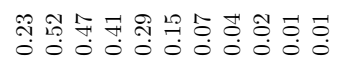 \\
\hline 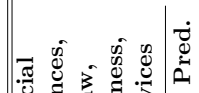 & 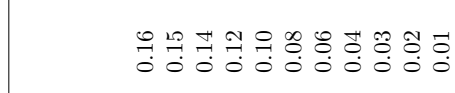 & 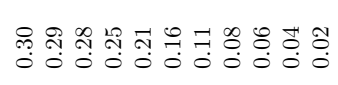 \\
\hline 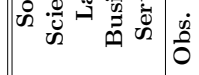 & 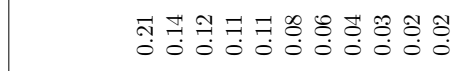 & 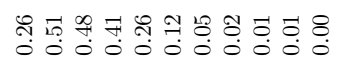 \\
\hline 总 & 记 & 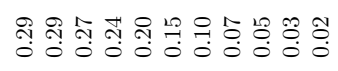 \\
\hline & 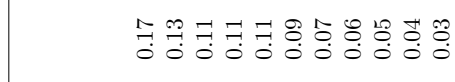 & 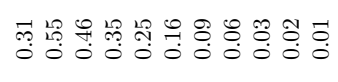 \\
\hline 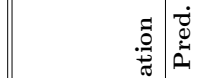 & 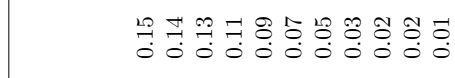 & 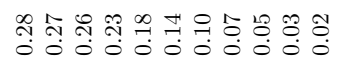 \\
\hline 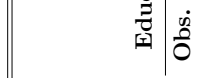 & 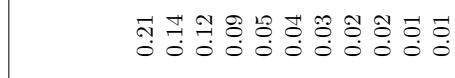 & 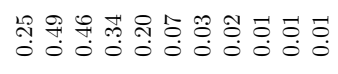 \\
\hline & 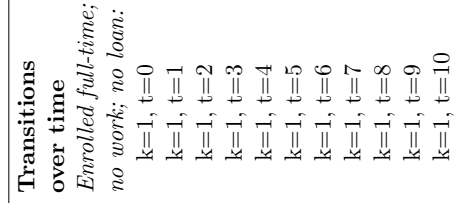 & \\
\hline
\end{tabular}




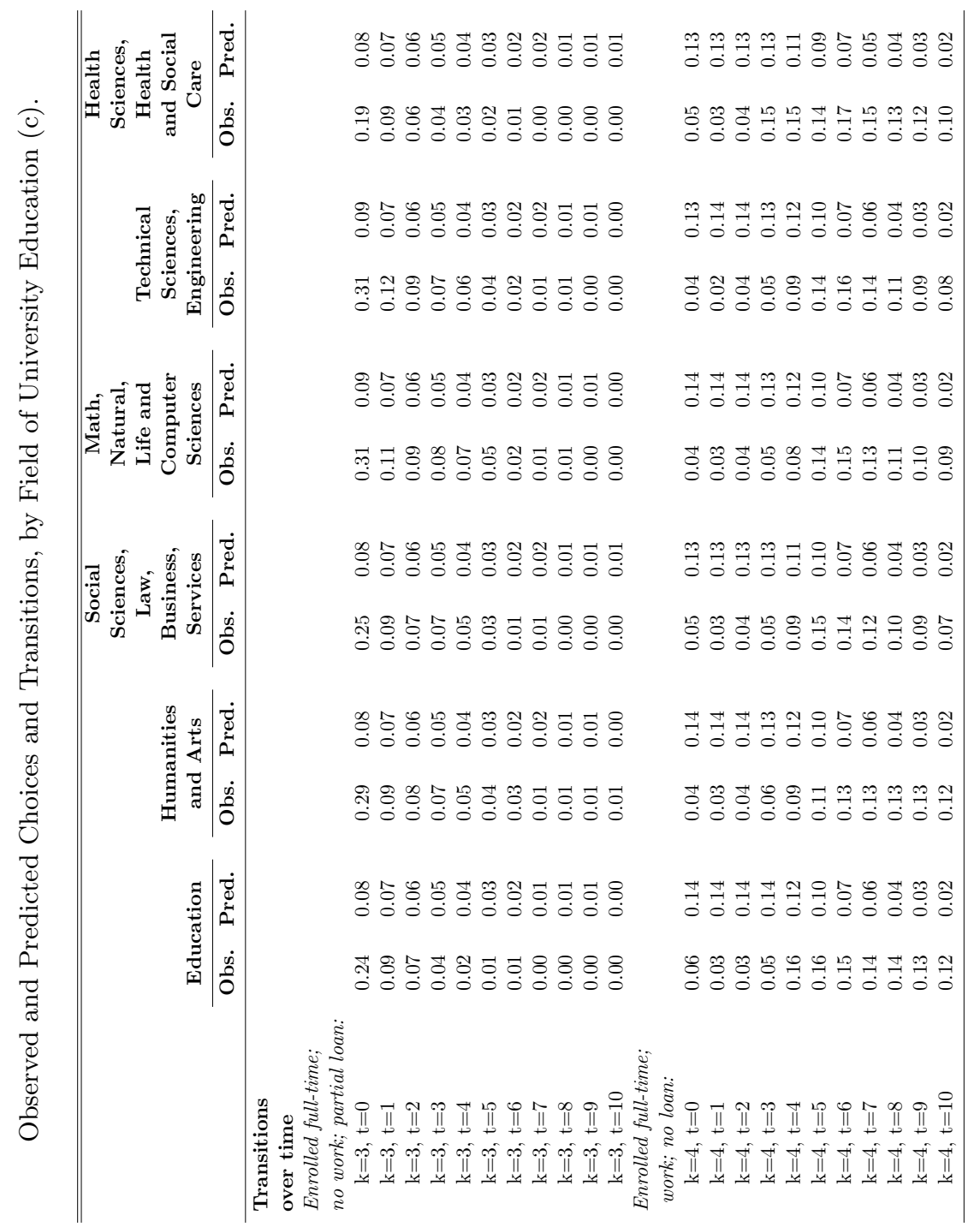




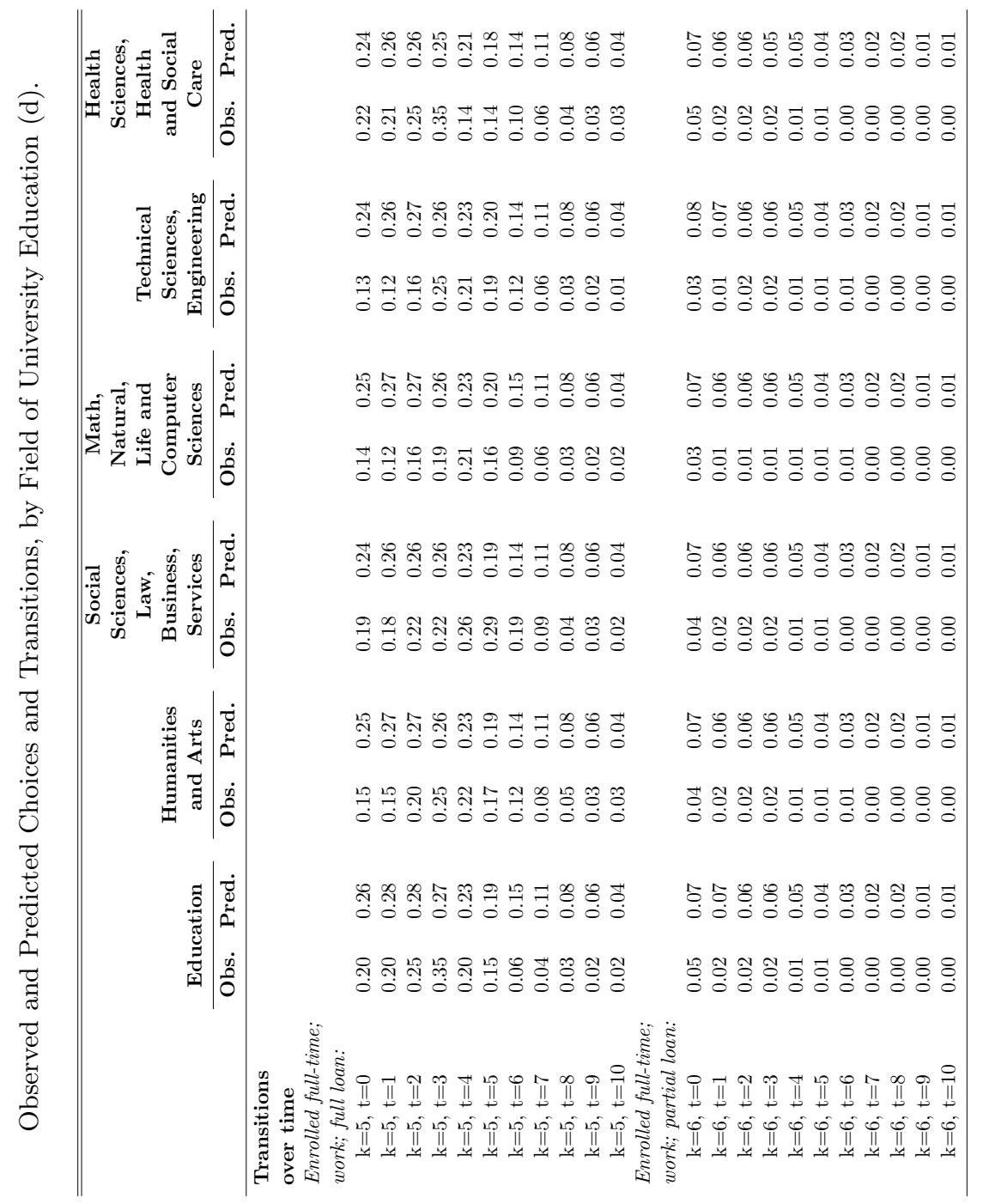




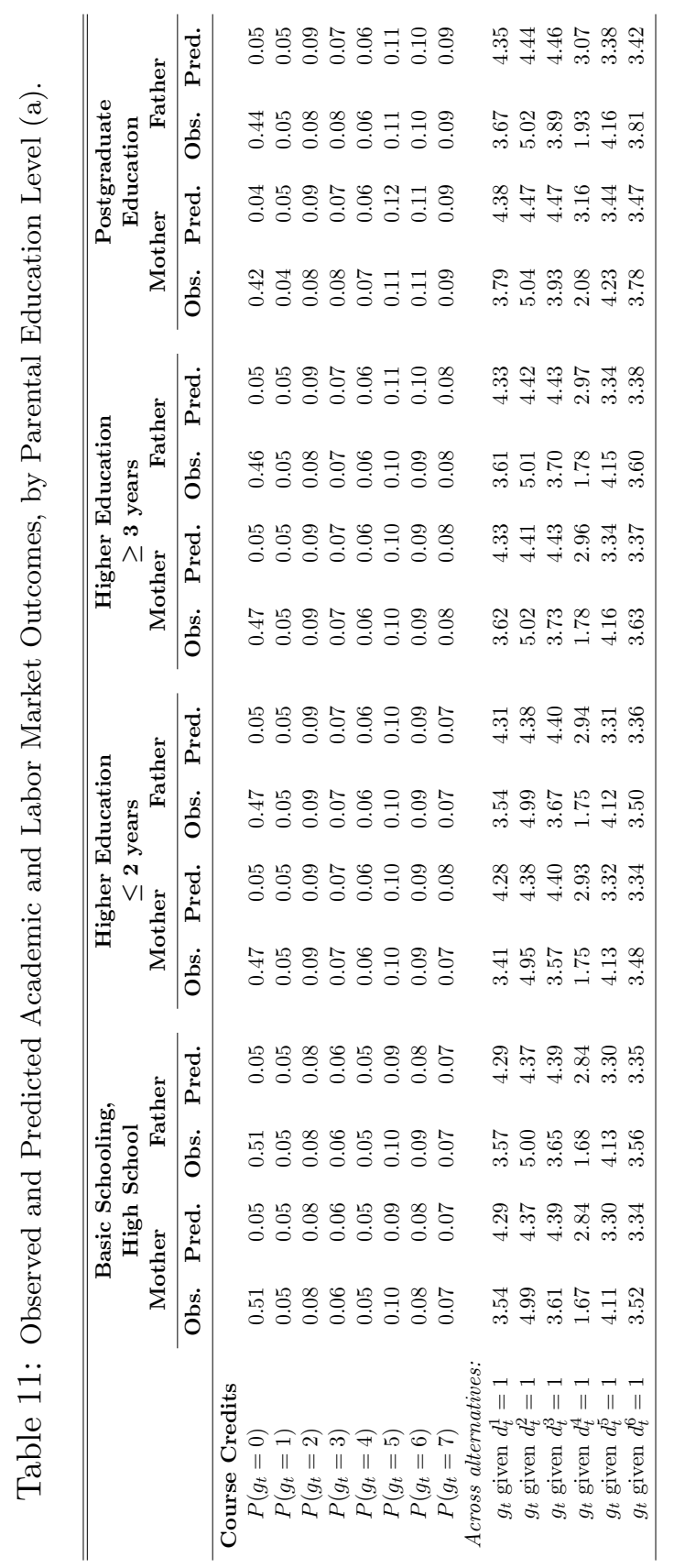




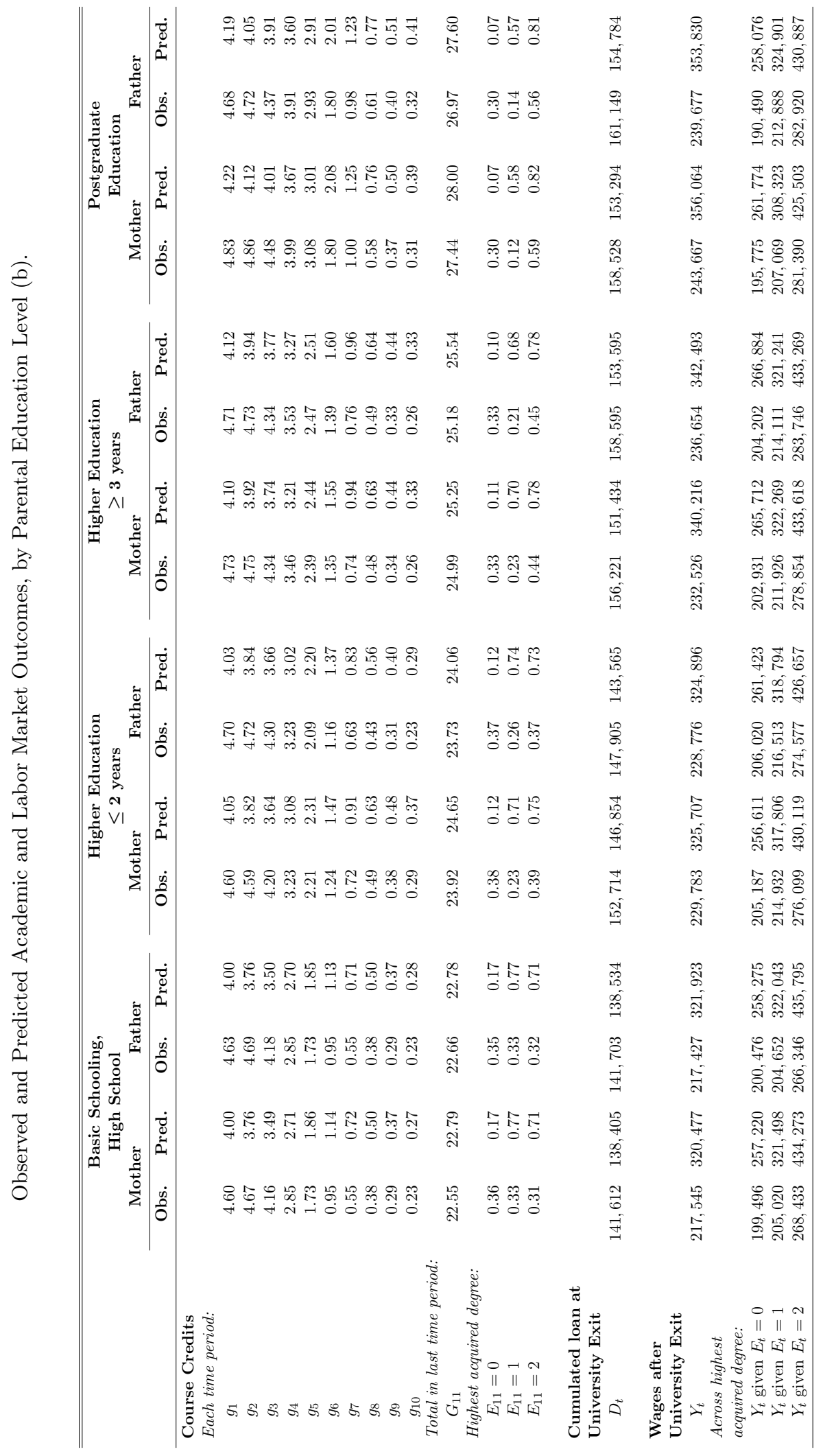




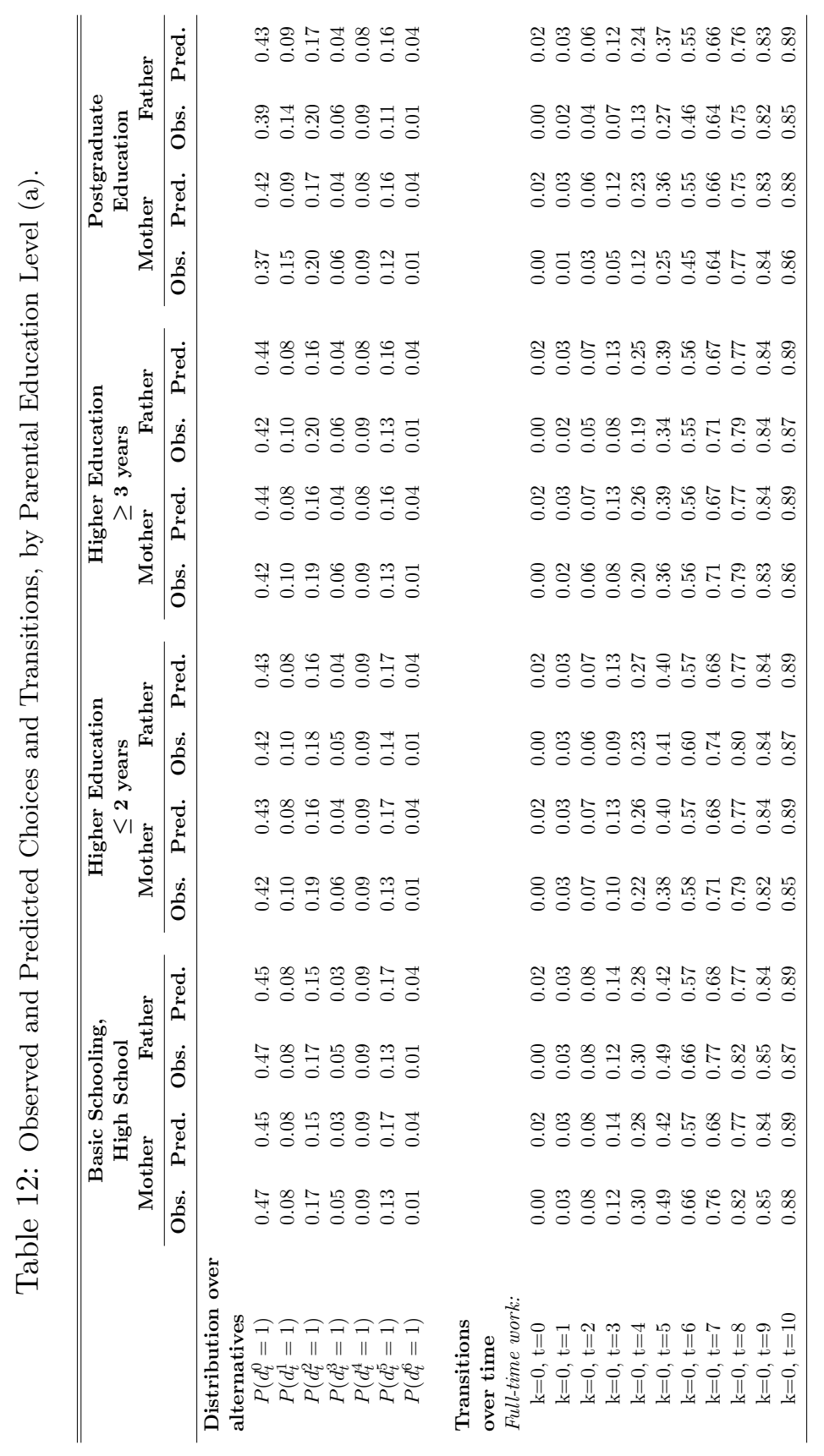




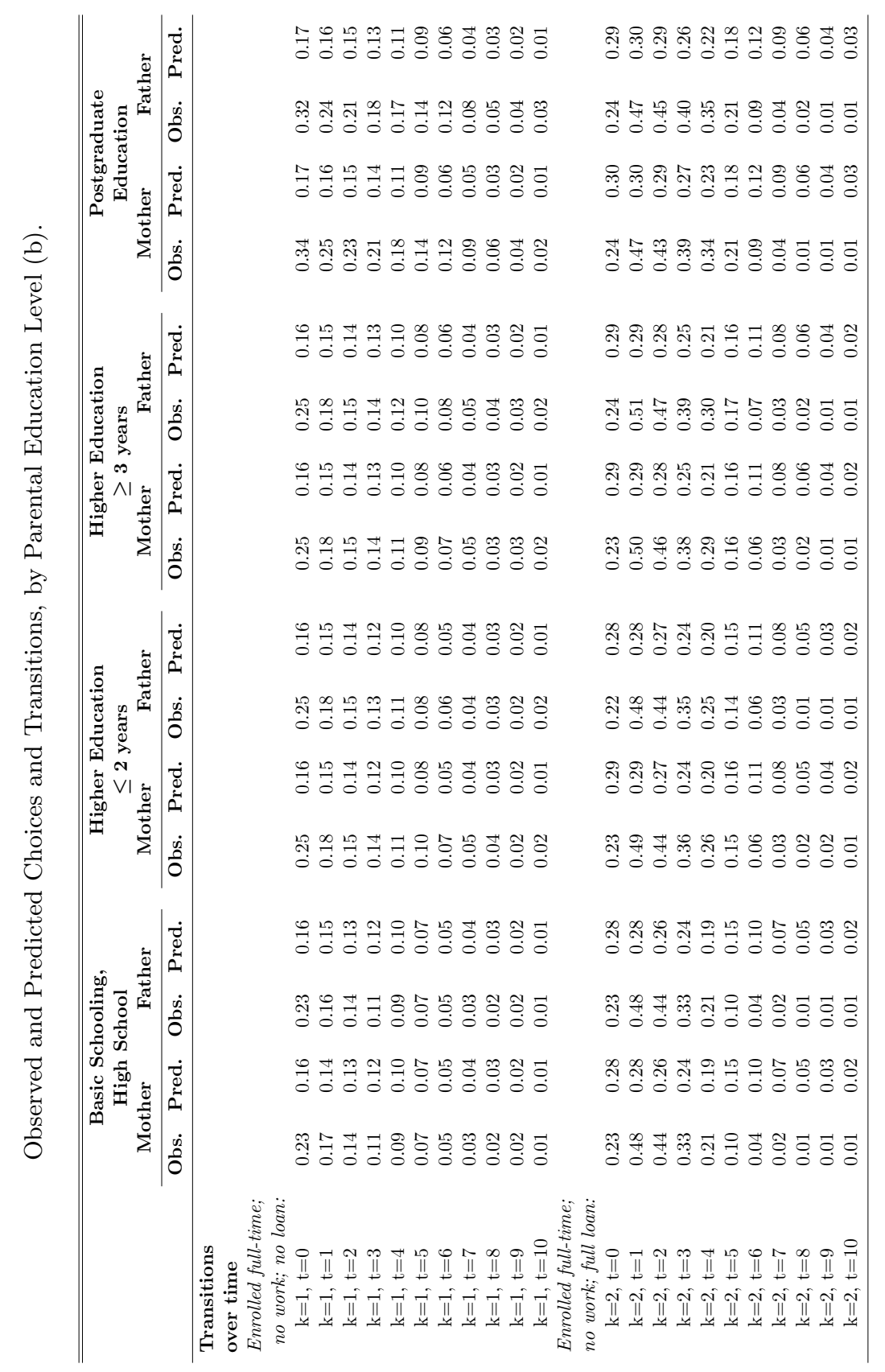




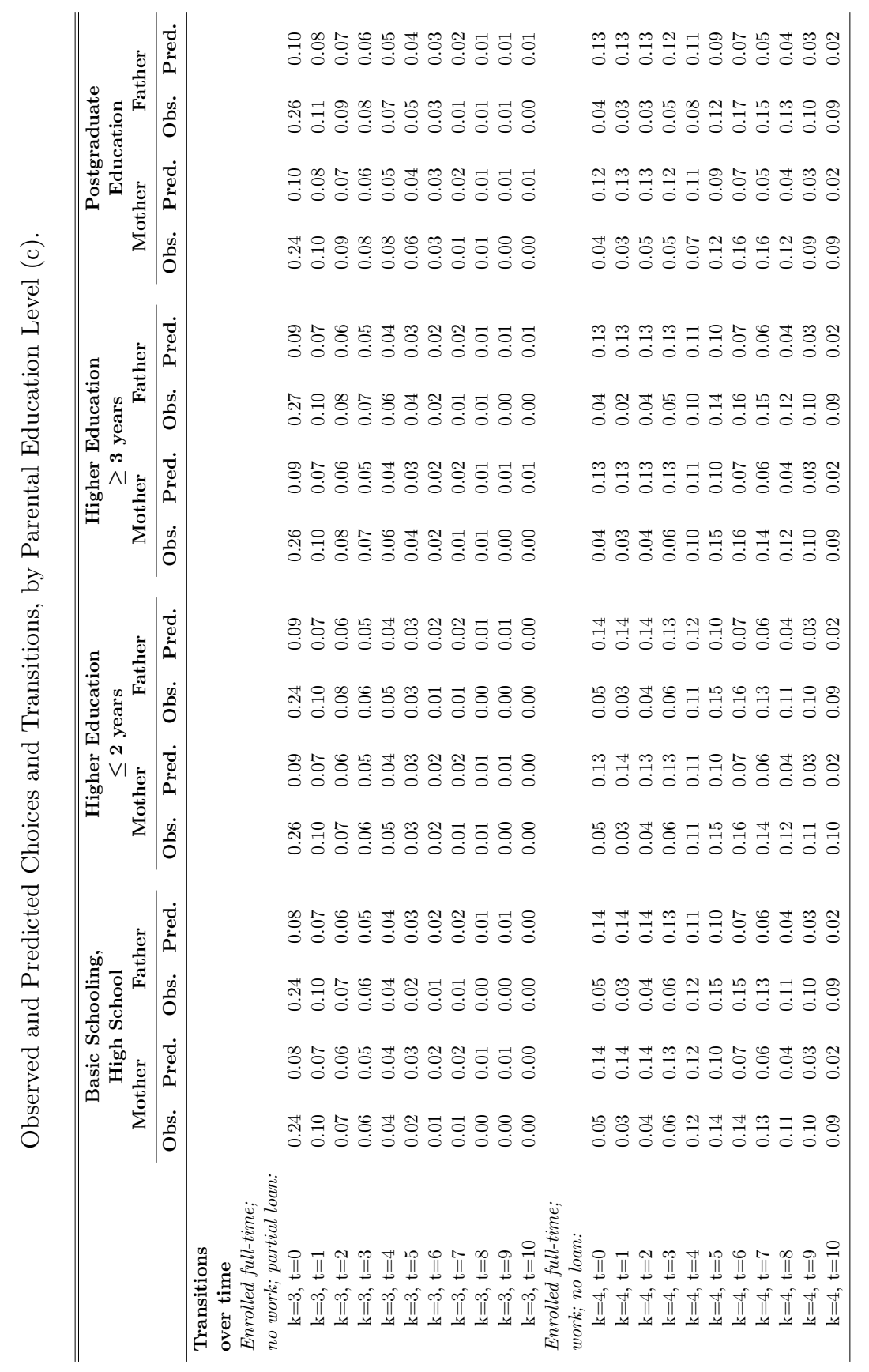




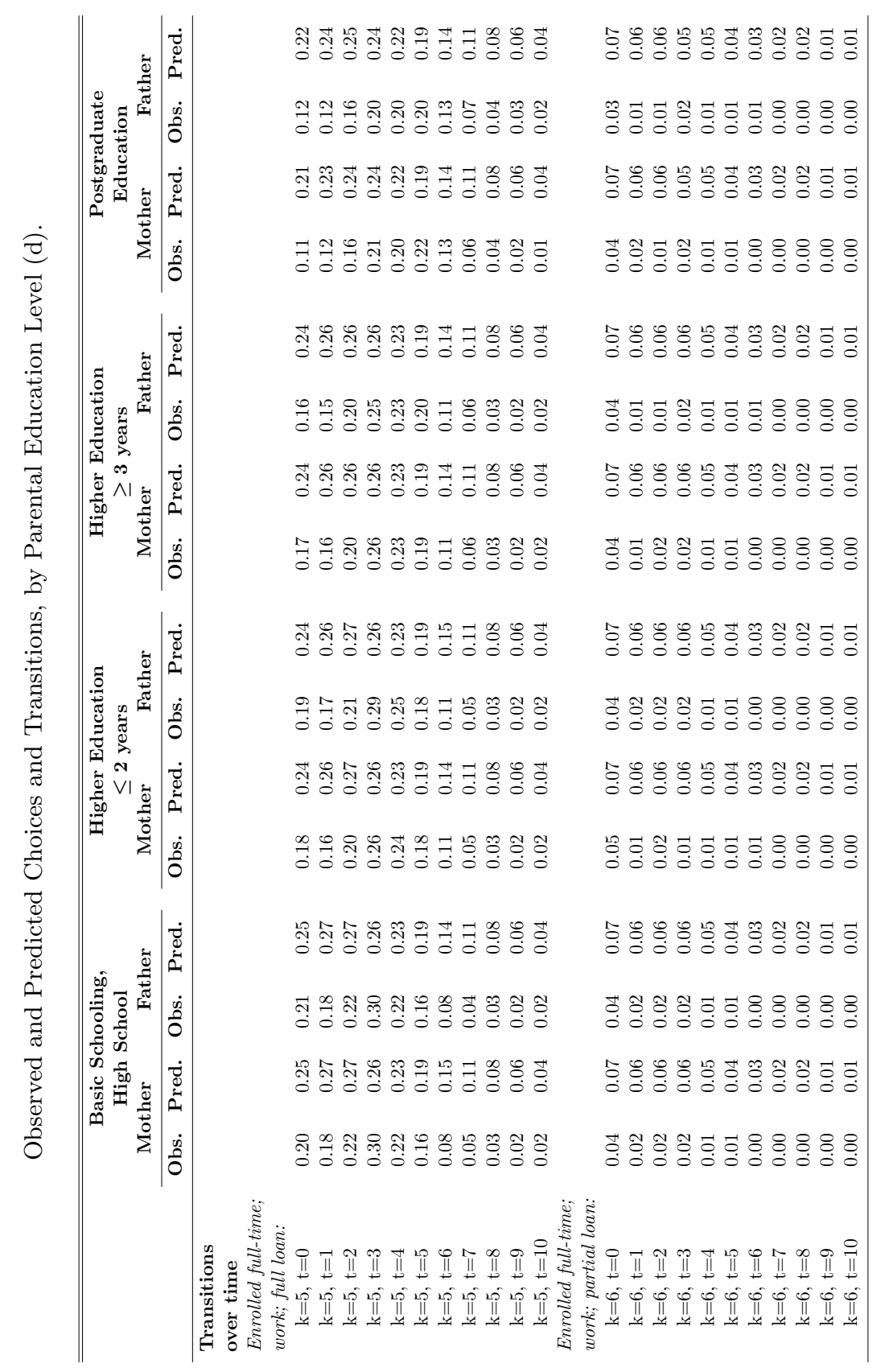




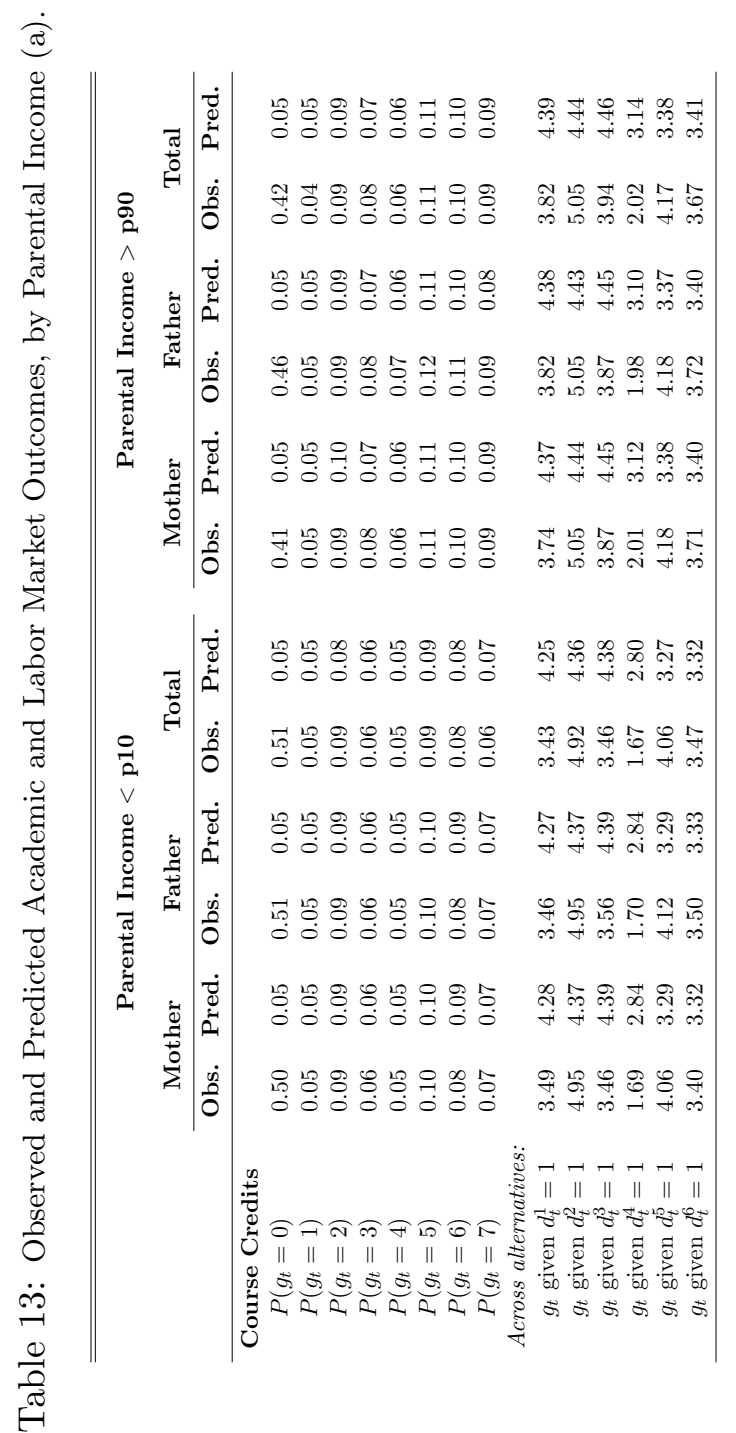




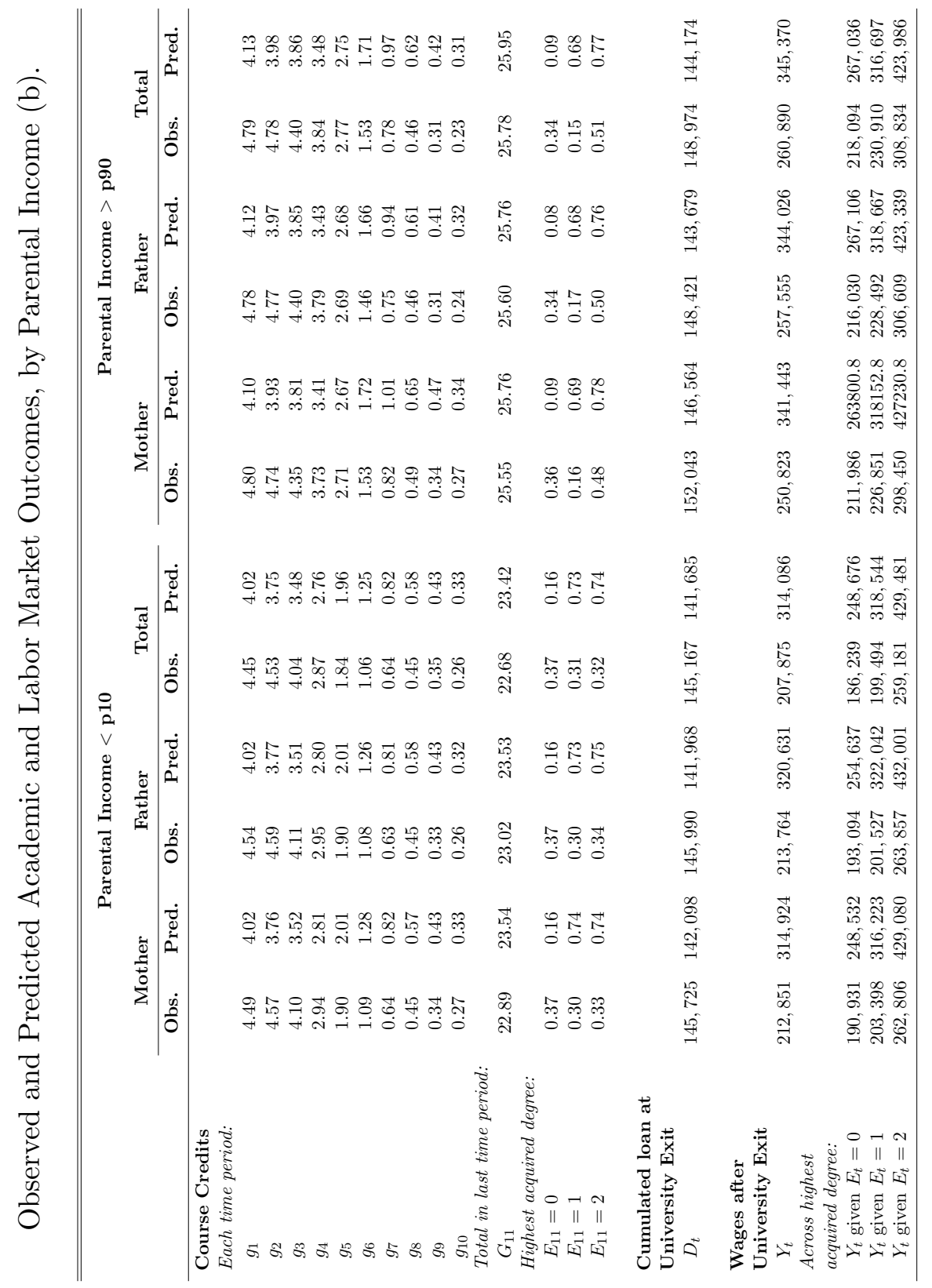




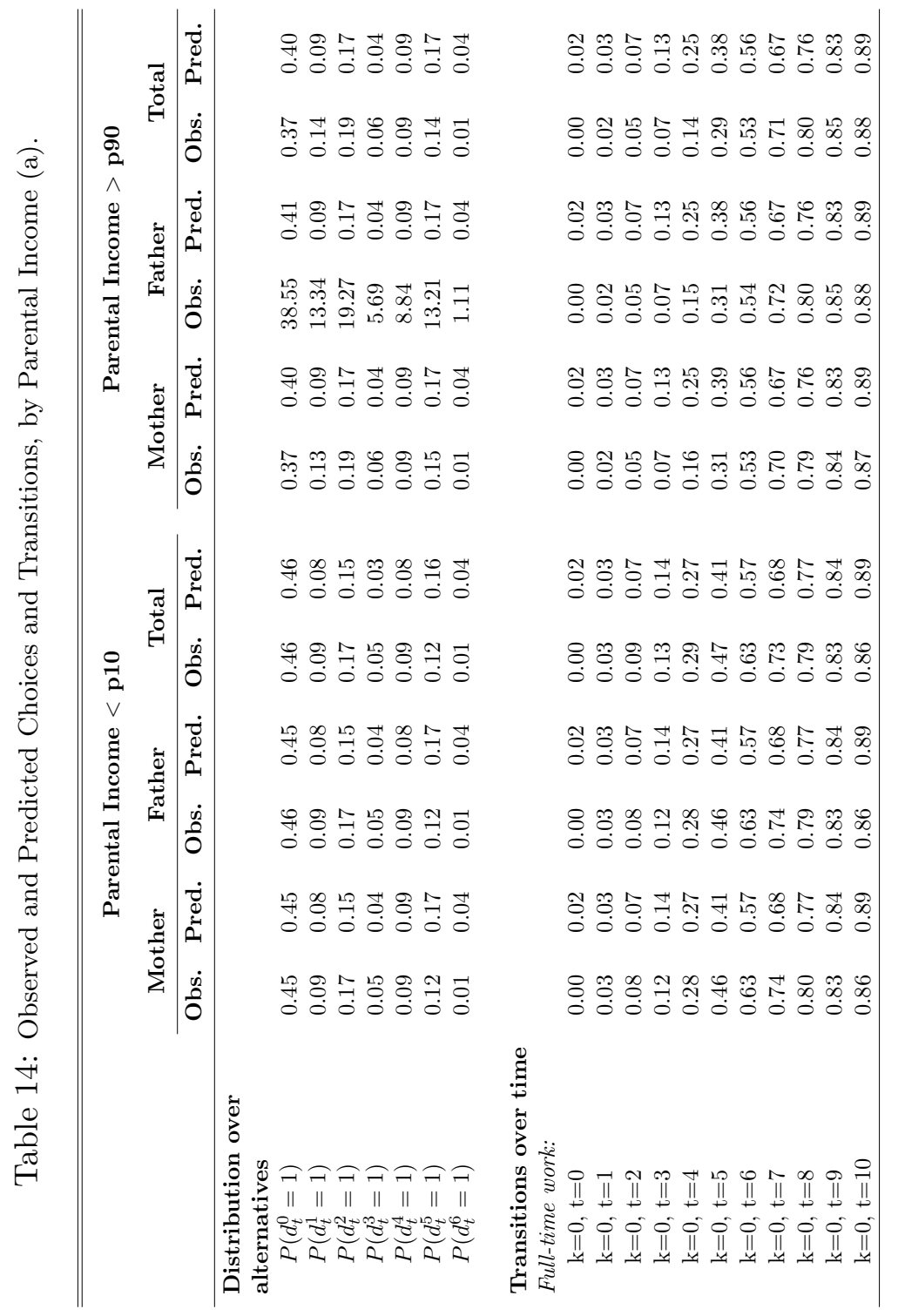




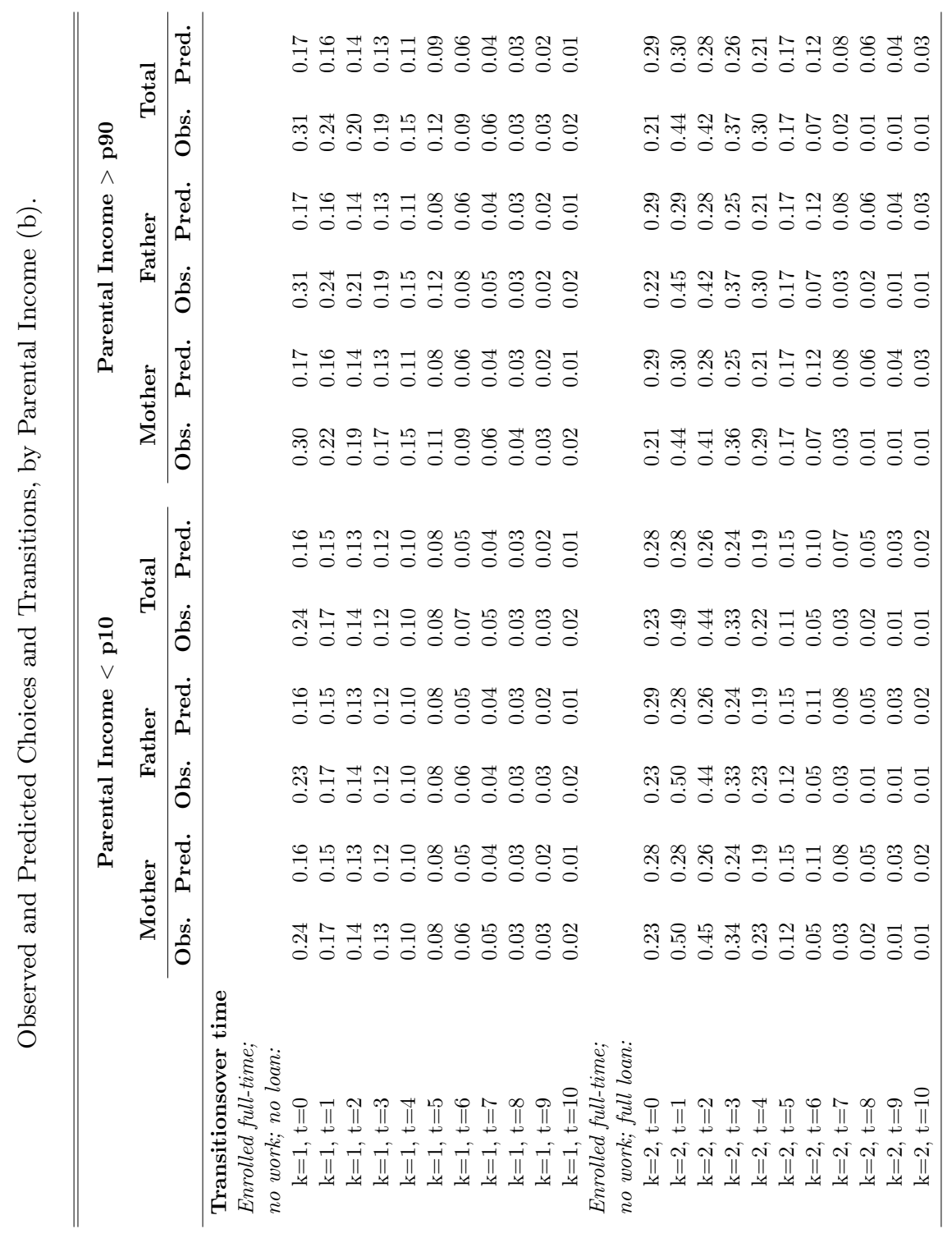




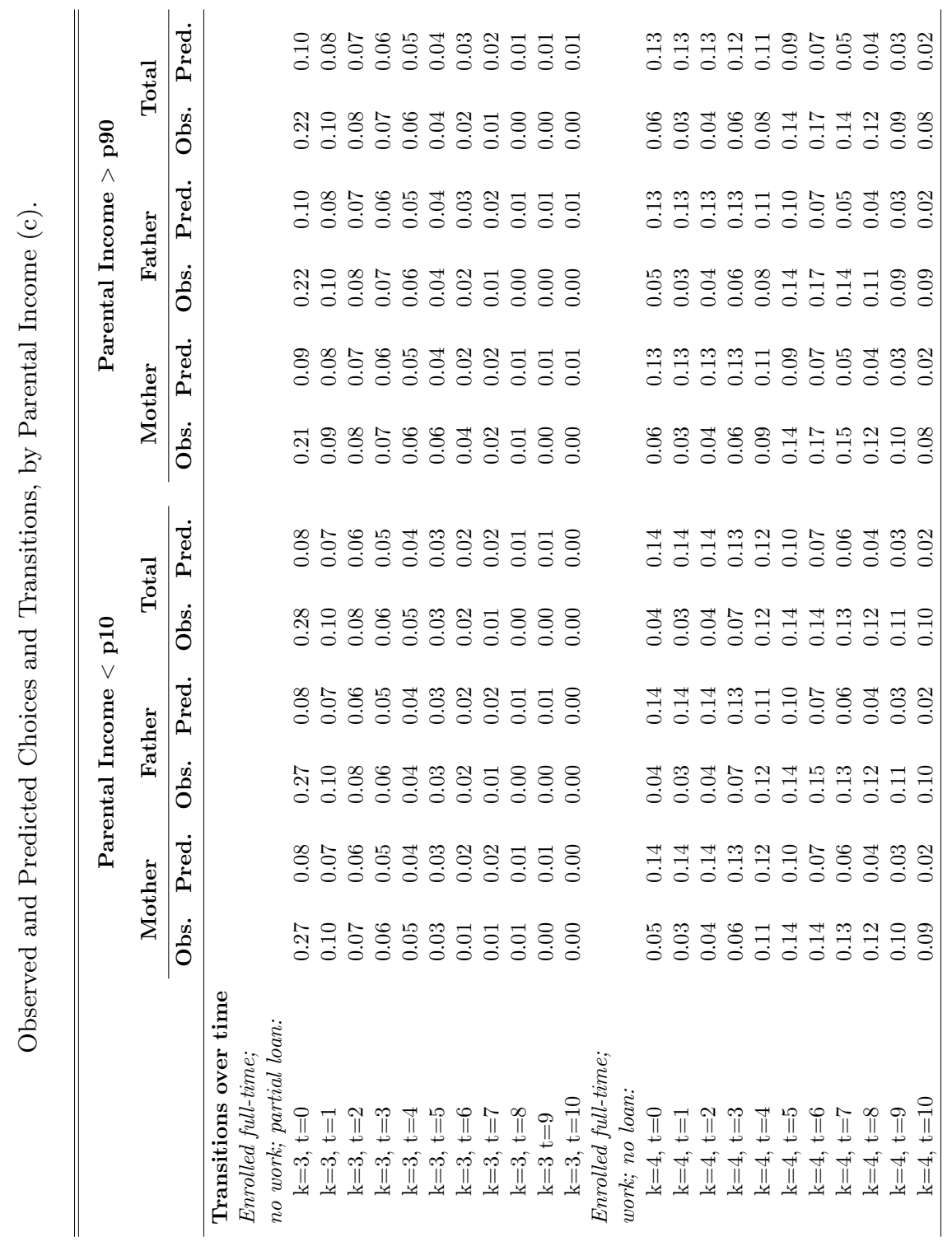




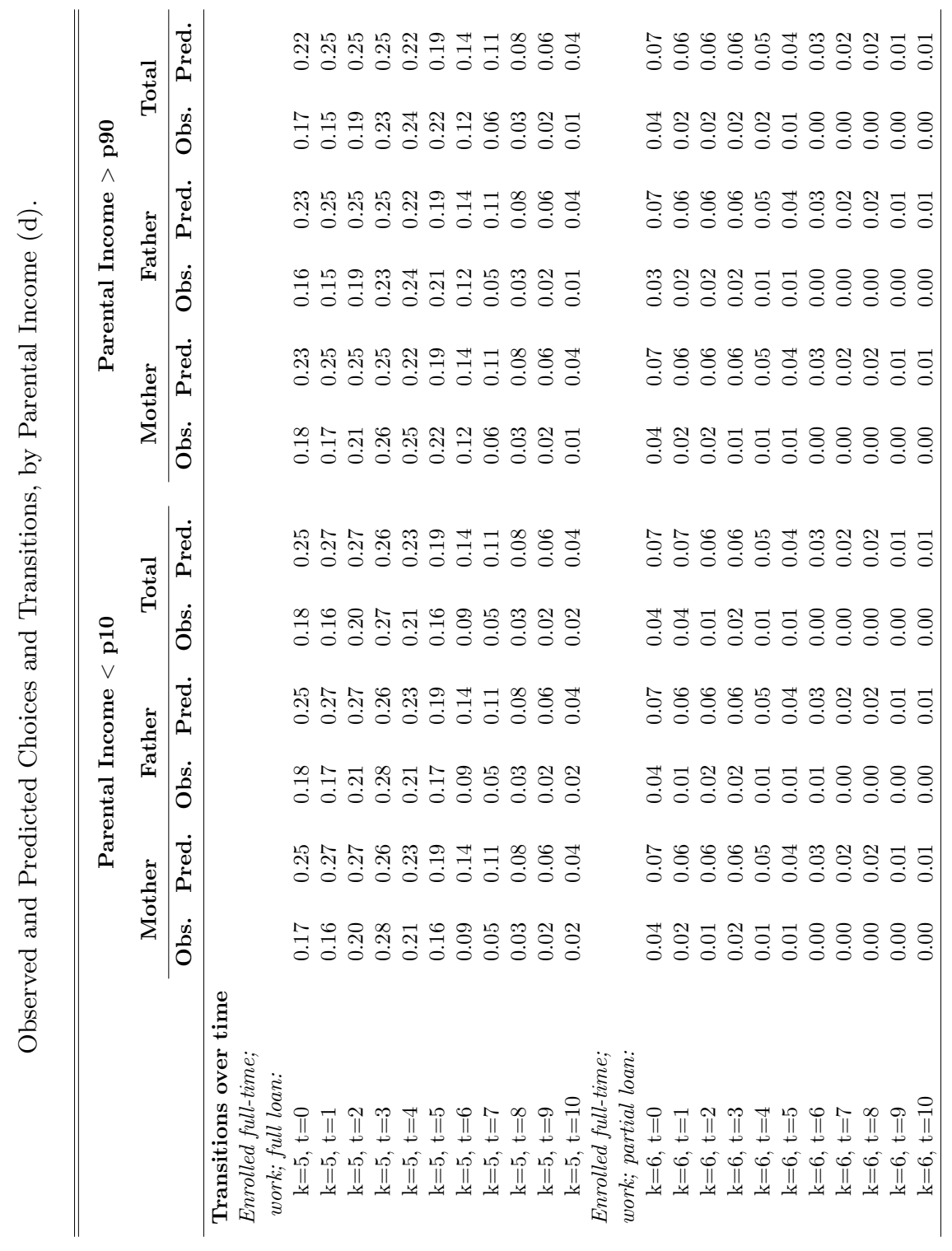


Table 15: Academic Outcomes, Debt, Parental and Family Background.

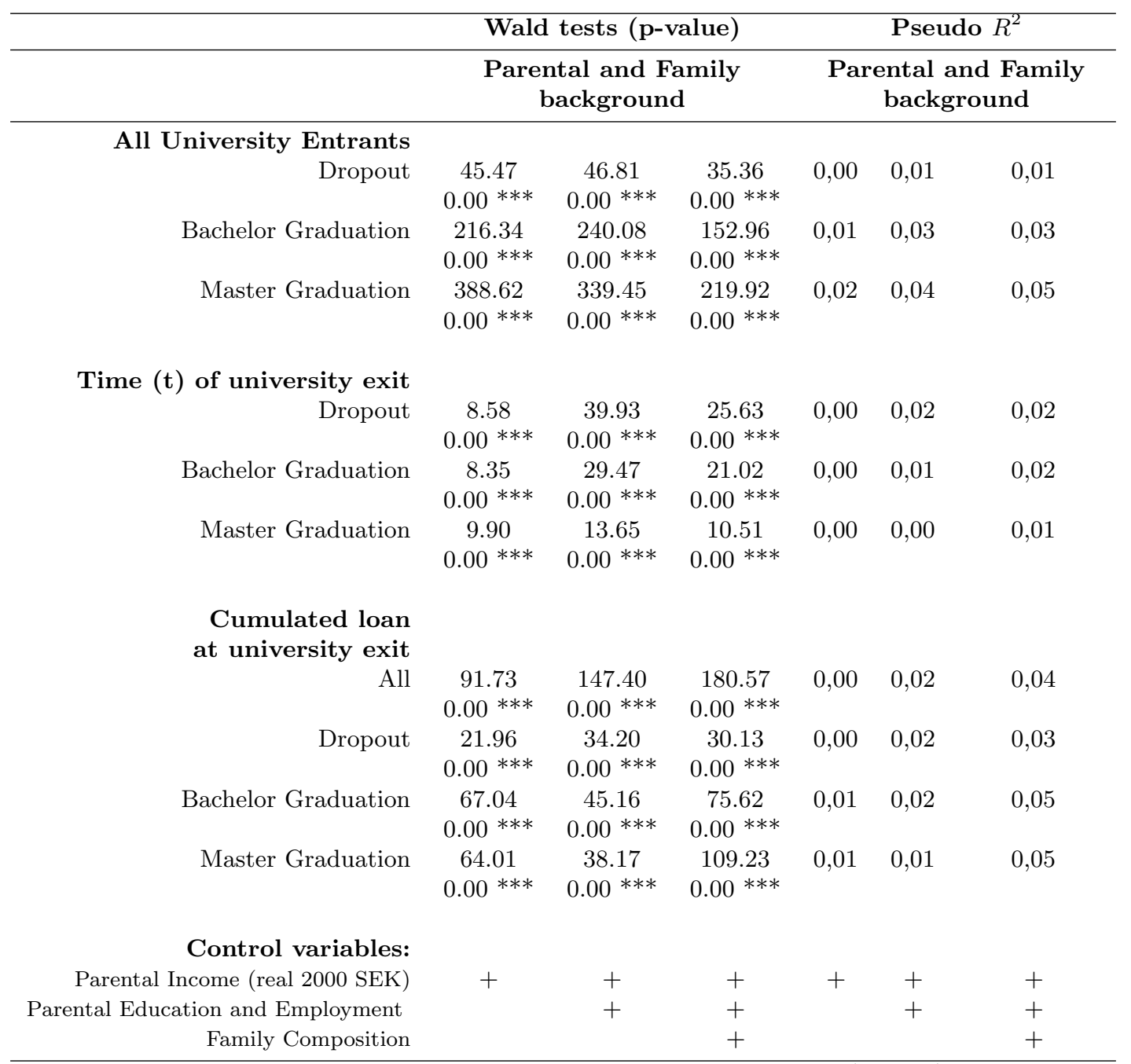

Wald tests of joint significance of parental and family background variables (p-value)

Control variables included in all columns are: Parental income variables in real 2000 SEK

(total income, disposable income both personal and of the family, and indicators for whether in top and bottom income percentiles. Additional control variables in columns two, three, five, and six are: parental education level and field, parental employment status. Columns three and six additionally include controls for family composition: parental marital status, parental age at birth, number of siblings, birth order, and sibling age composition. 